LBL- -14747

$D E \& 3 \quad 002623$

LBL- 14747

The Study of Intergranuler Embrittlement in Fe-12Mn Alloys

\author{
Hyung Jai Lee
}

Materials Science and Molecular Research Division

Lawrence Berkeley Laboratory

and

Materials Science and Mineral Engineering Department

University of California, Berkeley

(Ph.D. Thesis)

NOTICE

PORTIONS OF THIS RE-

'ELE. II

June 1982 has been reproduced f:. जिis

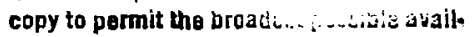
ability.

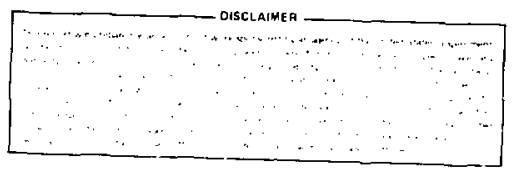

This work was supported by the Director, Office of Energy Research, Office of Basic Energy Science, Material Science Division

of the U. S. Department of Energy under contract No. LE-AC03-76SF00098. 


\section{Table of Contents}

Introduction

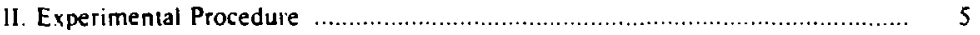

A. Material Preparation and Heat Treatment ....................................... 5

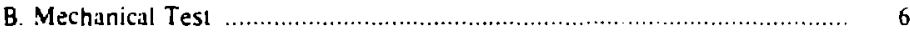

C. Measurements of Transformation Temperature and Phase ….................... 6

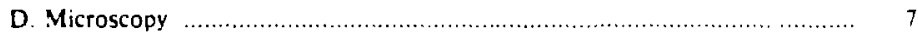

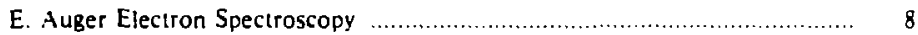

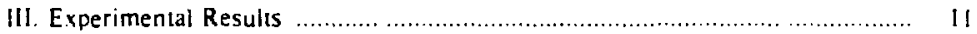

A. Intergranular Embrittlement of Fe-12Mn Steel in the As-austeritized

Condition

B. Effect of Alloying Elements

C. Effect of Tempering in Fe-12Mn Alloys

IY. Discussion 
Condition

B. Effect of Boron Addition

C. Effect of Tempering in Fe-12Mn Alloys

V. Conclusions

References

Figure Captions

Figures 


\title{
The Study of Intergranular Embrittlement in Fe-12Mn Alloys
}

\author{
Hyuns Jal Lee
}

\begin{abstract}
A high resolution scanning Auger microscopic study has been performed to investigate the chemical source of the intergranular fracture surfaces of Fe-12Mn steels in the as-austenitized condition. The fracture mode below the ductile- brittle transition temperature was found to be intergranular whenever the alloy was quenched from the austenite field, irrespective of the austenitizing time and temperature. High resolution chemical analyses of the intergranular fracture surface failed to reveal any consistent segregation of $\mathrm{P}, \mathrm{S}$, As, $\mathrm{O}$, or $\mathbf{N}$. The occasional appearance of $\mathrm{S}$ or $\mathrm{O}$ on the Iracture surface was found to be due to a low density precipitation of MnS and $\mathrm{MnO}_{6}$ along the prior austenite boundaries. An AES study with $\mathrm{Ar}^{+}$ion-sputiering showed no evidence of manganese enrichment along the prior austenite boundaries, but a slight segregation of carbon which does not appear to be implicated in the tendency toward ergranular fracture.
\end{abstract}

The addition of 0.002 weight percent boron with a $1000^{\circ} \mathrm{C} / \mathrm{hhr} / \mathrm{WQ}$ treatment yielded a high Charpy impact energy at liquid nitrogen temperature, preventing the intergranular fracture. The high resolution AES studies of the boron added alloy showed that the presence of approximately 3 atomic percent boron on the prior austenite grain boundaries is most effective in increasing the grain boundary cohesive strength in an Fe-12Mn ailoy. Trace additions of $\mathrm{Mg}, \mathrm{Zr}$, or $\mathrm{V}$, which are believed to be beneficial to the grain boundaries, had negligible effects on the intergranular 
embrittlement.

A $450^{\circ} \mathrm{C}$ temper of the boron-modified alloys was found to cause tempered martensite embrittement, leading to intergranular fracture. The embrittling treatment of the Fe-12Mn alloys with and without boron additions raised the ductile-brittle transition by $150^{\circ} \mathrm{C}$. This tempered martensite embrittlement was found to be due to the Mn enrichment of the fracture surface to approximately 32 atomic percent $M n$ in the boron-modified alloy and 38 atomic percent $\mathrm{Mn}$ in the unmodified alloy. The $\mathrm{Mn}$ enriched region along the prior austenite grain boundaries upon further tempering is believed to cause nucleation of austenite and to change the chemistry of the intergranular fracture surfaces. 


\section{ACKNOWLEDGEMENTS}

The author would like to express his deepesi appreciation to Professor J. W. Morris, Jr. for his continuous guidance and support throughout the course of this investigation. The author is also grateful to Professors A. Searcy and I. Finnie for their critical review of this manuscript. Special thanks are extended to Drs. Sunkeun Hwang, Chol Kyl Syn, and Jungihl Kim for their helpful advice.

The technical assistance provided by members of the Materials and Molecular Research Division. Lawrence Berkeley Laboratory, especially Brian Pope lingot melting), Herb Liebe and Wayland Wong (machining), John Hoithuis (alloy preparation!, Sandy Stewart (purchasing), and Gloria Pelatowski (line drawings) is gratefully acknowledged.

The author wishes to thank Mrs. Jeanne Shull for her careful preparation and help with this manuscript. Thanks are also extended to the author's colleagues, especially to Mr. K. Sakai and Mr. L. Summers for their help in reviewing this manuscript.

The author is greatly indebted to his family, especially to his parents and brother, fo: their patience and support.

This work was supported by the Director, Office of Energy Research, Office of Basic Energy Science, Material Science Division of the U.S. Department of Energy under contract No. DE-AC03-76SF00098. 


\section{INTRODUCTION}

A number of investigations have been made to study the mechanical properties of ferritic stepls at very low temperatures. Excellent cryogenic strength and toughness have been achieved in ferritic steel by the addition of nickel $(1-4)$ and proper heat treatment (5-7). With the hope that manganese could be successfully substituted for the tumparatively expensive nickel addition, research on the low temperature mechanical properties of Fe-Mn alloys has been undertaken in several laboratories (8).

Studies (9-17) of Ni-free cryogenic ferritic steels have been conducted over the composition range $\$-12 \% \mathrm{Mn}$ because of the microstructural and chemical similarities between $\mathrm{Mn}$ and $\mathrm{Ni}$ as $\mathrm{Fe}$ alloying elements. Appropriate thermal and thermomechanical treatments have led to excellent cryogenic strength and toughness in these Fe-Mn alloys. The characteristic phase transformation $(14,18)$ in Fe-Mn alloys with more than $10 \% \mathrm{Mn}$ is of particular interest since these allog's form a metastable phase, thep e-martensite, as one of the transformation products, whereas Fe-Mn alloys with less than $10 \%$ Mn do not form different phases from those of the Fe-Ni alloys of less than $28 \% \mathrm{Ni}$. With the presence of the hexagonal e-martensite. Fe-Mn alloys with composition over $8.12 \% \mathrm{Mn}$ are of interest because they show the highest stiength in the as-austenitized condition. As the $\mathrm{Mn}$ content is increased from 8 to $12 \%$, the yieid strength increases while the ductile-brittle transition temperature (DBTT) decreases slightly. Despite the low DBTT of the Fe-12 Mn alloy in the as-austenitized condition, below the DBTT this alloy fractures in a catastrophically intergranular mode while the Fe-8Mn alloy displays a transgranular cleavage fracture mode.

In earlier work (12-15) fundamental research into the embrittlement sources in Fe-12Mn alloy was conducted. The suppression of the low temperature intergranular embrittlement was successfully accomplished by a cold work plus temper, a controlled rolling treatment, or by adding a beneficial alloying element, specifically a trace addition of boron (19). These results suggested thai the origin of intergranular embrittlement in 
the Fe-12Mn steel in the as-austenitized condition is not due to the segregatior, of metalloid impurities or the formation of a deleterious second phase along the prior austenite grain boundaries, but is rather due to its inherent microstructures. However. this earlier conclusion $(12-15,18)$ induced a significant argument about the sources of intergranular embrittlement because of the relatively low resolution of Auger electron spectroscopy.

Many high strength steels with small amounts of metalloid impurities have been known to be very susceptible to temper embrittlement (20-32) over the temperature range of $550-650^{\circ} \mathrm{C}$, or tempered martensite embrittlement (33-38) around $300^{\circ} \mathrm{C}$. Subsequently, tempered martensite embrittlement was found to have a transgranula, cleavage fracture mode (39-40). In most cases, the intergranular brittleness due to tempering was attributed to austenite grain boundary carbide formation and metalloid impurities stich as P, S, As, Sn or Sb segregation, which decrease the cohesive strength between the two phases. On the other hand, the transformation of unstable retained austenite to the carbides along the lath boundaries is believed to cause brittleness appearing as a transgranular cleavage mode.

The current research was designed to clarify the nature and source of intergranular embrittlement in Fe-12Mn in the as-austenitized condition by employing high resolution scanning Auger microscopy (SAM) and to investigate tempered martensite embrittlement in these alloys. Brittleness always develops along the same fracture path, i.e., intergranular fracture along the prior austenite grain boundaries. Special emphasis was placed on the investigation of changes in chemical composition on the intergranular fracture facets.

Further research on boron additions an austenitizing treatment were carried out to achieve better mechanical properties at low temperature. Improvements in the cohesive strength of the prior austenite grain boundaries of the Fe-12Mn alloy resulted in the suppression of the brittle intergranular failure below the ductile-brittle transition tem- 
perature. Esveral alloying elements in addition to boron, which were believed to be beneficial to the grain boundaries, were added in the bope of changing the fracture mode from intergranular to transgranular. Tempered martensite embrittlement of the Fe-12Mn alloys with trace addition of beneficial alloying elements was also studied. 
4

$\backslash$ 


\section{EXPERIMENTAL PROCEDURE}

\section{A. Material Preparation and Heat Treatment.}

Alloys of nominal compositions Fe-12Mn were induction melted in an argon gas atmosphere. To study the effect of boron addition on the grain boundaries, minor additions of boron (ranging from $10 \mathrm{ppm}$ to $100 \mathrm{ppm}$ ) and $\mathrm{Ti}$ (approximately $0.2 \%$ ) were made. Special care was taken in the alloy preparation to reduce the effects of impurilies. Each ingot was cast from a separate batch into $\perp$ copper chill mold. The average weight of an ingot was $9 \mathrm{~kg}$. The chemical composition of alloys is shown in Table $\mathrm{l}$.

\section{TABLE I}

Chemical Composition of the Alloy Ingots in Wr. Pct.

\begin{tabular}{|cccccccccc|}
\hline \multicolumn{10}{c|}{ Chemical Compositions } \\
\hline $\mathrm{Mn}$ & $\mathrm{Ti}$ & $\mathrm{C}$ & $\mathrm{O}$ & $\mathrm{A}$ & $\mathbf{P}$ & $\mathrm{N}$ & $\mathrm{B}$ & $\mathrm{Fe}$ \\
\hline 12.0 & 0.000 & 0.003 & 0.004 & 0.006 & 0.008 & 0.005 & 0.00 & Bal. \\
11.7 & 0.14 & 0.002 & 0.001 & 0.006 & 0.006 & 0.001 & $0.002^{\circ}$ & Ba!. \\
\hline
\end{tabular}

- Other chemical composition of alloys with boron ranging from $10 \mathrm{ppm}$ to $1000 \mathrm{ppm}$ is not available.

Mechanical test specimens were cut from plates and pre-machined to oversized dimensions before heat treatment. The as-austenitized specimens were sealed in stainless steel bags filled with argon and treated from $850^{\circ} \mathrm{C}$ to $1200^{\circ} \mathrm{C}$ and water quenched. Holding time at $1100^{\circ} \mathrm{C}$ ranged from 1 hour to 100 hours. The specimens for studying tempered martensite embrittement were treated at temperatures ranging from $250^{\circ} \mathrm{C}$ io 
$650^{\circ} \mathrm{C}$ in $50^{\circ} \mathrm{C}$ increments for up to 200 hours. The specimens were usually water quenched after esch heat treatment. All of these heat treated oversized specimens were finally machined under flood cooling to the proper dimensions of standard mechanical property test specimens.

\section{B. Mechanical Testins}

\section{Hardness test.}

Specimens tested for the hardness of the alloy were usually cut from broken Charpy impact test specimens. The hardness was measured on a Wilson Rockwell hardness tester. The Rockwell $\boldsymbol{C}$ scale was used for most of the specimens. At least five indentations were made and the readings averaged for each specimen. The standard deviation of the test was always within \pm 0.5 for Rc scale.

2. Charpy impact test. The Charpy impact test specimens were machined to ASTM standard size shown in Figure 1. Notches of $45^{\circ}$ were machined perpendicular to the rolling direction of the plate. The impact tests were carried out as described in ASTM E23. Vat ous temperatures were obtained by a proper mixture of liquid nitrogen, isopentane, and Corning 710 oil. At least two Charpy V-notched specimens were tested at each testing temperature.

\section{Measurements of Transformation Temperature and Phases.}

\section{Transformation temperature.}

A Thet Dilatronic IlIR dilatometer was employed for measurine transformation temperatures. Specimens prepared from bulk material were machined to the specifications given in Figure 2. Each specimen was heated to $1100^{\circ} \mathrm{C}$ with a programmed linear heating rate of $440^{\circ} \mathrm{C} /$ min and quenched by a jet stream of He gas with \& quenchine rate of approximately $70^{\circ} \mathrm{C} / \mathrm{sec}$. Transformation temp:ratures were determined by points deviating from linearity on dilation and temperature vs. time curves. 


\section{Phase.}

$X$-ray diffraction analysis was carried out on specimens usually cut from broken Charpy specimens along the longitudinal direction. Specimen surfaces were carefully ground up to emery paper 600 grade and chemically polished in a solution of $100 \mathrm{ml}$ $\mathrm{H}_{2} \mathrm{O}_{2}+3 \mathrm{ml} \mathrm{HF}$ for 15 minutes in order to remove any strain-induced transformation phases from previous mechanical tests. A $C u K_{a}$ radiation in a Picker x-ray diffractometer was used. The volume percent of each ohase was calculated by compar-

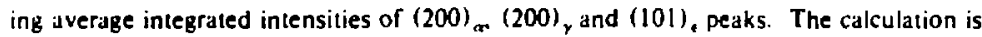
described in Schanfein's work (18).

\section{Microscopy.}

\section{Scanning electron microscopy (SEM).}

The fractographs of the broken Charpy specimens were oblained with an AMR 1000 scanning electron microscope operated at $20 \mathrm{kV}$. An energy dispersive analysis of $\gamma$-rays (EDAX) combined with the SEM was employed to quantitatively analyze the themical compositions of precipitates on the fracture surfaces.

\section{Optical microscopy.}

Specimens for optical microscopy wert cut from the broken Charpy bars along a longitudinal direction. After mounting in Kuldmount. they were ground on successive emery papers up to 600 grade. A final polishing was carried out on a $l_{\mu}$ diamond lapping wheel. The specimens were etched with either a $2 \%$ Nital or a picral $(1$ gm picric acid dissolved in $100 \mathrm{ml}$ ethyl alcohol and $5 \mathrm{ml} \mathrm{HCl}$ solutions. The microstructures were examined with a Carl Zeiss metallograph.

\section{Transmission electron microscopy (TEM).}

Specimens for transmission electron microscopy studies were sliced to about 12 mils thickness from the broken charpy specimen. They were then chemically thinned 
to sbout 5 mils in solution of $100 \mathrm{ml} \mathrm{H}_{2} \mathrm{O}_{2}$ and $4 \mathrm{ml} \mathrm{HF}$, spark cut into $3 \mathrm{~mm}$ discs and sanded down to about 2 mils thickness. Final thinning was cartied out by a twin jet electro-polishing apparatus operated at room temperature using a solution of $75 \mathrm{gr}$ $\mathrm{CrO}_{3} 400 \mathrm{ml} \mathrm{CH}_{3} \mathrm{COOH}$, and $2 \mathrm{l} \mathrm{ml} \mathrm{H}_{2} \mathrm{O}$. The optimum thinning condition was found at $30 \mathrm{~mA}$ and $50 \mathrm{~V}$. The thinned specimens were examined in a JEM $7 \mathrm{~A}$ or a Philips EM 301 operated at $100 \mathrm{kV}$.

\section{Seannim transmission electron microscopy (STEM).}

The grain boundary segregation was studied with a Philips $\mathbf{4 0 0}$ scanning transmission electron microscope operated at $100 \mathrm{kV}$. Thin foils for the STEM analysis weie prepared using the same method as described for TEM. Chemical analysis of prain boundaries were carried out with an EDAX unit attached to the STEM.

\section{E. Auger Electron Spectrosetpy (AES).}

Specimens for Auger electron spectroscopic studies were cut from the bulk plates and machined to oversized dimensions before heat treatment. The srecimens were sealed and heat treated in stainless steel bags filled with argon gas. Following heat treatment, the specimens were machined to the shape and dimension; illustrated in Figure 3. In order to prevent any severe contamination of their sur'aces, each specimen was dried following successive distilled water and ethyl alcohol rinses. They were then stored in a dessicator until being tested.

The Auger electron spectroscopic studies were carried out with a PHI model 590 scanning Auger microscope (SAM) combined with a sca:Ining electron microcope and as $\mathrm{Ar}^{+}$ion-sputtering gun. At least two specimens were put into the reaction chamber equipped with an in-situ fracturing and cooling stage shown in Figure 4. The temperature of the specimen inside the reaction chamber was controlled by liquid nitrogen Aowing through the fracture stage, monitored by a thermocouple. Each specimen was cooled to liquid nitrogen temperature within 30 minutes. The specimens to be frac- 
tured were subjected to a $5 \times 10^{-10}-1 \times 10^{-9}$ Torr vacuum attained by employing a differential ion pump, a Ti sublimation pump, and a liquid nitrogen cold trap. The specimens were always impact-fractured by hammer to reveal its fresh fracture surface.

After fracture, the specimen was positioned in front of the SAM cylindrical mirror analyzer (CMA). The time required for the first Auger electron spectrum usually took no more than 5 minutes. The primary electron energy and peak-to-peak modulation used were $2 \mathrm{kV}$ or $5 \mathrm{kV}$ and $3 \mathrm{eV}$ or $6 \mathrm{eV}$, respectively, depending on the energy scanning range. The primary electron beam size ranging $2 \mu \sim 0.3 \mu$ in diameter was regulated according to the places needed to be analyzed. In order to obtain a typical spectrum from a grain boundary, at least 10 points on an intergranular cleavage surface were analyzed with $0.3 \%$ energy resolution, monitored by the attached scanning electron microscope. The time constant per point and the sweep rate were 0.03 second/point and $0.5 \mathrm{eV} / \mathrm{sec}$, respectively. For automatic data acquisition, a multipletechnique analytical computer system (MACS) provided with the PHI model 590 SAM was employed with the parameters: time/point (T/P) - 50 msec, peak-to-peak modulation (Mod) $-6 \mathrm{eV}$, and volt/step (V/S) $-1 \mathrm{eV}$. Most of AES chemical analyses were carried out by this programmed MACS.

Following the AES analysis on the fresh fracture surface, the surface was sputtered by an $\mathrm{Ar}^{+}$ion gun at normal incidence. In most cases, a primary ion beam voltage of $3 \mathrm{kV}$ was used. In order to derive the sputtering rate for a $\mathrm{Fe}-12 \mathrm{Mn}$ alloys, the same sputtering conditions were maintained as those for $\mathrm{Ta}_{2} \mathrm{O}_{5}$ epitaxy thin film reference. It is expected from other works (52) that the sputtering rates for Fe-12 Mn alloys were approximately $100 \quad \lambda / \min$ at $3 \mathrm{kV}$ and $50 \quad \AA / \min$ at $1 \mathrm{kV}$, respectively, which does not differ from those for the $\mathrm{Ta}_{2} \mathrm{O}_{5}$ reference by less than a factor of 2 . The sputtered regions were always re-analyzed to compare the difference tetween the surface before and after sputtering. 
Whenever it was necessary to determine the degree of contamination on the fresh and sputtered surfaces, the chemical analysis of the residual gas inside the reaction chamber was performed with a residual gas detector $3 \mathrm{M}$ Model 710 secondary ion mass spectrometer (SIMS). The relative chemical composition of the residual gas and the pressure inside the AES analysis chamber were recorded during AES analysis. 


\section{EXPERIMENTAL RESULTS}

\section{A. Intergranular Embrittlement of Fe-12Mn Steel in the As-Austenitized Condition.}

\section{Austenitizing treatment.}

Previous research $(14,15)$ has shown that the Fe-12Mn steel in the as-austenitized condition fails in a strikingly brittle intergranular fracture mode below the DBTT. The austenitizing treatment was performed at $1100^{\circ} \mathrm{C}$ for 2 hours which was followed by water quenching. The ductile-brittle transition occurred sharply at room temperature in the Charpy impact test as shown in Figure S. The decrease in the Charpy impact energy value on lowering temperature is correlated with the change in the fracture mode from a ductile dimple rupture mode (transgranular) to catastrophic intergranular fracture mode, as shown in Figure 6. Brittle intergranular fracture always occurred along the prior austenite grain boundaries, whose dimension was approximately $170 \mu \mathrm{m}$.

To investigate the effect of austenitizin? temperature on the fracture mode, the austenitizing treatments were conducted either (1) at temperatures ranging from $850^{\circ} \mathrm{C}$ to $1200^{\circ} \mathrm{C}$ for $2 \mathrm{hrs}$, or (2) from 2 hrs to $100 \mathrm{hrs}$ at $1100^{\circ} \mathrm{C}$, all of which were followed by water quenching. Two hour heat treatments were sufficient to obtain both the fully recrystallized austenite phase and to form a consistent microstructure. Table II shows that the prior austenite grain size of the Fe-12Mn steel changed from $15_{\mu} m$ to

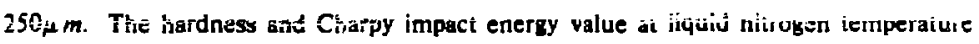
(LNT) were nearly independent of austenitizing temperature as shown in Figure 7. The fracture mode below the DBTT was $100 \%$ intergranular cleavsge irrespective of the prior austenite grain size. Figure 8 displays four different fractographs of very flat, smooth intergranular fracture facets alons prior austenite grain boundaries after austenitizing treatments at $850^{\circ} \mathrm{C}, 1000^{\circ} \mathrm{C}, 1100^{\circ} \mathrm{C}$, and $1200^{\circ} \mathrm{C}$, respectively. The change in holding time at $1100^{\circ} \mathrm{C}$ from $2 \mathrm{hrs}$ up to $100 \mathrm{hrs}$ affects neither the fracture mode nor the prior austenite grain size. The grain boundary microstructures are similar for all heat treatments, but the grain boundary chemistry will be disctissed in a later section. 
TABLE II

Changes in the Prior Austenite Grain Size and Fracture

Mode with Respect to Austeaitizint Temperature

\begin{tabular}{|ccc|}
\hline Heat Treatment & Grain Size $(\mu \mathrm{m})$ & Fracture Mode \\
\hline $850^{\circ} \mathrm{C} / 2 \mathrm{hrs} /$ WQ & -15 & Intergranular \\
$900^{\circ} \mathrm{C} / 2 \mathrm{hrs} /$ wQ & -30 & Intergranular \\
$1000^{\circ} \mathrm{C} / 2 \mathrm{hrs} /$ WQ & -85 & Intergranular \\
$1100^{\circ} \mathrm{C} / 2 \mathrm{hrs} /$ WQ & -170 & Intergranular \\
$1200^{\circ} \mathrm{C} / 2 \mathrm{hrs} /$ wQ & -250 & Intergranular \\
\hline
\end{tabular}

\section{High resolution AES analysis of Intergranulat cleavage surface.}

Chemical analyses of the intergranular cleavage surfaces of different grain sized specimeris were obtained using a high resolution scanning Auger microscope with a I $\mu m$ electron beam size, a $3 \mathrm{eV}$ peak-to-peak modulation, a $2 \mathrm{kV}$ primary electron voltage, and $0.3 \%$ energy resolution. A typical Auger electron spectrum obtained from the in-situ fracture surfaces of an Fe-12Mn steel in the as-austenitized condition is shown in Figure 9, together with the corresponding SEM fractograph. The surface-sensitive AES rechnique (41-45) was applied to detect any segregation within a monolayer of the surfase on the prior austenite grain boundaries, the fracture path of this alloy. High resolution AES analysis shows that in addition to the $\mathrm{Fe}$ and $\mathrm{Mn}$ Auger asctron peaks. there is a small carbon peak at $272 \mathrm{eV}$. Taking the sensitivity from $10 \mathrm{X}$ to $40 \mathrm{X}$, it is clear that there are no other significant peaks such as $P$ at $120 \mathrm{eV}$ and $S$ at $150 \mathrm{eV}$. Those Auger electron peaks are also consistently present in the specimens austenitized at different temperatures. Auger electron spectra obtained from the specimens which 
were gustenitized at $1100^{\circ} \mathrm{C}$ for either $40 \mathrm{hrs}$ or $100 \mathrm{hrs}$ show very similar chemistries except for the appearance of a small nitrogen Auger electron peak at $379 \mathrm{eV}$, as shown is: Figure 10. On occasion, a high intensity $S$ or $O$ peak was observed in the Auger electron spectra from an intergranular cleavage surface. First, a determination of the source of the $S$ or $O$ peak was carried out by a SEM fractographic study. As shown in Figure 11, high magnification SEM analysis revealed the presence of small precipitates along the cleavage surfaces. Precipitate size ranged from 0.5 to $5 \mu \mathrm{m}$ in diameter. On the average, five such precipitates were found to be associated with eac: - eavage surface. These precipitates were not easily distinguishable during lower magnification SEM examination. Chemical analysis of these precipitates using EDAX, shown in Figure 11, revealed that these precipitates are of two types. The first is $\mathrm{MnS}$, the other is an oxide or carbide precipitate of $\mathrm{Mn}$ which cannot be positively identified due to the limitations of the EDAX system. Second, a high partial resolution AES analysis was conducted over the fracture surface. In most cases a medium electron beam size $(1-2 \mu m)$ was used for the AES study. With a smaller electron beam size $(0.3 \mu \mathrm{m})$, chemical analyses of the precipitates and holes on the intergranular cleavage facets were carefully performed. Upon examining the fractograph in Figure 12, one interpretation could be that there possibly ixist four different chemistries. The chemistry detected is depende'it on the location of the point of analysis. From the Auger electron spectrum of Figure 12-a, this precipitate was identified as MnS which is in agreement with the EDAX result Figure 12-b reveals that this precipitate is a $\mathrm{Mn}$ oxide (possibly $\mathrm{MrO}_{2}$ ) whose surface was decorated by the segregation of S. The hole in the SEM fractograph of Figure 12-c was analyzed by Auger electron spectroscopy. Analysis of the spectrum shows at small amounts of $S, C$, and $N$ segregated along the interface between the precipitate and the prior austenite grain boundary. These segregations may reduce the interface energy so that the precipitate was easily separated from the matrix. An Auger electron spectrum identical to that produced by holes in the fracture surface was 
obtained from the flat fracture surface shown in Figure 12-d.

\section{C, N, or Ma on the prior austenite grain boundaries.}

As shown in the previous section, a small carbon or nitrogen peak in the Auger electron spectre (Figures 9 and 10) was always detected on fresh intergranular cleavage facets. It is believed that the grain boundary properties are influenced by the presence of carbon or nitrogen, which are assumed to have segregated to the prior austenite grain boundaries during austenitizing. To this extent a careful investigation into the source and effect of these elements was carefuily performed.

After AES analysis of the in-situ fractured surface, an $\mathrm{Ar}^{+}$ion-sputtering technique, which is described elsewhere (46-51) was employed. The use of this ionsputiering technique, combined with AES analysis, is very effective in studying the surface chemistry in two ways. First, it is possible that two different surface chemistries may be obtained before and after sputtering. Thus, AES analyses on the sputtered surface, as well as the unsputtered surface, may give evidence of some differences in the chemistry between the grain boundary and the matrix. Second, by comparing the peak-to-peak amplitude of definite elements by sputtering layer by layer, a depth profile of certain elements from the grain boundary to the inside matrix can be easily obtained within sub-layer sensitivity. This is possible because the AES analysis has a high depth resolution, on the order of one monolayer. Examination of this depth profile can tell how the concentration changes with respect to depth.

Figure 13 showy two different Auger electron spectra of the specimen austenitized at $1100^{\circ} \mathrm{C}$ for 2 hrs. Figure $13 \mathrm{a}$ was obtained from an intergranuiar fracture surface produced at LNT and thus indicates the prior austenite grain boundary chemistry. However, sputtering with $\mathrm{Ar}^{+}$ions for two minutes brought about a slightly different Auger electron spectrum of Figure 13b. The significant difference between the two spectra can be recognized as the existence of a carbon peak at $272 \mathrm{eV}$. An unsputtered surface has a small amount of carbon and a sputtered one does not. The small Auger 
electron peak at $215 \mathrm{eV}$ can be identified as an argon peak from $\mathrm{Af}^{+}$ions implantation. The occurrence of carbon segreffation in the specimen austenitized at $1100^{\circ} \mathrm{C}$ was partly proved by Figure 13. Employing higher sensitivity, it is easily recognized that carbon can be sputtered away from the grain boundaries, as shown in Figure 14.

An attempt to identify the status of carbon from the AES spectra was made by comparing carbon Auger electron peak shapes and peak energy shifts (42,52). As shown in Figure 15, the partial AES spectrum, produced by using higher sensitivity, furnisłtes more precise carbon peak shape and ensargy information. The comparison of carbon Auger peak shapes and energies between atomic carbon and a carbide is so distinct that the carbon reak in Figure 15 is believed to be one of carbides. However, despite this possibility, the existence of a continuous carbide film along the prior austenite grain boundaries in the specimens austenitized at $1100^{\circ} \mathrm{C}$ or even $1200^{\circ} \mathrm{C}$ is rejected. This theory could be confirmed by carbon depth profile analysis.

An AES analysis combined with an $\mathrm{Ar}^{+}$ion-sputtering technique (52) provides a concentration depth profile near the surface with less than a monolayer depth resolution. Determination between segregation and thin film (continuous second phase) phenomena was successfully accomplished by this depth profile analysis. The sputtering profile shown in Figure 16a depicts how carbon concentration changed with depth. The carbon depth profile indicates that carbon atoms are equilibrium-segregated to the prior austenite grain boundaries rather than as a thin carbide film. It was observed that the depth of carbon segregation is about 30 angstrom along the grain boundaries.

Small amounts of nitrogen were detected on the intergranular fracture surface in the specimens austenitized at $1100^{\circ} \mathrm{C}$ for $100 \mathrm{hrs}$. A small nitrogen Auger electron peak slowly appeared in the spectra when the specimens were austenitized at $1100^{\circ} \mathrm{C}$ for more than 40 hrs. The peak height of nitrogen is similar to that of carbon and it disappeared simultaneously with the carbon peak after 3 minutes of $\mathrm{Ar}^{+}$ion-sputtering. It is concluded from Figures $16 \mathrm{~b}$ and 17 that nitrogen had also segregated to the prior 
austenite grain boundaries.

Possible manganese segregation-was investigated by the $\mathrm{Ar}^{+}$ion sputtering technique. Manganese has four different major Auger electron transition peaks which are the KLL Auger transition peak at $40 \mathrm{eV}$, and the $\mathrm{LMM}$ peaks at $542 \mathrm{eV}, 589 \mathrm{eV}$, and $636 \mathrm{eV}$, respectively. Since the strongest $\mathrm{Mn}$ Auger electron peak at $589 \mathrm{eV}$ is very close to the strong Fe Auger peak at $598 \mathrm{eV}$, the strongest Mn peak at $542 \mathrm{eV}$ was used to obtain the $\mathrm{Mn}$ depth profile. As shown in Figure $115 \mathrm{a}$, the $\mathrm{Mn}$ concentration along the grain boundaries was not changed at all and thus, no Mn enrichment region exists along the prior gustenite grain boundaries to affect the grain boundary properties. However, the grain boundary composizion is presumably another important factor concerned with the intergranular embrittlement which will be discussed later.

Intergranular surface chemical composition was, calculated from the Auger peakto-peak amplitudes on the AES spectra of the specimen fractured in an ultra high vacuum $\left(6 \times 10^{-10}\right.$ Torr $)$. The atomic percent $C_{x}$ of element $\mathrm{x}$ is approximated by

$$
C_{x}=\frac{\frac{I_{x}}{S_{x} d_{x}}}{\sum \frac{I_{n}}{S_{n} d_{n}}}
$$

where $I_{x}$ is the peak-to-peak Auger amplitude, $S_{x}$ is the relative sensitivity between element $x$ and the standard, and $d_{x}$ is the scale factor which is $L_{x} E_{m, x} I_{p, x}$. The scale factor $d_{x}$ in this equation is constant if the lock-in amplifier sensitivity, $L_{x}$, modulation, $E_{m, x}$ and the primary beam current, $I_{p, x}$ settings used to obtain the test spectrum are the same for all peaks and cancel out. The relative sensitivity, $S_{w}$ is obtained from the "Handbook of Auger Electron Spectroscopy" (53), and is described in detail. Table III shows the chemical compositions of grain boundaries and matrix obtained by sputtering in two different austenitized specimens. The reported composition is the average of at least $S$ analyses. The chemical composition difference between the grain boundaries and the matrix is approximately 0.4 atomic percent carbon and 0.5 atomic percent nitrogen. 
TABLE III

Chemical Composition of Grain Boundaries and the Matrix Obtained by AES Analyses

\begin{tabular}{|ll|cccc|}
\hline \multirow{2}{*}{ Specimen } & \multicolumn{4}{c|}{ Chemical Composition } \\
\cline { 3 - 6 } & & Mn & C & N & Fe \\
\hline \multirow{2}{*}{$1100^{\circ} \mathrm{C} / 2 \mathrm{hrs} / \mathrm{WQ}$} & Grain Boundary & 12.5 & 0.4 & - & Bal. \\
& Matrix* & 12.6 & - & - & Bal. \\
\hline \multirow{2}{*}{$1100^{\circ} \mathrm{C} / 100 \mathrm{hrs} / \mathrm{WQ}$} & Grain Boundary & 12.4 & 0.4 & 0.5 & Bal. \\
& Matrix* & 12.4 & - & - & Bal. \\
\hline
\end{tabular}

- The chemical composition of the matrix. was obtained from the $A r^{+}$ions sputtered surface.

Despite an austenitizing treatment, the amount of carbon or nitrogen on the grain boundaries is consistent when the in-situ fractured surfaces was analyzed in UHV within a certain length of analyzing time. A significant build-up of carbon and oxygen peaks which occurred 30 minutes after fracturing, presumably is due to the decomposition of carbon monoxide (CO) (54) on the fresh surface. Surfice adsorption of $C$ and $O$, assumed to happen in UHV, was analyzed by the residual gas detector as shown in Figure 18. The adsorption of $\mathrm{C}$ or $\mathrm{O}$ in UHV is beyond the present research; however, most of the Auger data before 30 mitiutes are available for calculating the surface composition.

\section{Microstructure.}

Previous works (9.14,55-57) showed that an Fe-12 Mn alloy has three different crystal structures which are fcc austenite, bec a martensite, and hcp e martensite. The 
transformation temperatures measured by dilatometry are shown in Table IV. The various transformation temperatures of Fe-12Mn steel are slightly different from those of Fe-12Mn-0.2Ti because of the $\mathrm{Ti}$ addition. The appearance of the three different phases in Fe-12Mn alloy represent very unique submicrostructures. Figure 19 shows typical optical micrographs of specimens austenitized for 2 hrs at $900^{\circ}$ and $1100^{\circ} \mathrm{C}$, respectively. These micrographs show straight well-aligned martensite structures with different sized martensite packets. An attempt to reveal grain boundary etching $(58,59)$ due to impurity segregation as performed on other steels was not successful.

TABLE IV.

Transformation Temperature $\left({ }^{\circ} \mathrm{C}\right)$ af Fe-12Mn Alloy

\begin{tabular}{|c|c|c|c|c|c|c|}
\hline \multirow[t]{2}{*}{ Nominal Composition } & \multicolumn{6}{|c|}{ Temperature $\left({ }^{\circ} \mathrm{C}\right)$} \\
\hline & $A_{s 4}$ & $A_{f a}$ & $A_{s a^{\prime}}$ & $A_{/ a^{\prime}}$ & $M_{\text {sa }}$ & $M_{f a}$ \\
\hline Fe-12Mn-0.2Ti & 240 & 350 & 570 & 670 & 260 & 120 \\
\hline Fe-12Mn & 230 & 340 & 560 & 670 & 270 & 130 \\
\hline Fe-12Mn-0.2Ti-0.002B & 340 & 390 & 600 & 680 & 230 & 150 \\
\hline
\end{tabular}

- From Hwang's data.

In Figure 20, a transmission electron micrograph shows the microstructure of a region along the prior austenite grain boundary. The phases present in the microstructure are $\alpha$ - and e-martensite. An Fe-12Mn steel in the as-austenitized condition has blocky martensite structures which were often bound by thin -martensite. No apparent second phases were found along the grain boundary. The distribution of the 
e-martensite was also studied. A dark field transmission electron micrograph shown in Figure 21 displays no indication of a continuous film of -martensite along the boundary.

\section{B. Effect of Alloyint Elements}

\section{Addition of alloying elements.}

The present high resolution SAM studies, together with the previous results, strongly suggested that the intergranular fracture in Fe-12Mn was not caused by the formation of a deleterious phase on ar imfurity apqreqation th the prin- alsapn: boundaries. Hwang and Morris (19) also suggested that if the preference for intergranular fracture in $\mathrm{Fe}-12 \mathrm{Mn}$ is an inherent bias due to the relative difficulty of transgranular cleavage, then an appropriate approach to toughen the alloy, e.g., to change its fracture mode from intergranular to transgranular, would be to add a chemical species which segregates to the prior austenite boundaries and increase their relative c.uhesion. An addition of boron was successful in suppressing the intergranular embrittlement and improving the crygenic mechanical properties. However, the efiect of boron segregation on the impact toughness during austenitization was not fully investigated and the effect of the additions of other alloying elements on the intergranular לrittleness is unconfirmed.

Figure 22 shows the Charpy impact ene.gy ys. boron contents (ppm) in an Fe$12 \mathrm{Mn}$ alloy. austenitized at $1000^{\circ} \mathrm{C}$ for 1 hour. Regardless of austenitizing treatment, the maximum impact value was obtained in the specimen with $20 \mathrm{ppm}$ boron. This 20 ppm boron is the optimized content in evaluating the Charpy value even though an addition of boron ranging from $10 \mathrm{ppm}$ to $1000 \mathrm{ppm}$ changes its fracture mode. This result agrees with Hwang and Morris' work (19). Their autoradiography studies to reveal the segregation 0 : boron to grair. boundaries in the specimens austenitized at $1000^{\circ} \mathrm{C}$ were very successful, but not successful enough to quantitatively establish the 
amount of boron sezrezation.

As shown in Figure 23, austenitization at $1000^{\circ} \mathrm{C}$ for 1 hour followed by water quenchine sives maximum Charpy impact enersy value at LNT. If two major factors are considered to affect Charpy values, they are prior austenite grain size and the degree of boron segregation to the grain boundaries. Prior austenite grain size dramatically increases at temperatures higher than $1000^{\circ} \mathrm{C}$, as shown in Figure 24 . Careful examination of fractosraphs in Figure 25, shows that the specimen austenitized at $850^{\circ} \mathrm{C}$ for I hour displays $100 \%$ intergranular fracture and the fraction of intergranular fracture slowly decreases as heat treatment temperature soes up, yielding totally transgranular fracture in the specimen heat treated at $1000^{\circ} \mathrm{C}$. The build-up of boron sezrezation to the yrain bounderies was monitored by SAM study. An AES spectrum of Figure 26 shows the existence of boron on the grain boundaries. The amount of boron segregation was calculated to be approximately 0.7 atomic percent by using the previously described method. The specimens austenitized at higher temperatures have more boron segregation .0 the grain boundaries as shown in Figure 27. Unfortunately. the amount of boron sepresated in the austenite boundaries at $1000^{\circ} \mathrm{C}$ was not accurately obtained from this experiment. Since most of the segregation of metalloid impurities are reported to occur during an austenitizing treatment $(60,61)$, intergranular fracture was intentionally induced by short time tempering (10 minutes) at $650^{\circ} \mathrm{C}$ followed by eustenitizing at $1000^{\circ} \mathrm{C}$ for I hour and the amount of boron on the arain boundaries was calculated to be approximately 2.9 atomic percent. This result will be discussed later. It should, however, be aoted that austenitizing at $1000^{\circ} \mathrm{C}$ for 1 hour is the optimum condition for grain size effect and boron segregation. An attempt to find out other atloying elements which are also beneficial to increasing grain boundary cohesion was performed. Small amounts of Mt. Nb, or $\mathrm{Zr}$ are reported to segregate easily to the grain boundaries of $\mathrm{Ni-base}$ alloy or tigh strength alloys $(62,63)$. As for these alloying elements effect on the austenitization treatment, an addition of $0.1-0.5 \% \mathrm{Mg}$. 
$1 \% \mathrm{~V}$, or $0.1 \% \mathrm{Zr}$ did not segregate to the austenite boundaries and thus, are not assumed to affect the intergranular embrittlement. AES spectra obtained fron the iniergranulat fracture surface of the specimen are almost the same as that from the specimen without addition of $\mathrm{Mg}, \mathrm{V}$, or $\mathrm{Zr}$.

\section{Effect of sezretation of boron on the grain boundaries.}

As the austenitizing temperature for the Ie-12Mn with $20 \mathrm{ppm}$ of boron was raised from $850^{\circ}$ to $1000^{\circ} \mathrm{C}$. the fraction of intergranular fracture mode was dramatically reduced as shown in Figure 25 . Coincidentally, the change in the fracture mode was well-matched with the increase in the amount of boron segregated to the grain boundaries. The transformation temperature of the specimen with the addition of boron, measured by dilatometry, is shown in Table IV. Transformations for $\Leftrightarrow \gamma \quad$ and $\quad \alpha-\gamma$ in the specimen with boron occurred at slightly higher temperatures than in the specimens without boron and the $\gamma \rightarrow a^{\prime}$ transformation on cooling was obtained at a lower temperature. However, phases in the as-austenitized condition are fairly well preserved. Figure 28 provides TEM microstructures of the specimen with boron, which shows typical blocky type martensite. This microstructure was not affected by austenitizing temperature and time. As reported by Hwang and Morris (19), an addition of boron in Fe-12Mn acts as a 'grain boundary glue' and consequently prevents catastrophic intergranular failure along the prior austenite boundaries. The 'gluing effect' of boron largely depends on the grain boundary boron concentration. The fractograph of Figure $29 \mathrm{a}$ shaws that the specimen austenitized at $850^{\circ} \mathrm{C}$ has a completely intergranular cleavage surface which was analyzed to have less than 1 atomic percent boron. It is, however, noted that the fracture surface is not flat and smooth, but was plastically deformed. This phenome zon is more clearly seen in the specimen austenitized at a higher temperature. Figure $29 b$ displays less intergranular fracture and more ductility around the boundaries because more boron segregation to the grain boundaries. Optimum boron content on the grain 
boundaries (which was calculated to be about 3 atomic percent boron) develops fully transyranular fracture in the specimen austenitized at more than $1000^{\circ} \mathrm{C}$, as shown in Figure 30a. It is also noteworthy that transgranular fracture in this specimen is rather unique, not like dimple ruptured fracture. High magnification SEM fractograph of Figure $30 \mathrm{~b}$ clearly shows that failure occurred transgranularly with negligible plastic deformation.

\section{c. Efiect of Tempering in Fe-12Mn Alloys.}

In the previous sections, the investigation of intergranular embrittement of an Fe-12Mn steel in the as-augtenitized condition was investigated by high resolution SAM and the effect of a boron addition of the intergranular embrittlement were described. However, the boron-added $\mathrm{Fe}-12 \mathrm{Mn}$ alloy which was tempered at $450^{\circ} \mathrm{C}$ after ausienitizing treatment undergoes intergranular failure similar to that observert in an $\mathrm{Fe}-12 \mathrm{Mn}$ alloy without boron additions in the as-austenitized condition. In this section, the results of tempered martensite embrittlement in the Fe-12Mn alloy with and without the addition of boron are described.

\section{Tempered martensite embrirtlement.}

The variation of Charpy impact toughness (CVN) at LNT with tempering temperature for the boron modified Fe-12Mn alloy is shown in Figure 31. Tempering at a higher temperature of $450^{\circ} \mathrm{C}$ results in a large decrease in Charpy impact energy. The display of a 'toughness trough' around this temperature is the so-called tempered martensite embrittlement (TME). The variation of fracture mode with tempering temperature is shown in Figure 32. Specimens tempered at $250^{\circ} \mathrm{C}$ failed by a typical transgranular fracture mode (Figures $32 a$ and $b$ ) which is identical to the fracture mode in the as-austenitized specimen. As the tempering temperature was raised $10450^{\circ} \mathrm{C}$, the fracture mode chansed from almost transgranular to $100 \%$ intergranular clearage (Figures 3ic-f). Further tempering temperature increases result in a reversion to 
transgranular fracture (Figures $32 \mathrm{~g}-\mathrm{j}$ ). Examination of fractographs within this tempering temperature range leads to two significant results; one is that the specimen tempered in the embrittlement range always failed by intergranular cleavage along the prior austenite grain boundaries and the other is that the change in the fraction of the intergranular fracture mode is always coincidental with the change in Charpy impact energy values.

The ductile-brittle transition curves shown in Figure 33 represent the DBTT of the specimens in the as-austenitized and tempered $\left(450^{\circ} \mathrm{C}\right)$ conditions, respectively. The embrittling treatment results in an increase of the transition temperature by $150^{\circ} \mathrm{C}$. This increase in the transition temperature in the specimen tempered at $450^{\circ} \mathrm{C}$ after $1000^{\circ} \mathrm{C}$ austenitizing is accompanied by an appearance of a $100 \%$ intergranular fracture mode below the DBTT instead of a $100 \%$ transgranular fracture mode in the specimen in the as-austenitized condition. Since an Fe-12Mn steet without the boron addition always failed by intergranular cleavage below the transition temperature, the TME phenomenon of this alloy demonstrates an extension of the upper limit for observing intergranular fracture mode to a higher temperature by $150^{\circ} \mathrm{C}$ when the alloy was tempered at $400^{\circ} \mathrm{C}$ after austenitizing a: $1000^{\circ} \mathrm{C}$. This phenomenon is also illustrated in the ductile-brittle transition curves shown in Figure 34.

Since Hwang (14) pointed out some significant change of the grain boundary chemistry in the embrittled treated specimen, this present investigation toward tempered martensite emhrittement also concentrated on the AES study of the intergranular cleavage surface when the specimen became brittle. Due to its high sensitivity to surface chemistry and a need for one or two layers dimension detectability in studying the grain boundary structure, an AES technique could be applied only when the grain boundaries are exposed, as in the case of intergranular fracture surfaces. Before investigating the chemical source of the intergratiular embrittlement in the boron modified specimen tempered at $450^{\circ} \mathrm{C}$, extensive AES studies of the specimen without boron 
addition were performed due to their similarities. The reasons for starting with an Fe$12 \mathrm{Mn}$ alloy without boron are that this alloy always displays intergranuiar failure and tendency toward intergranular embrittlement by tempering, and is similar to the boronadded alloy. Some investigators (64) reported an application of AES technique in studying grain boundary chemistry by intentionally inducing intergranular fracture by means of hydrogen charging into the specimen, even though the specimen failed by transgranular cleavage or ductile rupture before charging treatment. The present research avoided this method for its complexity of explaining the embrittement phenomenon.

Two typical AES spectra obtained from the as-quenched (or quenched and tempered at $\left.250^{\circ} \mathrm{C} / 1 \mathrm{hr} / \mathrm{WQ}\right)$ and the embrittled $\mathrm{Fe}-12 \mathrm{Mn}$ steel are shown in Figure 35 . The most significant differences found between these two spectra were in the $\mathrm{Mn}$ Auger peaks. The relative intensity of the Mn peaks in the embrittled specimen is higher than that found in the other heat treated specimens by a factor of 3 . Except for the Mn Auger peaks, no other significant Auger peaks such as P, S, As or Sb appear. Figure 36 represents the chemistry of the intergranular fracture surface of the boronmodified Fe-12Mn alloy which was austenitized and tempered at $450^{\circ} \mathrm{C}$ for 1 hour. It is impossible to measure the change of the grain boundary chemistry during tempering with these specimens. However, this typical AES spectrum obtained from the embrittled boron-modified Fe-12Mn alloy can be summarized by the existence of the boron Auger peak at $179 \mathrm{eV}$, two Ti peaks, relatively strong $\mathrm{Mn}$ peaks and three major Fe peaks. It is plausible that the embrittled specimens without and with boron addition display higher Mn concentration on the intergranular fracture surfaces.

\section{Intereranular fructure surface chemistry.}

Tempering in the two-phase region has been extensively documented in many alloys (65-68), resulting in desirable cryogenic mechanical properties due to its effective grain refining through the two-phase decomposition. Tempering of Fe-12Mn alloys was 
initiated for this purpose. The definition for "grain boundary during tempering" in Fe$12 \mathrm{Mn}$ steels will be a priur austenite grain boundary in the martsnsite matrix because this boundary is a crystallographically high angle boundary and preserved during the two-phase decomposition. It should also be noted that a prior austenite grain boundary is believed to be the right unit for most chemical segregation, effective interruption of dislocation motion, and preferred sites for austenite nucleation.

The variation in grain boundary chemistry during tempering would be rather important if intergranular cleavage or Charpy impact energy is strongly dependent on chemistry of the grain boundary. An AES study of the intergranular cleavage surface obtained in an Fe-12Mn alloy was conducted for examining the varying chemistry on the prior austenite grain boundary, especially the $\mathrm{Mn}$ concentration. The variation of the Mn content during tempering was determined with the peak height ratio (PHR) of the Mn Auger peak at $542 \mathrm{eV}$ and the Fe peak at $703 \mathrm{eV}$. This ratio of $M_{n_{542}}$ and $\mathrm{Fe}_{03}$ demonstrates a very definite variation in intergranular fracture surface chemistry during tempering. It is, however, difficult to determine chemicai composition directly from this PHR. Figure 37 shows the variation in Mn concentration on the intergranular cleavage surfaces during tempering. As revealed by the curve, the PHR of Mn and Fe Auger peaks remains constant until the tempering temperature was raised above $300^{\circ} \mathrm{C}$ and then the PHR achieves a maximum value, approximately $38 \%$, at $400^{\circ} \mathrm{C}$. At higher temperatures, the PHR decreases to a slightly higher level than the primary PHR, which is about $13 \%$. The variation of the PHR of $\mathrm{Mn}$ and Fe, on isothermal treatment, is shown in Figure 38. The PHR curve shows an abrupt increase with holding time until 1 hour, after which grain boundary Mn enrichment is maximized. After 1 hour, the PHR gradually decreases to $28 \%$ on 280 hours treatment.

The chemistry of intergranular fracture surface of the boron-modified Fe- $12 \mathrm{Mn}$ alloy during heat treatment was regarded as rather difficult to analyze due to its tendency for transgranular fracture. However, the embrittling treatment on this alloy 
reveals an intergranular fracture surface. To monilor the change of fracture surface chemistry of the boron-added steel, an isothermal treatment at $450^{\circ} \mathrm{C}$ was conducted. Figure 39 shows the variation of Charpy impact energy of the specimen fractured at LNT with holding time up to 200 hours. The increase of hoiding time accompanied a gradual increase in Charpy impact value. Hardness remains relatively constant throughout the treatment. The upper curve of Figure 39 illustrates a decrease of intergranular fracture mode with holding time. This is also clearly seen in fractographs of Figure 40. The variation in intergranular fracture surface chemistry of the boronmodified Fe-12Mn alloy during isothermal treatment was successfully investigated by an AES study of the intergranular fracture surface exposed after fracturing. AES spectra obtained from the specimen which was isothermally heat treated for 1 hour, 10 hours, and $\mathbf{4 0}$ hours are shown in Figures 36, 41, and 42, respectively. Careful examination of these spectra is expected to show possible changes in Mn and B contents on the intergranular fracture surface. As illustrated in Figure 43, there are two significant curves which show the changes in the $\mathrm{Mn}$ and $\mathrm{B}$ contents. The upper curve in Figure 43 represents the change of PHR of Mn and Fe, which shows that Mn concentration on the intergranular fracture surface abruptly increase during treatment until 1 hour and slowly decreases to about $18 \%$ of PHR. This curve of te boron-modified alloy follows the same trend as that of an Fe-12Mn without the boron addition. The lower one shows the nearly consistent PHR of B and Fe during isothermal treatment. Ti was excluded due to its consistency throughout the heat treatments.

The $\mathrm{Mn}$ enriched region as well as $\mathrm{C}$ or $\mathrm{B}$ segregation, along the prior austenite grain boundaries was confirmed by the $A r^{+}$ion-sputtering technique, which was described in an earlier section. The sputtering profile obtained by this technique not only gives evidence of enrichment within one monolayer, but also makes it possible to calculate the thickness of the enriched region in angstrom. The sputtering piofiles in Figure 44 show the changes in $\mathrm{Mn}$ and $\mathrm{C}$ contents with sputtering depth in the speci- 
mens which were tempered at $250^{\circ} \mathrm{C}$ for 1 hour and $400^{\circ} \mathrm{C}$ for 1 hour, respectively, after austenitizing. The $M n$ concentration in the embrittled specimen dramatically decreases to that of the bulk composition after 0.2 minutes sputtering and $C$ concentration follows the same trend as described in the previous section. The boron-madified Fe- $12 \mathrm{Mn}$ alloy austenitized and tempered at $450^{\circ} \mathrm{C}$ for 1 hour snows the same characteristics of the sputtering profile of $\mathbf{M n}$ contents as that of an identically treated Fe$12 \mathrm{Mn}$ steel without boron, as illustrated in Figure 45 . The only difference between the two specimens is recognized as the existence of boron instead of carbon in the boronadded alloy.

In order to investigate the segregation of $\mathrm{Mn}$ in $\mathrm{Fe}-12 \mathrm{Mn}$ alloys with and without boron additions by comparing the same embrittling phenomena, AES studies combined with $\mathrm{Ar}^{+}$ion-sputtering of the embrittled specimens on the isothermal heat treatment were performed. The Mn sputtering profiles obtained by Fe-12Mn without boron were shown in Figures $46-49$. An Fe-12Mn alloy on the isothermal treatment at $400^{\circ} \mathrm{C}$ after austenitizing shows the variation of the Mn-enriched region on the intergranular fracture surfaces. The Mn-enriched region gradually increases as holding time progresses, while the Mn concentration abruptly increases until 1 hour and gradually decreases. The boron-modified alloy also shows the same characteristics of sputtering profiles as the alloy without boron, which is illustrated in Figures 45, 50, and 51. These sputtering profiles indicate that $\mathrm{Mn}$ segregated to the grain boundaries during tempering either at $400^{\circ} \mathrm{C}$ or $450^{\circ} \mathrm{C}$ for 1 hour and the chemistry of intergranular fracture surface was changed due to its microstructural change along the prior austenice boundaries. Figures 52 and 53 show the variation of the Mn-enriched region with the holding time on the intergranular fracture surfaces in the specimens with and without boron additions, respectively. Calculations of the enriched region were performed, based on the method described earlier, the trend is the same for both alloys except for the existence of boron segregation. These phenomena will be discussed later in relation to microstructural 
changes on the grain boundaries.

Figure 54 displays the TEM micrograph of the prior austenite grain boundary in the embrittled $\left(400^{\circ} \mathrm{C} / \mathrm{lhr}\right) \mathrm{Fe}-12 \mathrm{Mn}$ steel and the EDAX analysis on the grain boundary. The scanning transmission electron analytical microscopic (STEM) technique always shows an advantage in quantitative analysis with the microstructure. Since the Mn-enriched region from this embrittling phenomenon is far less than the STEM resolution capability ( $\$ 0 \AA$ minimum spot size), the EDAX study of the austenite boundary shows only that the grain boundary has quantitatively more Mn than the matrix by a factor of two. This STEM analysis, however, agrees well with the formation of the Mnenriched rezion studied by an AES analysis.

\section{Microstructure.}

Microstructural changes on the prior austenite grain boundaries during tempering were examined because the chemistry of intergranular fracture surface was found to vary significantly with tempering after austenitizing. The optical microstructures of the tempered Fe-12Mn without boron addition are shown in Figure 54. Tempering up to $450^{\circ} \mathrm{C}$ for 1 hour did not affect the optical microstructures even though $\mathrm{Mn}$ segregated to and formed an enriched region along the boundaries during this heat treatment, as shown in Figure 55a and 55b. Figure 55c clearly shows the prior austenite grain boundaries which, upon close examination, show the presence of a newly nucieated phase. The optical micrograph of Figure 55d shows that this new phase formed from austerite nucleation growing rapidly along the prior austenite boundaries to a recognizable size. These microstructures obtained after tempering and quenching are fresh inartensite (denoted by the lighter phase) and tempered martensite (dark phase).

As described earlier, an Fe-12Mn alloy without boron failed intergranularly below the DBTT and thus, the fracture surface reveals the intergranular cleavage facet along the prior austenite boundaries. The fractographs shown in Figure 56 represent the microstructural change on the austenite boundaries. The fractographs of Figure $56 \mathrm{a}$ 
and $56 \mathrm{~b}$ which were obtained from the specimens tempered at $250^{\circ} \mathrm{C}$ and $400^{\circ} \mathrm{C}$. respectively, show no change in grain boundary mic:ostructure during tempering. The intergranular fracture surfaces remained rather flat and smooth until tempering temperature was raised above $400^{\circ} \mathrm{C}$. Figure $56 \mathrm{c}$ shows that the specimen tempered at $550^{\circ} \mathrm{C}$ has relatively irregular boundaries which are different from the specimen tempered at lower temperatures. A higher temperature of $650^{\circ} \mathrm{C}$ brought more irregular intergranular fracture surfaces, as illustrated in Figure 56d. By somparing these fractographs with optical microstructures, it was noticed that the specimen always failed along the prior austenite boundaries and that the irregularity on the fractured surface is almost equal to the size of newly nucleated austenite phases which were shown in the optical micrographs. This irregularity on the grain boundaries is closely associated with austenite nucleation and growth during tempering. The microstructure change on the isothermal treatment was illustrated in the fractographs of Figure 57 and optical micrographs of Figure 58. Optical microstructures as well as fractographs clearly show the change from a flat and smooth surface to an irregular surface as hold time at $400^{\circ} \mathrm{C}$ increases.

The irregularities on the intergranular fracture surfaces (Fig. 56) can be explained by two possibilities, which are illustrated by the TEM micrographs. Firstly, the prior austenite grain boundaries were changed from the typical straight, flat boundaries to irregular boundaries by the intrusion of second phases between $\alpha$-martensite phases. A TEM micrograph of the intrusion of second phases between $\alpha$-martensite phases of the embrittled $\left(400^{\circ} \mathrm{C} / \mathrm{l} \mathrm{hr}\right)$ specimen shown in Figure $60 \mathrm{a}$ displays the unaffected and preserved boundaries while a long tempered $\left(400^{\circ} \mathrm{C} / 200\right.$ hrs $)$ specimen displays different boundaries as shown in Figure $60 \mathrm{~b}$. The TEM micrograph in Figure 60b reveals that the phases between the blocky a-martensite structures grew and intruded the previous straight boundaries. This intrusion of either retained austenite or \&martensite into the boundaries turned out to be the irregularity of the intergranular 
cleavage facets which were revealed after fracturing. Secondly, the preferential austenite nucleation along the boundaries formed after Mn enrichment, made the boundary irregular. A TEM micrograph of the long-tempered specimen shown in Figure 61a displays the microstructures along the austenite boundaries. From the schematic diagram of $61 \mathrm{~b}$, it can be clearly seen that the prior austenite boundaries have small new austenite grains (transformed to fresh martensite) and after fracturing, the fracture surface shows the observed irregularity. These TEM micrographs are well matched with the fractographs of Figures 56 and 57.

The boron-modified Fe-12Mn alloy presumably shows a similar trend, but due to its transgranular fracture during tempering except for the embrittling treatment around $450^{\circ} \mathrm{C}$, there can be no comparison of fractographs to show the changes in grain boundary microstructures. Isothermal treatment at $450^{\circ} \mathrm{C}$, however, snows a rather definite grain boundary microstructural change with time revealing the intergranular fracture surface. As holding time increases, the fraction of intergranular fracture (Fig. 39) gets smaller and grain boundaries gradually change from the flat, smooth surface to a rather irregular one as shown in Figure 59, hence, the grain boundary irregularity of the boron-modified Fe-12Mn alloy which was shown in the fractographs presumably has two sources; one is from the austenite nucleation and growth and the other from the boron 


\section{DISCUSSION}

\section{A. Intergranular Embrittlement of Fe-12Mn in the As-Austenitized Condition.}

\section{The source of interzranular brittleness: chemistry.}

Intergranular fracture due to crack propagation along prior austenite grain boundaries in Fe-12Mn alloy in the as-austenitized condition was well documented by Hwang and Morris $(14-16,19)$. It was assumed that the typical s.?rces of intergranular fracture are the segregation of metalloid impurities to the austenite boundaries (20-32) and the formation of a deleterious second phase on the boundaries $(39,40,60)$. The previous conclusion that the intergranular brittleness in Fe-12Mn arises from neither of these causes, but is from its inherent microstructure (14), lead to a further investigation concerning possible chemical sources on the grain boundaries. Since an attempt to reveal the second phase along the boundaries never succeeded, the effect of a deleterious second phase on intergranular embrittlement was excluded and thus, most of these studies were focused on individual chemical species found by employing high resolution SAM.

Mais, ..uvesugacivas $(29,69-71)$, attempted to relate tive existence and extent of impurity segregation to decreasing cohesive strength of the interphase boundaries as a consequence of especially $\mathbf{P}$ or $\mathbf{S}$ segregation. The impurity segregation which could affect the boundary failure should present a suitable amount of impurities on the boundaries. Detection of the existence and the amount of chemical species on the intergranular fracture surface varies with the sensitivity of the Auger spectrometer, involvins spatial and spectroscopic resolution. A primary interest lies in the detection of $\mathbf{P}$ segregation on the boundaries, since chemical composition of the buik material (Table II shows a very small amount of $\mathbf{P}$. High tesolution SAM studies using high sensitivity nevertheless never show a reasonable amount of $\mathbf{P}$ (more than 0.1 atomic percent) on the intergranular fracture surface. Segregation of $S$ is thought to be one of the sources of the tempered martensite embrittlement of high purity steel $(37,38)$. Occasionally a 
relative large $S$ Auger peak was detected, but this $S$ peak came not from the segregation of $S$ but from sulfide precipitates on the boundaries (Figures 11 and 12).

The effect of oxygen on intergranular fracture has been extensively irvestigated in many alloys, especially with high temperature mechanical tests (72-76). Grain boundary diffusion of oxygen in addition to oxidation is assumed to accelerate this oxygeninduced intergranular embrittlement. However, detection of oxygen is considered to be the most difficult AES analysis, even in the ultra high vacuum, due to the fast build-up of oxygen contamination on the fracture surface. However, like the S Auger peak, the source of the $O$ Auger peak results not from segregation, but from oxide precipitates $\left(. \mathrm{H}_{n} \mathrm{O}_{2}\right)$ on the grain boundaries. The minor second phase which is not continuous along the grain boundaries may affect the grain boundary properties, but the observed precipitates on the fracture surface facet are very rare in number and the denuried grain boundary facets show little plasticity. However, due to the sulfur segregation on the precipitate surface, it is recognizable that those precipitates were easily differentiated from the matrix (Figures 12 and 13 ).

The roles of $\mathbf{C}$ and $\mathbf{N}$ in alloy design are important issue. It is reported that $\mathrm{C}$ or N not only enhances the strength $(77,78)$ of most steel alloys, but also affects their fracture modes $(34,79-82)$. The $\mathbf{N}$ Auger peak appeared on the frarture surface in the specimen austenitized at $1100^{\circ} \mathrm{C}$ for more than 40 hours. Since the intergranular fracture appeared the absence of $\mathrm{N}$ peak shown in Figure 9, nitrogen is assumed not to be the source of the intergranular embrittlement. As reported by McMahon (82), increasing the carbon content showed the beneficial effect of suppressing the intergranular intergranular fracture. Carbide formation, however, promoted to intergranular fracture $(33,34)$, but attempts to show active carbon contents on the prior austenite grain boundaries to influence the cohesive strength of the boundaries were unsuccessful. The present AES study represents ne carbon contents on the intergranular fracture surface in Table III. The chemical a calysis was very carefully conducted, usually within 5 
minutes after being fractured before the $C$ can build up under an ultra-high vacuu . If the impurity segregation on the prior austenile boundaries is considered when the alloy undergoes intergranular fracture, according to other cases (10-32.70), about 0.4 atomic percent carbon which segregated during austenitizing is believed to be insufficient to affect the fracture mode. Also, the boron-modified alloy, which was subjected to an embrittling treatment, shows intergranular fracture in the absence of carbon. The roles of carbon and nitrogen, however, remain unsolved and require further investigation.

\section{The source of intergranular brittleness: microstructure.}

The cause of the intergranular brittleness of Fe-12Mn in the as-austenitized condition does not appear to be due to segregation of deleterious species. Nor is brittleness caused by a microstructural disturbance such as the formation of a precipitate or a second phase on the prior austenite grain boundaries. From the results obtained by high resolution AES and TEM studies, it seems more plausible to detect the source of the intergranular weakness in the inherent resistance of the internal microstructure to the transgranular cleavage mode.

The previous work by Hwang and Morris $(16,19)$ detailed the characteristic microstructure of Fe-12Mn steel in the as-austenitized condition. Typically in the Fe$12 \mathrm{Mn}$ alloy, a competing transformation of the present austenite to the hexagonal emartensite phases intrudes during the $\gamma \rightarrow \alpha$ transformation. The intrusion of the emartensite phases results in a substantial change in the substructure of the alloy with a unique, blocky type, dislocated $\alpha$-martensite divided by regions which contain 6 martensite, as shown in Figure 20. This rather irregular substructure formed on cooling Fe-12Mn after austenitizing furnishes the alloy with a high resistance to transgranular cleavage fracture. Consequently, when the alloy undergoes brittle fracture, the fracture path is preferentially intergranular rather than transgranular. On the other hand. the Fe-8Mn alloy forms a lath martensite structure on cooling which resembles that of a typical Fe-Ni steel of intermediate nickel content (83). As in the Fe-Ni steels, the 
substructure of Fe-8Mn consists of well-aligned lath martensite and provides preferable cleavage fracture through packets of adjacent laths (14). The compurison between two substructures of Fe-12Mn and Fe-8Mn alloy ofiers a straight forward explanation of the difference between the intereranular failure of Fe-12Mn and the transgranular cleavage fracture of Fe-8Mn tested below its DBTT.

The mechanism of fracture in an Fe-12Mn is also illustrated by the schematic diagram, as shown in Figure 62. Ductile-to-brittle transition behevior is well described by the yield strength $(\sigma \mathrm{y})$, the fracture stress for transgranular cleavage ( $\sigma \mathrm{fc})$ and the fracture stress for intergranular crackin ( $\sigma$ fab). The fracture stresses are assumed relatively insensitive to temperature. The ductile-to-brittle transition is then associated with a chante in the fracture mode from ductile rupture to brittle fracture when the vield strength rises above the lower of the two critical fracture stresses. While the inherent strength of the grain boundaries $(\sigma \mathrm{fg})$ for both alloys was assumed comparable, the transgranular cleavage fracture stress $(\sigma \mathrm{fc})$ in Fe-12Mn is assumed higher than that in Fe-8Mn due to their submicrostructures. As a consequence, the Fe-12Mn alloy with its inherent microstructure always failed intergranularly because $\sigma$ fgb $<\sigma$ fc. However, the effect of grain boundary chemistry on o fgb is uncertain and will be discussed later.

\section{B. Efiect of Boron Segregation}

\section{Sezrepation of boron.}

The basic approsch to segregation behavior was first described by Langmuir (84) by using saturated typ of solid/zas adsorption. His assumptions of fixed saturation level and no adsorbate interactions were inadequate. A more satisfactory derivation was

proposed for grain boundary segregation by McLean (85), who provides a relatively desirable equation which minimizes of the free eneryy (by usins vacant lattice sites and crain boundary adsorption ener(y). His model was criticized. modified and extended to 
represent the ternary regular solution model of Guttmann (86). While McLean's model, in zeneral, shows that sezregation rises as the solute content rises and the temperature falls, the equation developed by Guttmann involves the interaction coefficients which are more important in evaluating the amount of segregation.

The equilibrium segregation of impurities such as $\mathrm{P}, \mathrm{S}$, and $\mathrm{Sb}$ was widely studied in order to explain the consequences of tempered embrittlement and tempered martensite embrittlement of steel alloys because of the availability of surface sensitive instruments. These embrittling phenomena involved two different heat treatments which might control impurity segregation to the prior austenite grain boundaries; austenitizing and tempering treatment. Most segregations to the austenite grain boundaries (which might be sufficient to affect the grain boundary cohesive strength) are believed to proceed during austenitizing. However, due to easy access to monitoring the change of grain boundary chemistry from embrittling treatment (tempering after austenitizing), studies of equilibrium segregation of impurities during tempering were widely performed. The segregation of boron in the boron-modified Fe-12Mn alloy is mainly restricted to austenitization due to its simple treatment. The austenite grains in an Fe$12 \mathrm{Mn}$ also have crystallographically high angle boundaries and thus provide most preferable vacant sites for impurity segregation during austenitizing treatment (87-89).

The boron-added Fe-12Mn alloy austenitized at $850^{\circ}$ for I hour showed the $100 \%$ intergranular fracture and made it possible to determine the boron contents on the boundaries at this temperature. The boron contents from austenitizing treatment at higher than $900^{\circ} \mathrm{C}$ obtained by an AES study of the austenitized $\left(1000^{\circ} / 1 \mathrm{hr} / \mathrm{WQ}\right)$ and tempered $\left(650^{\circ} / 10 \mathrm{~min} / \mathrm{WQ}\right)$ specimen because this treated specimen showed the $100 \%$ intergranular fracture mode and the change of boron contents by short tempering (10 $\mathrm{min}$ ) is believed not to be significant from low ditusivity of boron at $650^{\circ} \mathrm{C}$ and most of the B segregation sccurred during austenitizing. The relative boron contents were also confirmed by the autoradiography works $(19,90)$. As shown in Table $V$, the boron 
content on the prior austenite boundaries increases as the austenitizing temperature is raised. This result is contrary to other work on equilibrium segregation (91). However, the increase of austenitizing temperature causes the grain size to increase from $15 \mu$ at $850^{\circ} \mathrm{C}$ to approximately $85 \mu$ at $1000^{\circ} \mathrm{C}$. This increase in grain size could affect the boron content on the boundaries because the grain boundary area would decrease alone with the fixed boron contents in the matrix. It is also assumed that the kinetics of boron diffusion at different temperatures played a practical role in affecting segregation. As a consequence, the optimized boron content ( 3 atomic percent), segregated to the prior austenite grain boundaries from the austenitizing treatment $(1000 \% 1 \mathrm{hr})$, could carry its most beneficial effect on the grain boundary cohesive strength.

\section{TABLE V}

\begin{tabular}{|ll|ccc|}
\hline \multicolumn{2}{|c|}{ Heat Treatment } & Mn & B & Fe \\
\hline $850^{\circ} \mathrm{C}, 1 \mathrm{hr}$ & Grain boundary & 12.7 & 1.1 & Bal. \\
& Matrix & 12.6 & - & Bal. \\
\hline $900^{\circ} \mathrm{C}, 1 \mathrm{hr}$ & Grain boundary & 12.0 & 1.8 & Bal. \\
& Matrix & 12.8 & - & Bal \\
\hline $1000^{\circ} \mathrm{C}, 1 \mathrm{hr}{ }^{\circ}$ & Grain boundary & $(29.0)$ & 2.9 & Bal. \\
& Matrix & 12.7 & - & Bal \\
\hline $1000^{\circ} \mathrm{C}, 1 \mathrm{hr}$ and $450^{\circ} \mathrm{C}, 1 \mathrm{hr}$ & Grain boundary & 28.4 & 2.9 & Bal. \\
& Matrix & 12.7 & - & Bal. \\
\hline $450^{\circ} \mathrm{C}, 40 \mathrm{hrs}$ & Grain boundary & 17.1 & 2.4 & Bal. \\
& Matrix & 12.6 & - & Bal. \\
\hline
\end{tabular}

- The specimen was embrittled at $650^{\circ} \mathrm{C} / 10 \mathrm{~min}$ after austenitizing treatment $\left(1000^{\circ} \mathrm{C} / 1 \mathrm{hr} / \mathrm{WQ}\right)$. 


\section{The beneficial efiect of boron sezrezation.}

A microaddition of boron in medium carbon steel was found to improve its ductility as well as impact toughness at low temperature. Pyatakava and his coworkers (9295) concluded that boron segregation may leas to $a$ uniform microstructure to relieve local stresses from an uneven distribution of carbon and/or carbide precipitates. Other works (96-98) showed that boron appears to be exceptionally beneficial in that it segregates to austenite grain boundaries and improves creep-rupture life and ductility. These effects were attributed to the formation of more stable boron-precipitates or retardation of oxygen diffusion along the grain boundaries. However, none of these works proposed the improvement of the cohesion of the grain boundaries by boron segregation. Previous work by Hwang and Morris (19) implies that the segregation of boron may be attributed to the increase of the net change in surface energy per unit area of fresh fracture surface by reducing the grain boundary tension due to grain boundary surfactant, and this increase causes the suppression of DBTT. In this study, a more quantitative approach to investigate the effect of boron on surface tension was not carried out due to its intrinsic complexity.

TEM microstructures (Fig. 27) show the typical blocky a-martensite in the austenitized $\left(1000^{\circ} / 1 \mathrm{hr} / \mathrm{WQ}\right)$ specimen. This boron-modified specimen displays no TEM microstructural difference from an Fe-12Mn without boron addition. Furthermore, the increase in austenitizing temperature from $850^{\circ} \mathrm{C}$ tc $1000^{\circ} \mathrm{C}$ did not affect its TEM microstructure. However, if we compare the fractographs of two different specimens with and without boron additions (Figure 8 and Figure 29, respectively), there appear to be significantly different in the intergranular fract : surfaces in that the boron-added alloy displays more plastic deformation along the boundary than does the alloy without boron. This plastic deformation develops more significantly when the boron alloy was austenitized at a higher temperature (Figure 29). Since the boron content on the boundary is believed to be the only factor (Table V), the increase in boron 
content along the boundary enhances the resistance to a fracture path along the prior austenite grain boundaries and a totally transgranular fracture mode (Figure 30) is presumably due to the increase of grain boundary cohesive strength by optimized segregation of boron to the boundary. This 'gluing effect' of boron appears speculative and needs further investigation.

\section{Efiect of Tempering.}

\section{Te mpered martensite embrittlement.}

Embrittlement in ferritic Fe-Mn al loys were reported by several workers (11,99). In this study the tempered martensite embrittlement in Fe-12Mn alloys with and without boron addition could be described as raising the DBTT by $150^{\circ} \mathrm{C}$. This DBTT increase would be the main consequence of the formation of a Mn-enriched region along the prior austenite grain boundaries as shown in the present observations. The possibility of Mn enrichment on the austenite boundaries during tempering could be predicted to be dus to the following reason: the tempering effects in is-Mn alloys are assumed to provide more vacant sites along the high angle grain boundaries in the highly dislocated martensite structure during tempering. The dislocation interaction along the high angle boundaries during tempering is rather speculative, but, in most cases, the dislocation density in matrix during tempering greatly decreases $(100)$ and presumably the decrease in dislocation density results in more vacant sites for manganese segregation to the austenite boundaries during tempering. Since Mn segregation to the austenite boundaries requires both sufficient vacant sites along the boundaries and a low free energy of segregation, the following two factors could explain this segrepation phenomenon which is assumed to cause the DBTT increase: 1.) more vacant sites on the boundaries provided during tempering or 2.) the low vapor pressure of $\mathrm{Mn}$. This segregation phenomenon could be easily confirmed by the following indirect evidence: As holding time at $400^{\circ} \mathrm{C}$ increases in Fe-12Mn steel, the amount of $\mathrm{Mn}$ segre- 
pation abruptly increases and the Mn-enriched region was obtainable by a submicro scale diffusional process, as shown in Figure 37. However, the growth of the Mnenriched region does not continue after 1 hour of tempering. reaching a $20 \AA$ thickness. This is because the diffusion of the substitutional Mn atoms must be limited to short distances at the relatively low temperature of $400^{\circ} \mathrm{C}$.

Tempered martensite embrittlement was widely investigated in many rnartensitic steels. The embrittlement causes a deterioration of toughniess and the embrittling sites have been delineated to be either transgranular or intergranular. Thomas (39) and Ritchie, et al. (40) proposed the model which shows that thermally unstable retained austenites along the lath boundaries transform to carbide during low temperature tempering resulting in a transgranular fracture mode, while McMahon (60) and Banerji, et al. $(37,38)$ showed that impurity segregation and carbide formation are the cause of the intergranular brittleness. The present experimental evidence follows neither of these embrittling models. From the experimental observations, it appears that there is no impurity segregation or carbide formation either along the prior austenite boundaries or the lath boundaries.

From the present observations, it was deducted that the segregation of $\mathrm{Mn}$ in these alloys is directly responsible for the TME. It is rather difficult to investigate the effect of Mn segregation on the embrittlement by any mechanical tests because the enriched regions are of submic n dimensions as described in Figures 52 and 53 . However, two possible explanations can be drawn from the investigation. First, a hypothetically brittle interface forms between two thin layers of Mn-enriched and Mn-depleted regions. Depth profiles shown in Figures 44 and $\mathbf{4 6}$ display two different regions along the austenite grain boundaries. As the Mn-depleted region slowly disappeared as the holding time increased (Figures 49.50), the fraction of intergranular fracture decreased and finally settled to less than 5\% (Figure 38). Second, the segregation of Mn causes inhomogeneity of solute atoms along the boundaries and may induce solution- harden- 
ins along the boundaries as similarly described in other works $(99,100)$. These solution-hardened regions provide at. asy fracture path along the austenite boundaries.

As described earlier, the preference of fracture mode below the DBTT was made by the comparison between the fracture stress for transgranular cleavage $(\sigma \mathrm{fc})$ and the fracture stress for intergranular crackings ( $\sigma$ fgb) as shown in Figure 62 . The yield strength $(\sigma \mathrm{y})$ and the transgranular cleavage fracture stress $(\sigma \mathrm{fc})$ are assumed insensitive to the grain boundary chemistry. On the other hand, the intergranular cleavage fracture stress $(\sigma \mathrm{fBb})$ is not sensitive to temperature, but is increasing or decreasing depending on the grain boundary chemistry. Consequently, the Fe-12Mn without boron always display intergranular fracture because the $\sigma$ fc due to the formation of the enriched region, otherwise the $\sigma \mathrm{fgb}$ is kept lower than the $\sigma \mathrm{fc}$ due to the effect boron segregation.

\section{Grain boundary chemistry and microstructure.}

The chemical composition of the grain boundary has been regarded as one of the most important subjects when the alloy becomes embrittled, especially in an intergranular fracture mode. Much research work $\left(2^{\circ} 64,101,102\right)$ have been done on the determination of grain boundary chemistry to interpret the intergranular embrittlement by using surface-sensitive instruments or scanning transmission electron microscopic studies. In most cases, solute enrichment at grain boundaries was restricted to the more common impurities in iron such as P, S, N, Sn and Sb. These solute atoms were found to be at grain boundary concentrations more than $10^{2}$ times the bulk concentrations, which are at least several hundred ppm.

However, segregations of boron and ranganese to the austenite boundaries in the Fe-Mn alloy during tempering are rather feculiar. Boron, in particular, strongly segregates to the austenite boundaries with the highest concentrations during austenitizing. The tempering treatment after austenitizing did not affect the amount of boron segregation (Figure 43). The boron concentrations on the boundaries remain nearly constant 
even after lons isothermal heat treatment at $450^{\circ} \mathrm{C}$. The boron enrichment ratio between the boundary and the matrix was obtained with difficulty because the boron content in the matrix could not easily be detected (actual bulk content is 20 ppm). The enrichment ratio, however, is presumably higher than any reported ratios $(104,105)$.

Manganese, as reported earlier, had not formed the enriched region along the austenite boundaries after austenitizing. The tempering treatment around $400^{\circ} \mathrm{C}$ promotes the manganese segregation to the boundaries. The Mn enrichment on the intergranular fracture surfaces suddenly reached its peak concentration at the embritting temperature and slowly decreased as the tempering temperature or the tempering time increared (Figure 37). As shown in Figure 37, the Mn enrichment ratio in an Fe-12Mn boron-free alloy is approximately on the order of 3, while the boron-modified Fe-12Mn alloy has a slightly lower enrichment ratio. This is due to the amount of previous boron segregation. As demonstrated earlier (Figures 60 and 61 ), the chemistry of intergranular fracture surfaces siudied by AES could not apply to the chemistry of the prior austenite grain boundaries because the change of grain boundary structures affects the fracture path along the boundaries and, thus, most of the AES analyses showed the chemistry of intergranular fracture surface, not exactly of the prior austenite grain boundaries. There is always competition between chemical species for grain boundary sites in many steels due to their different segregation free energies. In the present study, boron did not hinder manganese segregation to the austenite boundaries during tempering. The tendency of Mn enrichment during tempering in Fe-12Mn alloys with and without boron additions is identical.

The response of intergranular fracture surface chemistry to tempering treatment in the boron-added alloy is well described by the changes in the peak height ratios (PHR) for Mn/Fe and B/Fe (Figure 43). Thermodynamically, the PHR at grain boundaries will either increase or equilibrate with that of the matrix. However, the PHR, $\mathrm{Mn} / \mathrm{Fe}$ decreases as the tempering time increases. This phenomenon may be explained 
by the fractographs (Figure 56) and grain boundary microstructures (Figure 55). Mn segregation to the boundaries reaches approximately 32 atomic percent $\mathrm{Mn}$ after 1 hour tempering at $450^{\circ} \mathrm{C}$. Longer tempering time provides for either the intrusion of phase into the boundaries or the nucleation of new austenite on the highly Mnconcentrated region (Figures 60 and 61). Other results on Ni-steel (106) has shown that newly nucleated austenite appears not only on the prior austenite boundaries but also along the lath boundaries during two-phase tempering because both boundaries furnished equal opportunity for nucleation from the highly dislocated martensite. The predominant austenite nucleation on the prior austenite boundaries can be easily confirmed by the optical micrographs of the tempered $\left(650^{\circ} \mathrm{C} / 1 \mathrm{hr}\right) \mathrm{Fe}-12 \mathrm{Mn}$ steel (Figure S5). The PHR change with respect to tempering temperature is virtually identical to the PHR change with respect to isothermal treatment time. Furthermore, the intergranular fracture surfaces from the fractographs of Figure 57 are also similar. As the PHR, Mn/Fe decreases, the irregularity along the prior austenite boundaries becomes more apparent, which suggests that nucleated austenite grain growth is occurring. This austenite grain growth along the prior austenite boundaries affets not only the change of PHR, Mn/Fe on the fracture surface, but also the fracture mode in the boron-modified steel. The intergranular fracture mode in the boron-modified Fe-12Mn steel after tempering at $450^{\circ} \mathrm{C}$ for 1 hour is caused by the Mn-enriched region ( 3 times higher than the matrix) along the boundaries. The Mn-enrichment ratio decreases during isothermal treatment through a change in the grain boundary structure from austenite grain growth. The Mn-enriched region has a very slow tomposition gradient from the intergranular fracture surface (Figure 49). The fracture mode then reverts to transgranular as in the as-quenched specimen. This conclusion is based on the similarity of the Mn enrichment ratios on the intergranular fracture surface of the Fe-12Mn alloy with and without boron additions. 


\section{v. CONCLUSIONS}

The main results from the present research may be summarized as follows:

\section{A. Interzranular Embrittlement of an Fe-12Mn in the As-Austenitized Condition.}

1. The alloys fractured below the DBTT have an intergranular fracture mode, irrespective of grain size over the range of $15-250_{\mu} \mathrm{m}$.

2. High resolution AES analyses on the intergranular fracture surface revealed no consistent impurity segregation such as $\mathrm{P}, \mathrm{S}, \mathrm{Sb}$, As or $\mathrm{O}$, but did show a slight segregation of cirbon. Some nitrogen, logether with carbon, were found in the further austeniizid $\left(1100^{\circ} \mathrm{C} / 100 \mathrm{hrs} / \mathrm{WQ}\right)$ specimen.

3. An occasionai presence of $S$ or $O$ Auger peak on the intergranular fracture surface was associated with $\mathrm{MnS}$ or $\mathrm{MnO}_{2}$ precipitates along the prior austenite boundaries.

4. $\mathrm{Ar}^{+}$ion sputtering on the fracture surface showed equitibrium segregation of carbon with approximately $30 \AA$ depth to the boundaries, but not any $M n$ enrichment at the grain boundaries.

5. The intergranular brittleness of an Fe-12Mn alloy in the as-austenitized condition is not due to chemical changes on the prior austenite boundaries but is rather due to the microstructural effect on the preferential fracture path along the grain boundaries.

\section{B. Efiect of Alloying Elements on Intergranular Embrittlement.}

1. A $20 \mathrm{ppm}$ boron addition with $1000^{\circ} \mathrm{C} / 1 \mathrm{hr} / \mathrm{WQ}$ heat treatment yielded the highest Charpy V-notch impact energy at LNT and changed the fracture mode from intergranular to transgranular.

2. The AES studies on the grain boundaries in the boron-modified alloy showed thas the increase in concentration of boron segregation from 0.7 atomic percelat to 
about 3 atomic percent to the prior austenite boundaries results in the highest 'Rluing effect' of boron.

3. Trace additions of $\mathrm{Mg}$. $\mathrm{Zr}$, or $\mathrm{V}$ in an Fe-12Mn steel hardly segregated to the grain boundaries during the austenitizing treatment and, thus, had negligible effects on the intergranular embrittlement.

\section{Efiect of Tempering in Fe-12Mn Alloys.}

1. A $400^{\circ}$ or $450^{\circ} \mathrm{C}$ tempering for 1 hour of the Fe-12Mn glloys without and with boron addition raised the ductile-brittle transition by $150^{\circ} \mathrm{C}$. The tempered martensite embrittlement in Fe-12Mn alloys was found to be mainly due to a $\mathrm{Mn}$ enriched region along the prior austenite boundaries.

2. The high resolution AES studies combined with $\mathrm{Ar}^{+}$ion-sputtering showed that the Mn-enriched region of the embrittled specimens was approximately 32 atomic percent $M n$ with boron addition and 38 atomic percent $M n$ without, with a $20 \AA$ thickness.

3. The change in Mn-entichment on the intergranular fracture surfaces of the boron-modified Fe-12Mn alloy is directly associated with the change in the fracture mode as well as the CVN values.

4. After Mn enrichment further tempering causes preferential austenite nucleation along the prior austenite boundaries, affects the grain boundary microstructures, and changes the chemistry of intergranular fracture surfaces. 


\section{REFERENCES}

1 G. R. Brophy and A. J. Miller: Trans. ASM, 1949, vol. 41, 1185.

2 B. E. Hopkins and H. R. Tipler: J. Iron Steel Inst., 1958, vol. 188, 118.

3 W. Jolley: J. Iron Steel Inst., 1968, vol. 206, 170.

4 W. C. Leslie, R. J. Sober, S. G. Babcock and S. J. Green: Trans. ASM, 1969, vol. 62,690 .

5 T. Ooka, H. Mimura, S. Yano, K. Sugine and T. Toizumi: J. Japan Inst. Metals, 1966, vol. $30,442$.

6 H. Sakurai, S. Yano. T. Inoue, H. Mimura and K. Aoki: J. Japan Inst. Metais, 1969, vol. 33, 856 .

7 D. Mann: "LNG Material and Fluids", Cryogenic Div., Inst. for Basic Standard, NBS, Ist ed., 1977.

8 J. W. Morris, Jr., S. K. Hwang. K. A. Yuschenko, V. T. Belotzerkovetz and O. G. Kvasnerskii: Advances in Cryogenic Engineering, 1978, vol 24, 91.

9 M. J. Roberts: Met. Trans., 1970, vol. 1, 3287.

10 A. Holden, J. D. Bolton and E. R. Petty: J. Iron Steel Inst., 1971, vol. 209, 721.

11 J. D. Boiton, E. R. Petty and G. B. Allen: Met. Trans., 1971, vol. 2, 2915.

12 S. K. Hwang, S. Jin and J. W. Morris, Jr.: Proc. 4th Int. Conf., Strength of Metals and Alloys, Laboratoire de Physique due Solide, Nancy, France, 1976, vol. $2,842$.

13 S. K. Hwang and J. W. Morris, Jr.: Proc., USSR-US Seminar on Applied Problems of Low Temperature Materials, E. O. Paton Inst. of Electro-Welding, Kiev, USSR, 1976. 
14 S. K. Hwang: Ph.D. Thesis, University of California, Berkeley, 1977.

15 S. K. Hwans and J. W. Morris, Jr.: Met. Trans., 1979, vol. 10A, 545.

16 S. K. Hwang and J. W. Morris, Jr.: Advances in Cryogenic Engineering, 1978, vol. $24,137$.

17 M. Niikura and J. W. Morris, Jr.: Met. Trans., 1980, vol. 11 A, 1531.

18 M. J. Schanfein, M. J. ‘okota, V. F. Zackay, E. R. Parker and J. W. Morris, Jr.: ASTM STP 579, 1975, .61.

19 S. K. Hwang and J. W. Torris, Jr.: Met. Trans., 1980, vol. 11A, 1197.

20 M. Guttmann, P. R. Kr ne, F. Abel, G. Amsel, M. Bruneaux and C. Cohen: Met Trans., 1974, vol. 5, 16

21 R. Viswanathan: Met. 7 ans., 1971, vol. 2, 809.

22 R. O. Ritchie: Met. Tr. 3., 1977, vol. 8A, 1131.

23 J. Q. Clayton and J. F Knott: Fracture 1977, vol. 2, ICF4, Waterloo, Canada, June, 287.

24 C. J. McMahon, Jr., A. K. Cianelli and H. C. Feng: Met. Trans., 1977, vol. 8A, 1055 .

25 H. Ohtani, H. C. Feng and C. J. McMahon. Jr.: Met. Irans., 1976, vol. 7A, 1123.

26 A. K. Cianelli, H. C. Fs and C. J. McMahon. Jr.: Met. Trans., 1977, vol. 8A, 1059.

27 M. Guttmann and P. R. . irahe: Scrip. Met., 1971, vol. 5, 479.

28 C. L. Smith and J. R. Lc $*$ Jr.: Met. Trans., 1974, vol. 5, 279.

29 Y. E. Glikman: Fiz. me I. metalloved., 1968, vol. 26, 233.

su F. Dumoulin, M. Guttman, M. Foucault, M. Palmier, M. Wayman, and $M$. Biscondi: Metal Sci., 1980, January, I. 
31 J. Yu and C. J...McMahon, Jr.: Met. Trans., 1980, vol. 11 A, 277.

32 J. Yu and C. J. McMahon, Jr.: Met. Trans., 1980, vol. 11A, 291.

33 C. L. Briant and S. K. Banerji: Met. Trans., 1979, vol. 10A, 1729.

34 S. K. Banerji, C. J. McMahon, Jr. and H. C. Feng: Met. Trans., 1978, vol. 9A, 237.

35 G. Delisie and A. Galibois: J. Iron Steel Inst., 1969, December, 1628.

36 E. B. Kula and A. A. Anctil: J. Metals, 1968, vol. 4, 817.

37 C. L. Briant and S. K. Banerji: Met. Trans., 1979, vol. 10A, p. 1151.

38 C. L. Briant and S. K. Banerji: Met. Trans., 1981, vol. 12A, 309.

39 G. Thomas: Met. Trans., 1978, vol. 9A, 439.

40 R. M. Horn and R. O. Ritchie: Met. Trans., 1978, vol. 9A, 1039.

41 L. A. Harris: J. Appl. Phys., 1968, vol. 39, 1419.

42 C. C. Chang: "Characterization of Solid Surfaces", Kane and Larrabee, eds., Plenum Press, 1974, 509.

43 P. W. Palmberg: "Electron Spectroscopy", D. A. Shirley, ed., 1972, 385.

44 R. L. Park: Physics Today, 1975, April, 52.

45 H. L. Marcus: J. Metals, 1977, vol. 29, 20.

46 B. Navinsek: Prog. in Surf. Sci., 1977, vol. 7, 49.

47 H. L. Bay, J. Bohdansky and E. Hechtl: Rad. Effects, 1979, vol. 41, 77.

48 T. J. Chuang and K Wandelt: IBM J. Res. and Dev., 1978, vol. 22, 277.

49 P. S. Ho and J. E. Lewis: Surf. Sci., 1976, vol. 57, 393.

50 g. S. Ho and J. E. Lewis: Surf. Sci., 1979, vol. 85, 19.

51 P. S. Ho: Surf. Sci., 1978, vol. 72, 253. 
52 D. F. Stein, W. C. Johnson and C. L. White: 'Grain Boundaries in Engineering Metal", G. A. Chadwick and D. A. Smith, eds., New York, Academic Press, 1976. 388.

53 L. E. Davis, N. C. McDonald, P. W. Paimhers, G. E. Riach and R. E. Weber: Hundbook of AES, 2nd ed., 1976, Phy. Elec. Ind., Inc., Minnesota.

54 T. W. Hass, 3. T. Grant and G. J. Dooley: "Adsorption-Desorption Phenomena", Ricca, ed., Academic Press, 1972, 359.

5S H. Schumann: Arch. Eisenhatteavesen, 1967, vol. 38, 743.

56 H. Schumann: Z. Metallk., 1967, vol. 58207.

57 H. Schumann: Arch. Eisenhutterwesen, 9967, vol. 38, 647.

58 J. B. Cohen, A. Hurlich and $M$. Jacobso. Trans. Amer. Soc. Metals, 1947, vol. 39, 109.

59 P. R. Krahe and M. Guttmann: Metallograshy, 1974, vol. T, 5.

60 C. J. McMahon, Jr.: "Grain Boundiaries in Engineering Metals", J. L. Walter, etl al., eds., Claitors Pub., 1974, 525.

61 C. J. McMahon, Jr., J. R. Rellick and B. J. ذchultz: "Fracture", P. L. Pratt, ed. Chapmann and Hall. 1969, 278.

62 R. L. Cairns and C. J. Novak: Met. Trans., 1571, vol. 2, 1837.

63 R. F. Decker and J. W. Freeman: Trans. TMS. AIME. 1960, vol. 218, 277.

64 G. S. Was, H. H. Tixhner and R. M. Latanision: Met. Trans., 1981, vol. 12A. 1397.

65 S. Jin, S. K. dwane and J. W. Morris, Jr.: Met. T rans., 1975, vol. 6A, 1721.

66 C. K. Syn, S. Jin and J. W. Morris, Jr.: Met. Trans, 1976, vol. 7A, 1827

67 M. Enomoto and E. Furubayashi: Mat. Sci. Ens., 1976, vol. 24, 123. 
J. Koo and G. Thomas: Met. Trans., 1977, vol. 8A, 525 .

69

J. E. Doherty, B. H. Kear, A. F. Giamei and C. W. Steinke: "Grain Boundaries in Engineering Metals", J. L. Walter, et al., eds., Claitors Pub., 1974, 619.

70 T. Matsuyama and H. Suto: Trans. JIM, 1979, vol. 20, 44.

71 M. C. Inman and H. R. Tipler: Acta Met., 1953, 185.

72 A. E. Dias and R. E. Reed-Hill: Scrip. Met., 1979, vol. 13, 491.

73 C. Lea: Met. Sci., 1979, May, 301.

74 R. H. Bricknell and D. A. Woodford: Met. Trans., J981, vol. 12A, 1673.

75 D. A. Woodford: Met. Trans., 1981, vol. 12A, 299.

76 D. A. Woodford and R. H. Bricknell: Met. Trans., 1981, vol. 12A, 1467.

17 T. G. Digges: Trans. ASM, 1938, vol. 26, 408.

78 E. D. Bain and H. W. Paxton: "Alloying Elements in Steel", ASM Pub., Metals Park, 1966.

19 T. Inoue: "Grain Boundaries in Engineering Metals", J. L. Walter et al., eds., Claitors Pub., 553.

BO T. E. Swarr and G. Krauss: ibid., 127.

$\$ 1$ R. G. Rowe: Met: Trans., 1979, vol. 10A, 997.

82 C. J. McMahon, Jr.: Acta Met., 1966, vol. 14, 839.

83 J. W. Morris, Jr., C. . Syn, J. I. Kim and B. Fultz: "International Conference on Martensitic Transformations (ICOMAT)", Cambridge, Mass., June 1979.

84 I. Langmuir: J. Amer. ( 'em. Soc., 1918, vol. 40, 1361.

85 D. McLean: "Grain Boundaries in Metals", Oxford Univ. Press, 1957, 118.

86 M. Guttmann: Surf. sci., 1975, vol. 53, 213. 
87 H. Taga and A. Youshikawa: Trans. Iron Steel Inst., Japan (Suppl.), 1971, vol. I1, 1256

88 T. M. Williams, D. R. Harris and J. Furnival: J. Iron Steel Inst., 1972, vol, 210. 351.

89 G. F. Melloy, P. R. Slimmon and P. P. Podgursky: Met. Trans., 1973, vol. 4, 2279.

90 J. D. Garnish and J. D. Hughes: J. Mat. Sci., 1972, 7.

91 Y. Ohmori and K. Yamanake: "Boron in Steel", S. K. Banerji and J. e. Morral, eds., AlME, Milwaukee, Wisc., 1979, 44.

92 L. L. Pyatakova: Steel in the USSR, 1974, 994.

93 L. L Pyatakova, M. V. Mozharov, M. A. Sirotkina and T. A. Dyuzheva: Metal i Termich. Obrab. Metallov, 197!, No. 2, 62.

94 V. I. Arkharov, L. L. Pyatoakova and Ye. S. Markhasin: Fiz. met. metallov., 1974, vol. 37,661 .

95 L. L. Pyatakovy, I. I. Mints. T. G. Berezina and M. A. Sirotkina: Metal i Termich. Obrab. Metallov, 1976, No. 1, 39.

96 B. J. Thomas and G. Henry: "Boron in Steel", S. K. Banerji and J. E. Morral, eds., AIME, Milwaukee, Wisc., 1979, 80.

97 T. M.Williams: Metal Sci. J., 1972, vol. 6, p. 68.

98 T. M. Williams, A. M. Stoneham and D. R. Harries: Met. Sci., 1976, 14.

99 Ya. E. Goldsteyn, G. A. Charushnikova and A. M. Belikov: Russ. Met. and Mining, 1963, No. 4, 72.

100 J. Friedel: "Dislocations", Pergamon Press, Oxford, 1964, 224.

101 J. H. Westbrook and K. T. Aust: Acts Met., 1963, vol. 11, 1151. 
102 K. T. Aust, R. E. Hanneman, P. Niessen and J. H. Westbrook: Acta Met., 1968, vol. 16, 291.

103 M. Guttmann, P. R. Krahe, F. Abel, G. Amsel, M. Bruneaux and C. Cohen: Met. Trans., 1974, vol. 5, 167.

104 I. N. Shabenova, A. B. Kutin, L. V. Smirnov and V. A. Trapeznikov: Fiz. metal. metallov., 1976, vol. 42, 318.

105 R. V. Ramasubramaniun and D. F. Stein: Met. Trans., 1974, vol. 4, 1735.

106 R. H. Jones, S. M. Bruemmer, M. T. Thomas and D. r. Baer: Met. Trans., 1981, vol $12 A, 1621$.

107 J. I. Kim: Ph.D. Thesis, University of California, Berkeley, 1979. 


\section{FIGURE CAPTIONS}

1 Standard Charpy impact test specimen.

2 Dilatometry specimen for measuring phase transformation temperature.

3 Single notched AES specimen for fracturing.

4 Schematic diagram of the ultra high vacuum reaction chamber with in-sim fracturing and cooling stage for AES study.

5 Ductile-brittle transition in austenitized $\left(1100^{\circ} \mathrm{C} / 2 \mathrm{hr} / \mathrm{WQ}\right) \mathrm{Fe}-12 \mathrm{Mn}$.

6 SEM fractographs taken from Chapy specimens tested (a) above the DBTT and (b) below the DBTT.

7 Changes of structures and properties on austenitizing for 2 hours (a) grain size (b) hardness at room temperature (c) Charpy impact energy at LNT.

8 SEM fractographs of Fe-12Mn steel tested below the DBTT after austenitizing at $850^{\circ} \mathrm{C} / 2 \mathrm{hrs}, 1000^{\circ} \mathrm{C} / 2 \mathrm{hrs}, 1100^{\circ} \mathrm{C} / 2 \mathrm{hrs}$, and $1200^{\circ} \mathrm{C} / 2 \mathrm{hrs}$, respectively.

9 AES spectrum obtained from intergranular fracture surface of the specimen austenitized at $1100^{\circ} \mathrm{C} / 2 \mathrm{hrs} / \mathrm{W}$ ) and SEM fractograph.

10 AES spectra obtained from intergranular fracture surfaces of the specimen austenitized at $1100^{\circ} \mathrm{C}$ for 2 hours and 100 hours, respectively.

11 SEM-ED AX analyses of particles on the intergranular fracture surface.

12 SEM-AFS gnalyses of (a) sulfide particle, (b) manganese particle, (c) crater made by a particle which was separated from the grain boundary, and (d) intergranular fracture $s$ srface.

13 AES syectra obtained from (a) the sputtered surface and (b) the sputtered surface of an austenitized $\left(1100^{\circ} \mathrm{C} / 2 \mathrm{hrs} / \mathrm{WQ}\right)$ specimen. 
14 Partial AES spectra of (a) the unsputtered surface and (b) the sputtered surface showing the disappearance of carbon peak.

Is Partial AES spectrum obtained from the intergranular fracture surface with higher sensitivity.

16 Depth profiles obtained from the intergranular fracture surfaces of the specimens austenitized at $1100^{\circ} \mathrm{C}$ (a) for 2 hours and (b) for 100 hours, respectively.

17 AES spectra obtained from (a) the unsputtered surface and (b) the sputtered surface of an austenitized $\left(1100^{\circ} \mathrm{C} / 100 \mathrm{hrs} / \mathrm{WQ}\right)$ specimen.

18 Residual gas analysis of inside reaction chamber at ultra-high vacuum.

19 Optical micrographs of Fe-12Mn specimens austenitized at (a) $850^{\circ} \mathrm{C}$ and (b) at $1100^{\circ} \mathrm{C}$.

20 TEM micrograph of Fe-12Mn specimen austenitized at $1100^{\circ} \mathrm{C}$ for 2 hours.

21 TEM micsograph of Fe-12Mn specimen. (a) bright field image and (b) dark field image.

22 Changes of Chaspy impact energy at LNT as a function of boron contents.

23 Changes of Charpy impact energy of an Fe-12Mn with 20 ppm B at LNT on austenitizing treatment.

24 Fractographs showing the different austenite grain sizes on austenitizing treatment.

25 SEM fractographs showing the fracture modes on 1 hour austenitizing treatment at (a) $850^{\circ} \mathrm{C},(\mathrm{b}) 900^{\circ} \mathrm{C}$, (c) $950^{\circ} \mathrm{C}$, and (d) $1000^{\circ} \mathrm{C}$.

26 AES spectrum obtained from the austenitized $\left(850^{\circ} \mathrm{C} / 1 \mathrm{hr} / \mathrm{WQ}\right)$ specimen with boron additions.

27 AES spectrum oblained from the austenitized $\left(900^{\circ} \mathrm{C} / \mathrm{lhr} / \mathrm{WQ}\right)$ specimen with boron additions.

28 TEM microtraph of the boron-modified Fe-12Mn alloy austenitized at $1100^{\circ} \mathrm{C}$ for 1 hour followed by water quenching. 
29 SEM fractoyraphs showing the fracture surface of austenitizing treatment at (a) $850^{\circ} \mathrm{C}$ and $(\mathrm{b}) 900^{\circ} \mathrm{C}$.

30 SEM fractographs showins the transgranular fracture mode obtained from the austenilized $\left(100^{\circ} \mathrm{C} / \mathrm{lhr} / \mathrm{WQ}\right)$ specimen.

31 Changes in Charpy impact energy at $77^{\circ} \mathrm{K}$ as a function of tempering temperature.

32 SEM fractographs showing the fracture modes on tempering treatment at (a) and (b) $250^{\circ} \mathrm{C}$. (c) and (d) $350^{\circ} \mathrm{C}$, (e) a and (f) $450^{\circ} \mathrm{C},(\mathrm{g})$ and (h) $550^{\circ} \mathrm{C}$, and (i) and (j) $650^{\circ} \mathrm{C}$.

33 Shift of ductile-brittle transition temperature by tempered martensite embrittlement in a boron-modified Fe-12Mn.

34 Shift of ductile-brittle transition by tempered martensite embrittlement in an Fe$12 \mathrm{Mn}$ withoul boron additions.

35 AES spectra obtained from the tempered specimen at (a) $250^{\circ} \mathrm{C}$ and (b) $400^{\circ} \mathrm{C}$.

36 AES spectrum obtained from the boron-added Fe-12Mn tempered at $450^{\circ} \mathrm{C}$ for $\mathrm{l}$ hour.

37 Changes in peak height ratio of $\mathrm{Mns42}_{42}$ and $\mathrm{Fe}_{703}$ Auger peaks as a function of tempering temperature.

38 Changes in peak height ratio of $M n_{542}$ and $F e_{703}$ Auger peaks as a hoiding time at $400^{\circ} \mathrm{C}$.

39 Changes of structures and properties on tempering (a) fraction (\%) of intergranular fracture mode, (b) hardness at room temperature, (c) Charpy impact energy at LNT.

40 SEM fractographs showing the fracture modes on isothermal treatment at $450^{\circ} \mathrm{C}$ for (a) 1 hour, (b) 2 hours, (c) 80 hours, and (d) 200 hours. 
41 AES spectrum obtained from tine tempered $\left(450^{\circ} \mathrm{C} / 1 \mathrm{hr} / \mathrm{WQ}\right)$ specimen.

42 AES spectrum obtained from the tempered $\left(450^{\circ} \mathrm{C} / \mathrm{m}^{4} \mathrm{rs} / \mathrm{WQ}\right)$ specimen.

43 Changes in peak height ratio of $\mathrm{Mn} / \mathrm{Fe}$ and $\mathrm{B} / \mathrm{Fe}$ Auger peaks as a function of holding time at $450^{\circ} \mathrm{C}$.

44 Depth profiles obtained from an Fe-12Mn on temperine treatment at $250^{\circ} \mathrm{C}$ and $400^{\circ} \mathrm{C}$

45 Depth profile oblained from the tempered $\left(450^{\circ} \mathrm{C} / 1 \mathrm{hr} / \mathrm{WQ}\right) \mathrm{Fe}-12 \mathrm{Mn}$ with the boron additions.

46 Depth profile obtained from the tempered $\left(400^{\circ} \mathrm{C} / 10 \mathrm{~min} / \mathrm{WQ}\right) \mathrm{Fe}-12 \mathrm{Mn}$.

47 Depth profile obtained from the tempered $\left(400^{\circ} \mathrm{C} / 1 \mathrm{hr} / \mathrm{WQ}\right) \mathrm{Fe}-12 \mathrm{Mn}$.

48 Depth profile obtained from the tempered $\left(400^{\circ} \mathrm{C} / 48 \mathrm{hrs} / \mathrm{WQ}\right) \mathrm{Fe}-12 \mathrm{Mn}$.

49 Depth profile obtained from the tempered $\left(400^{\circ} \mathrm{C} / 290 \mathrm{hrs} / \mathrm{WQ}\right) \mathrm{Fe}-12 \mathrm{Mn}$.

50 Depth profile obtained from the tempered $\left(450^{\circ} \mathrm{C} / 10 \mathrm{hrs} / \mathrm{WQ}\right) \mathrm{Fe}-12 \mathrm{Mn}$ with the boron additions.

51 Depth profile obtained from the tempered $\left(450^{\circ} \mathrm{C} / 20 \mathrm{hrs} / \mathrm{WQ}\right) \mathrm{Fe}-12 \mathrm{Mn}$ with the boron additions.

52 Changes in Mn-enriched depth as a function of holding time at $400^{\circ} \mathrm{C}$ in an Fe$12 \mathrm{Mn}$ alloy.

53 Changes in Mn-enriched depth as a function of holding time at $450^{\circ} \mathrm{C}$ in the boron-modified Fe-12Mn alloy.

54 TEM-EDAX analyses of grain boundary and matrix in Fe-12Mn alloy tempered at $400^{\circ} \mathrm{C}$ for 1 hour.

55 Optical micropraphs of Fe-12Mn specimens on tempering treatment at (a) $250^{\circ} \mathrm{C}$, (b) $400^{\circ} \mathrm{C}$, (c) $550^{\circ} \mathrm{C}$, and (d) $650^{\circ} \mathrm{C}$. 
56 SEM frectosraphs of Fe-12Mn specimens showing the fracture surfaces on tempering treatment at (a) $250^{\circ} \mathrm{C}$, (b) $400^{\circ} \mathrm{C}$, (c) $550^{\circ} \mathrm{C}$, and $650^{\circ} \mathrm{C}$.

57 SEM fractographs of Fe-12Mn specimens showing the fracture surfaces on isothermal treatment at $400^{\circ} \mathrm{C}$ for (a) 1 hour, (b) 3 hours, (c) 6 hours, (d) 12 hours, (e) 24 hours, and (f) 48 hours.

58 Optical micrographs of Fe-12Mn specimens on isothermal treatment at $400^{\circ} \mathrm{C}$ for (a) 1 hour, (b) 3 hours, (c) 6 hours, (d) 12 hours, (e) 24 hours, and (f) 48 lours.

59 SEM fractographs of the boron-modified Fe-12Mn specimens showing the fracture surfaces on isothermal treatment at $450^{\circ} \mathrm{C}$ for (a) 1 hour, (b) 20 hours, (c) 80 hours, and (d) 200 hours.

60 TEM micrographs of Fe-12Mn specimens tempered at $400^{\circ} \mathrm{C}$ for (a) 1 hour and (b) 200 hours.

61 TEM micrograph of Fe-12Mn specimen tempered at $400^{\circ} \mathrm{C}$ for 200 hours and schematic diagram showing the newly nucleated austenite grains along the prior austenite grain boundaries.

62 Schematic diagram showing the fracture mode below the DBTT in an Fe-12Mn alloy. 


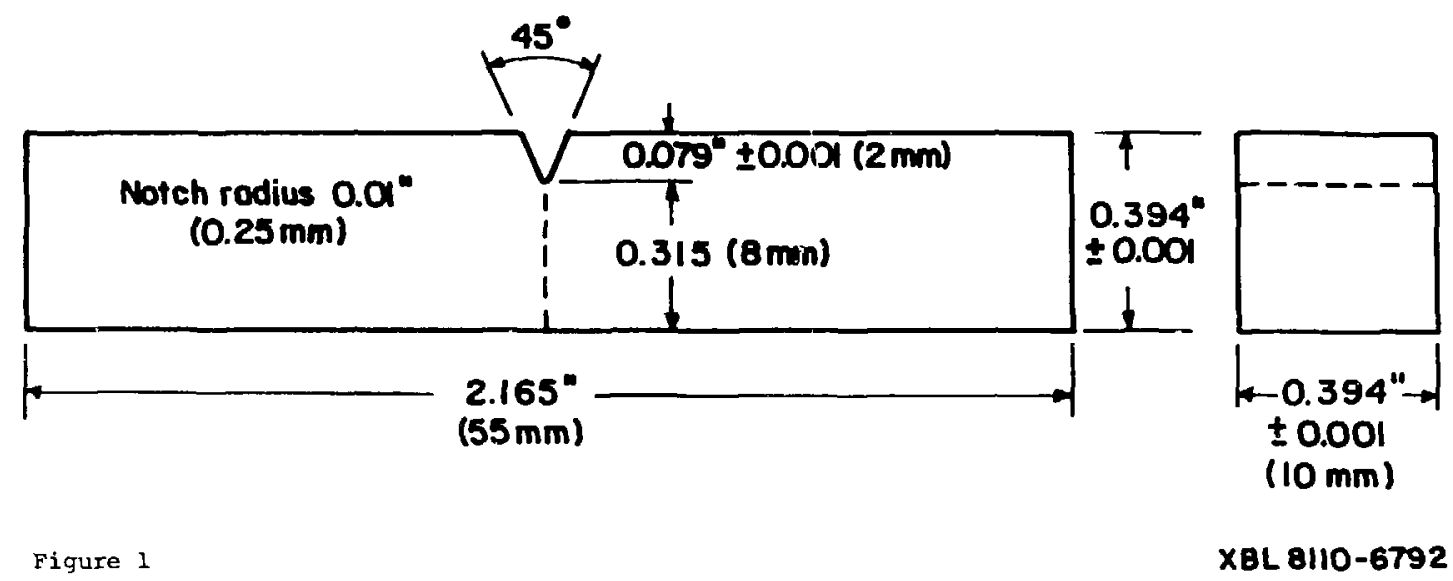



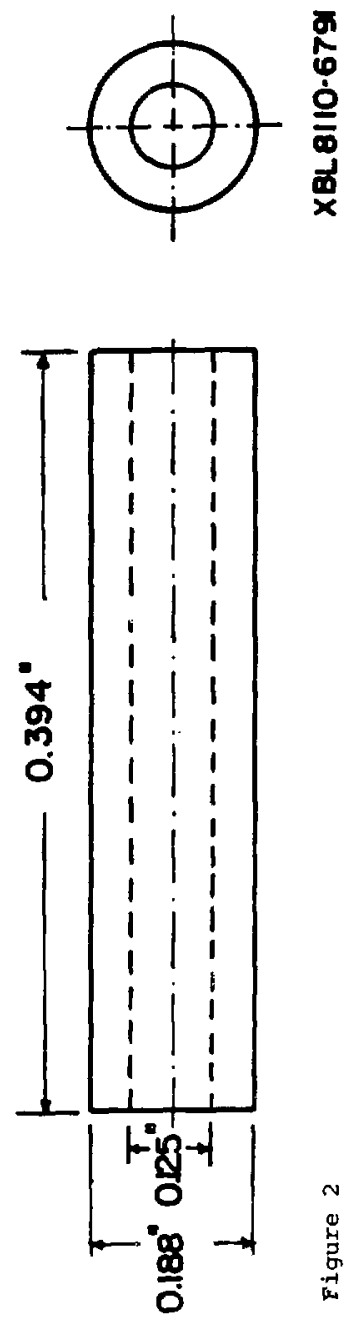

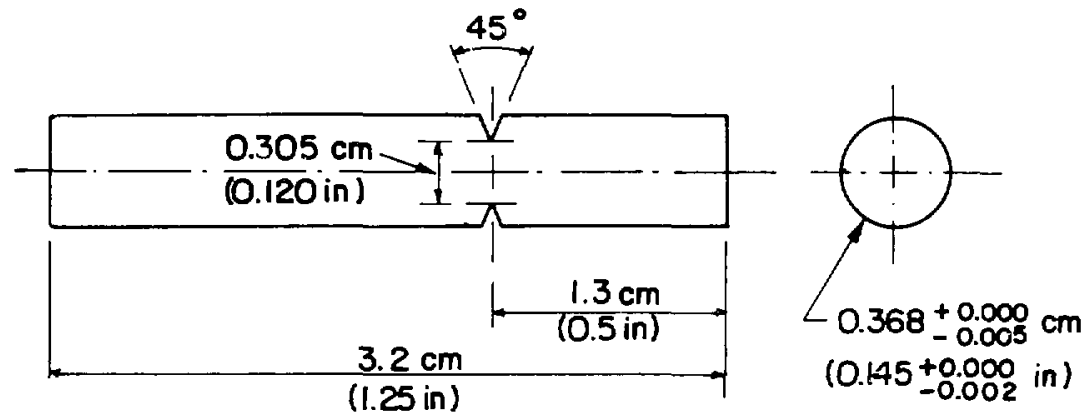

Figure 3

Xㅂㄴ 812-5242 


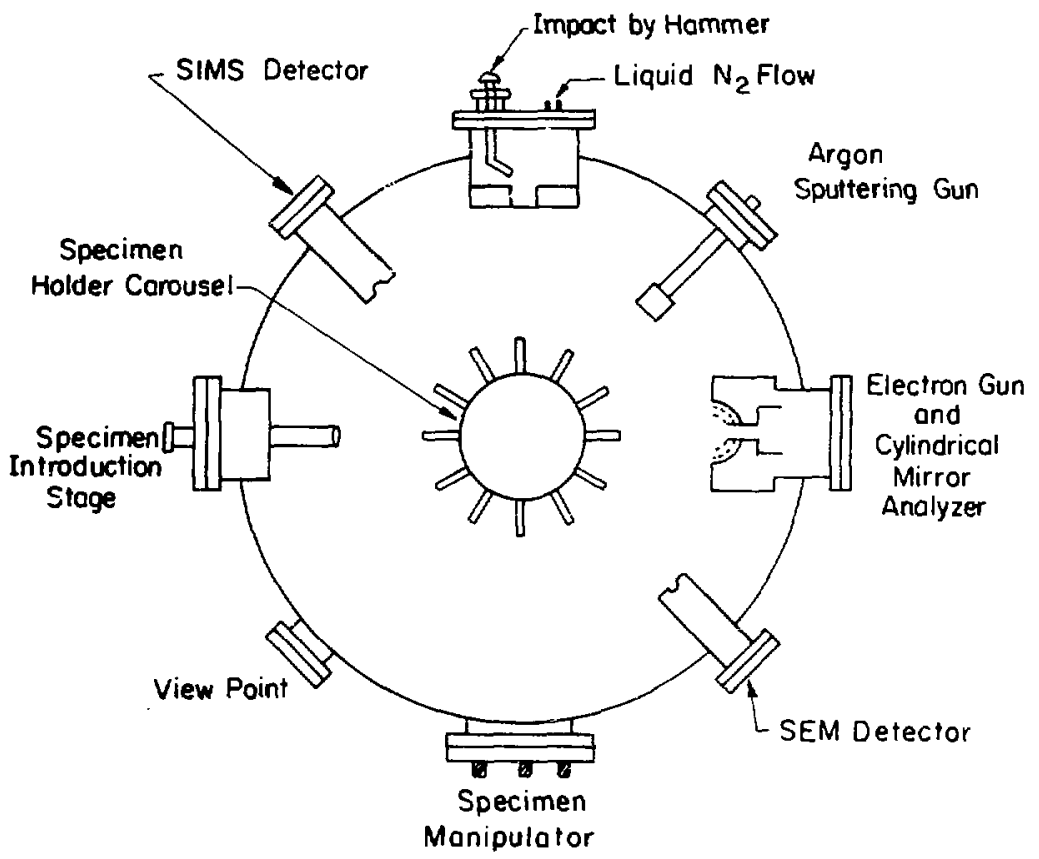

Figure 4

$X 8 L 812-5241$ 


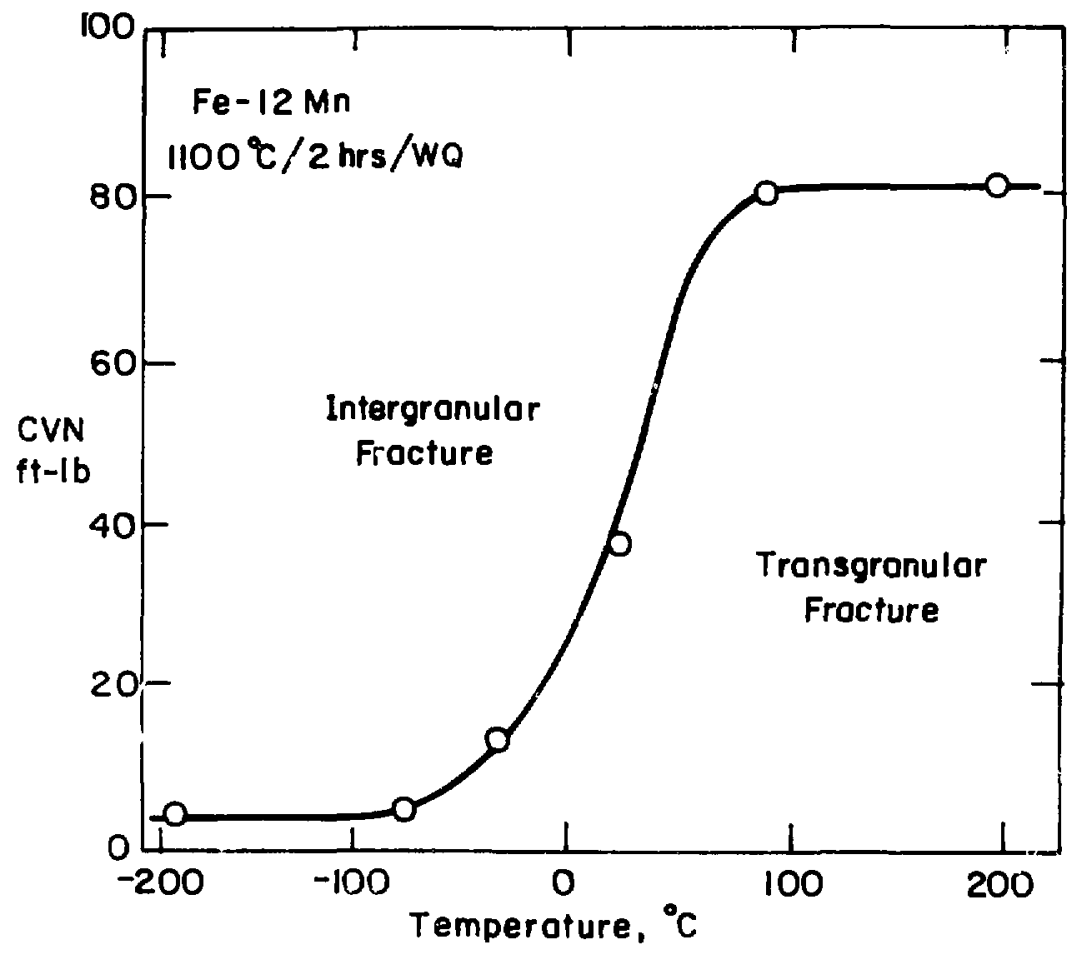

Figure 5

XBL 8110-6793 

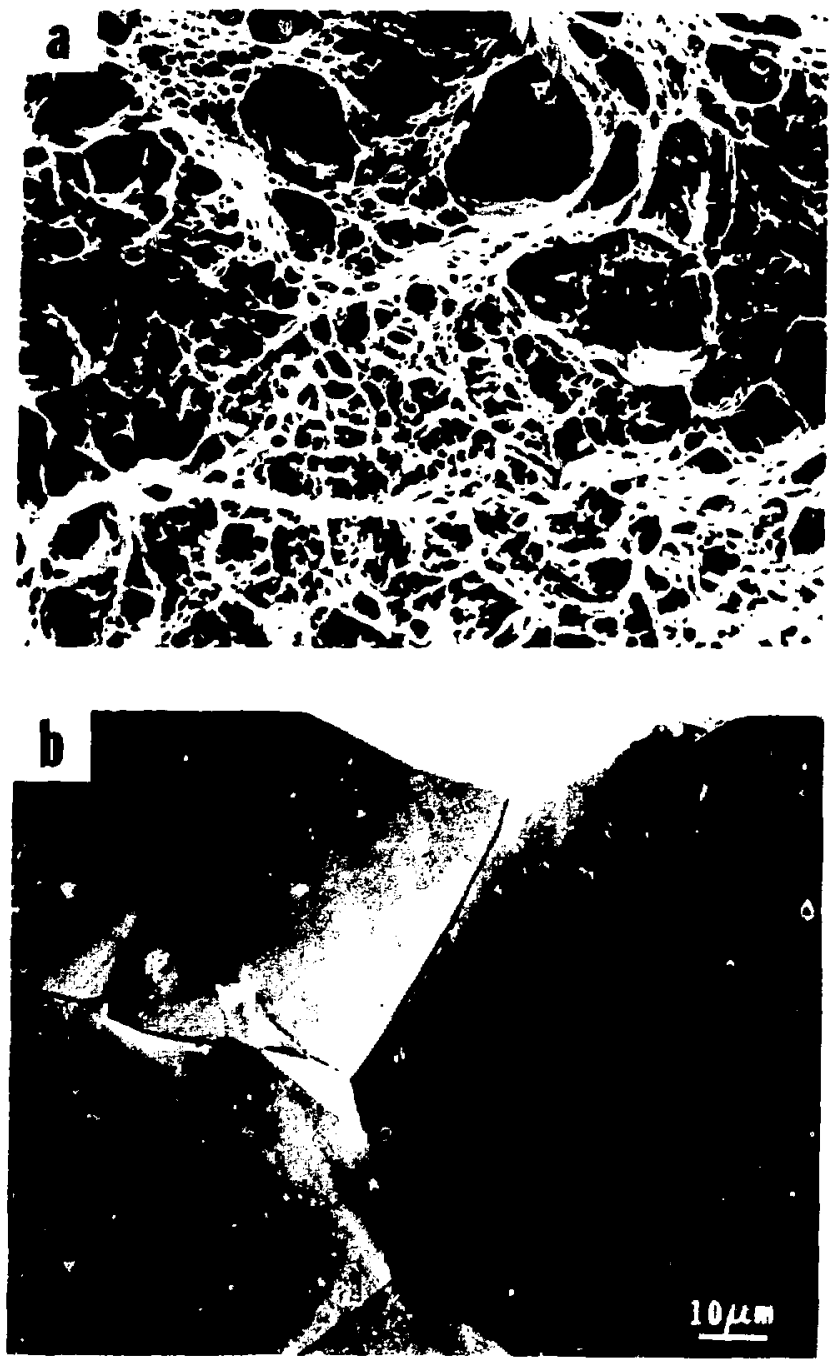

Fiqure 6 

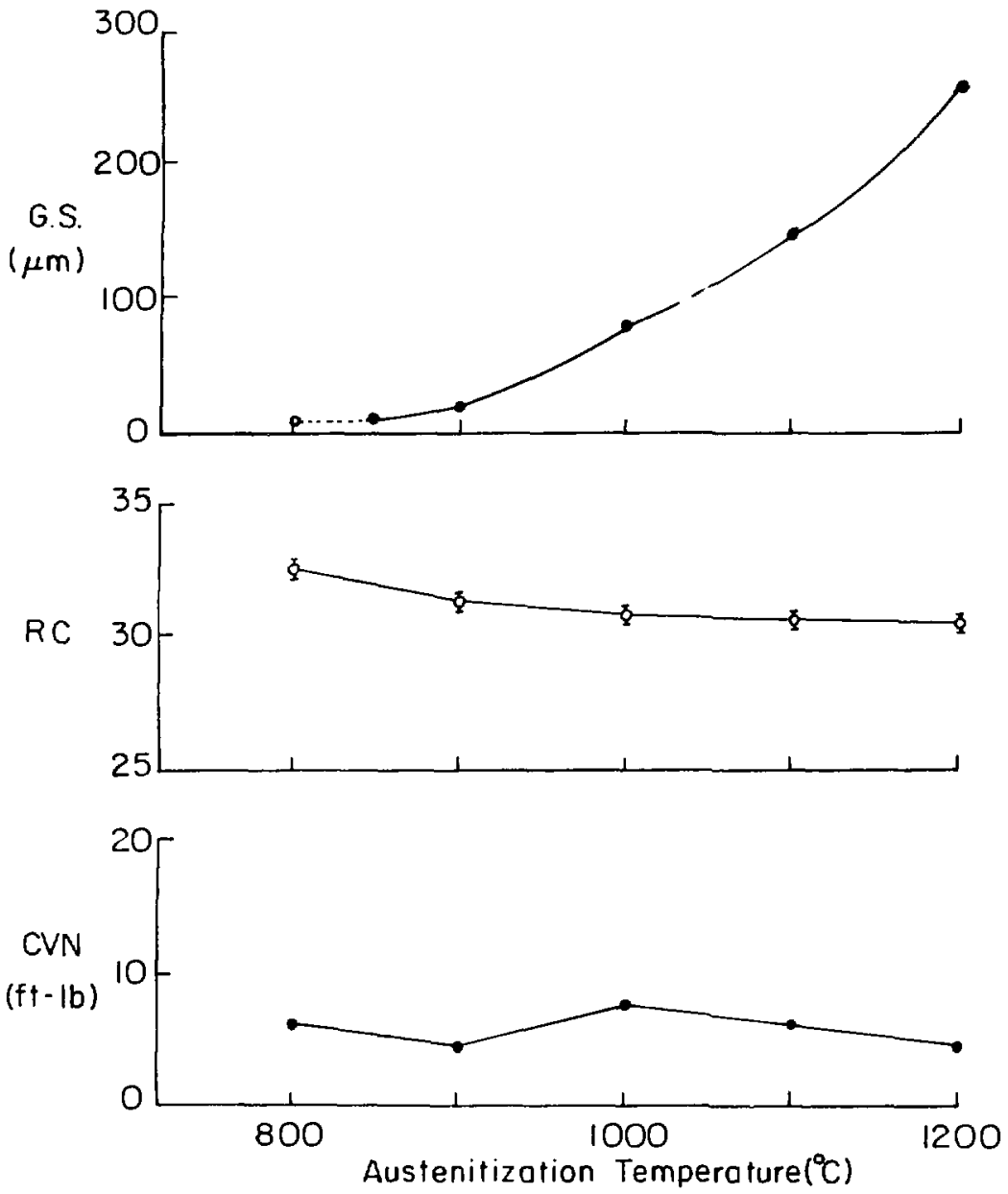

Figure $?$ XBL 8010-6241 

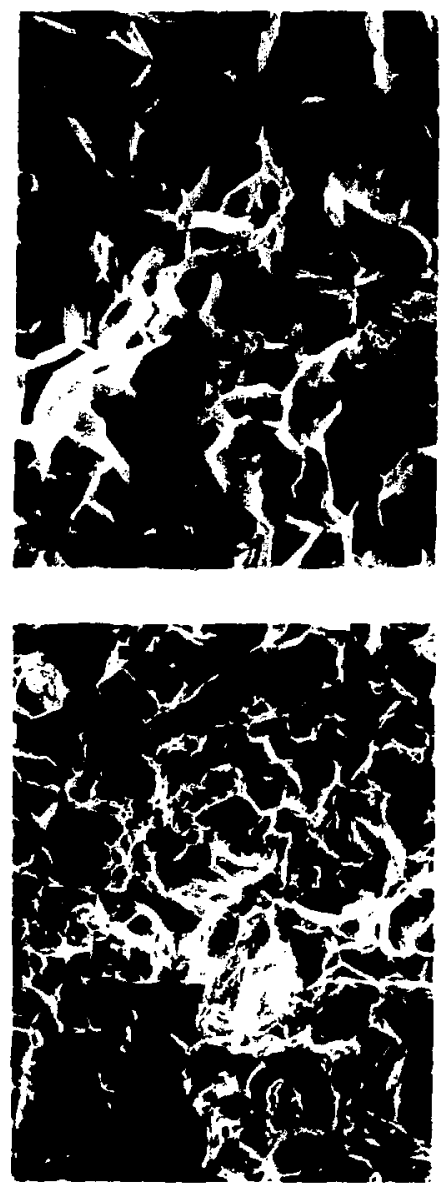

Figure 8

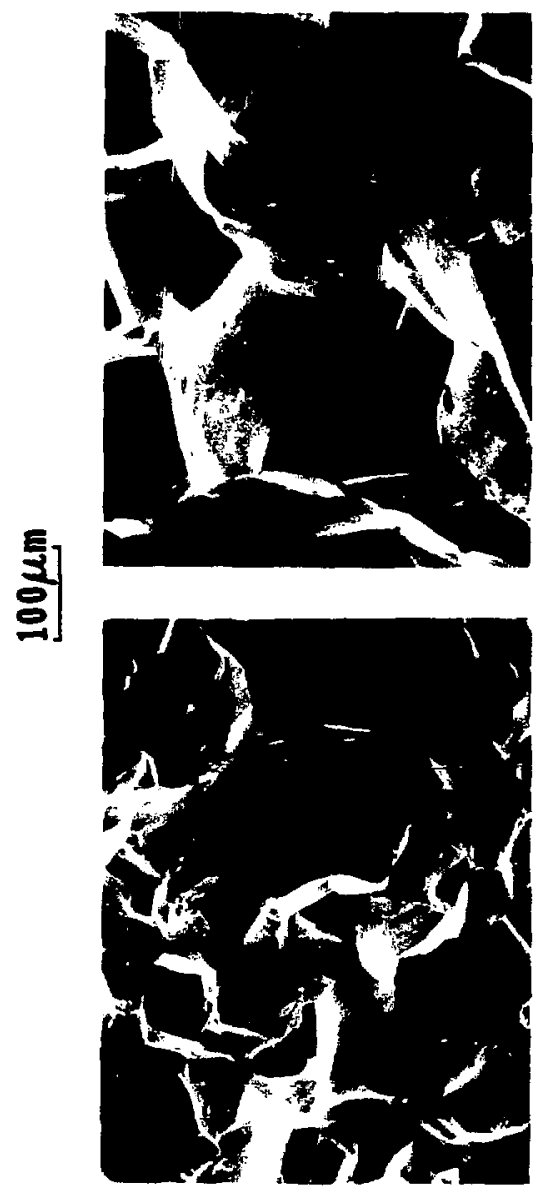

XBB $800-12306$ 


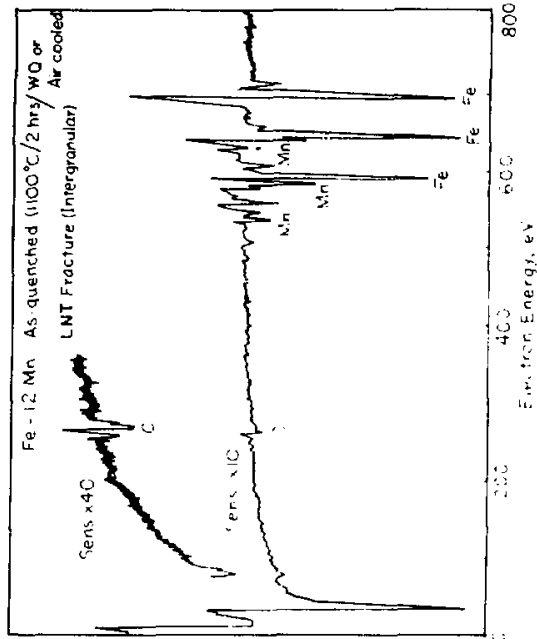

\begin{tabular}{l}
8 \\
8 \\
0 \\
1 \\
0 \\
0 \\
0 \\
0 \\
0 \\
\hdashline
\end{tabular}

$\therefore$

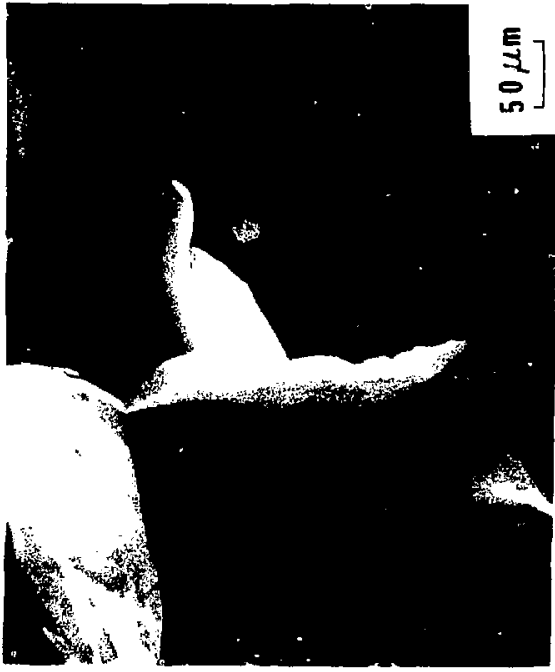

$\sigma$
0
4
3
5
-1
-4 

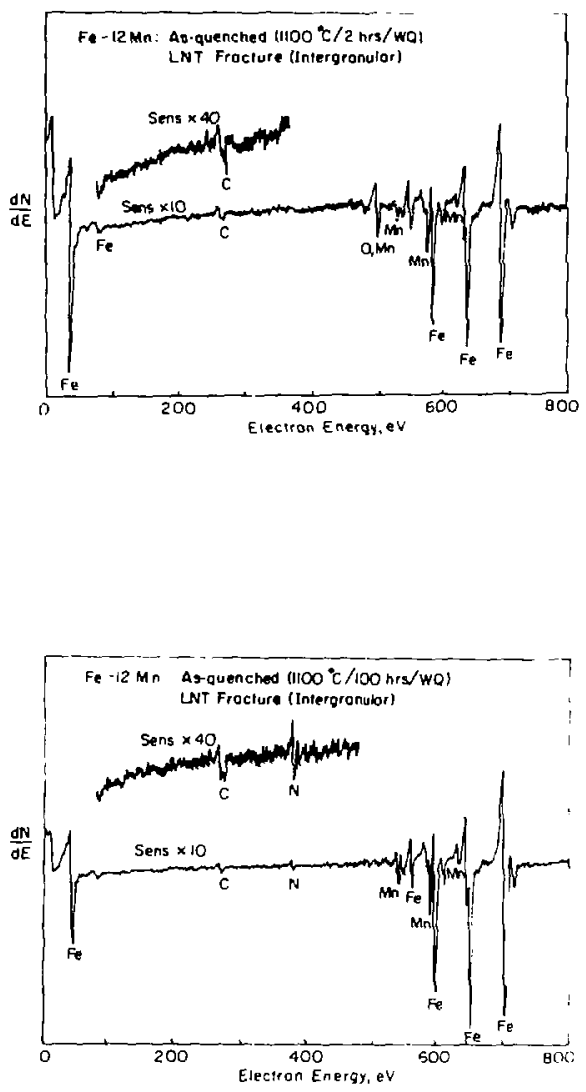

Fiqure 10

XBL 8011-12713 

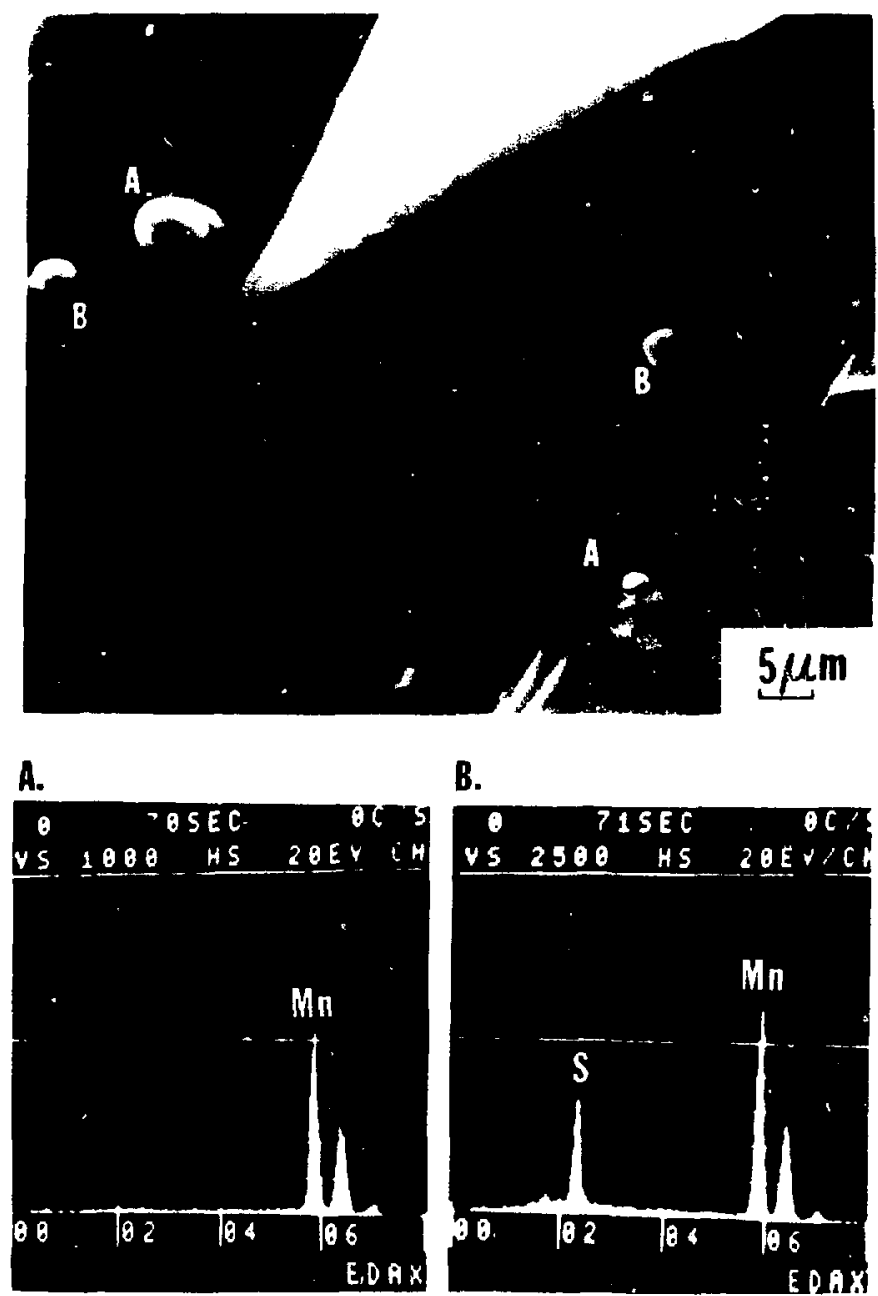

B.

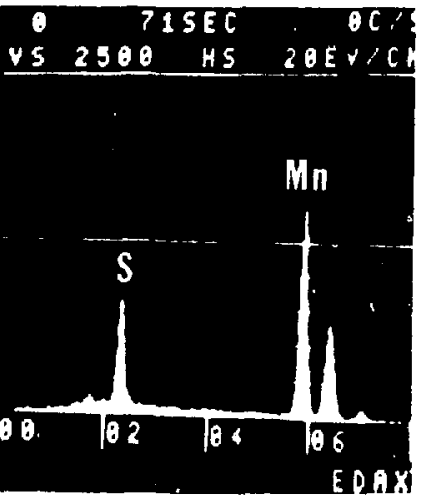

Fiqure 11

Xi3R 8Oก-I $307 A$ 

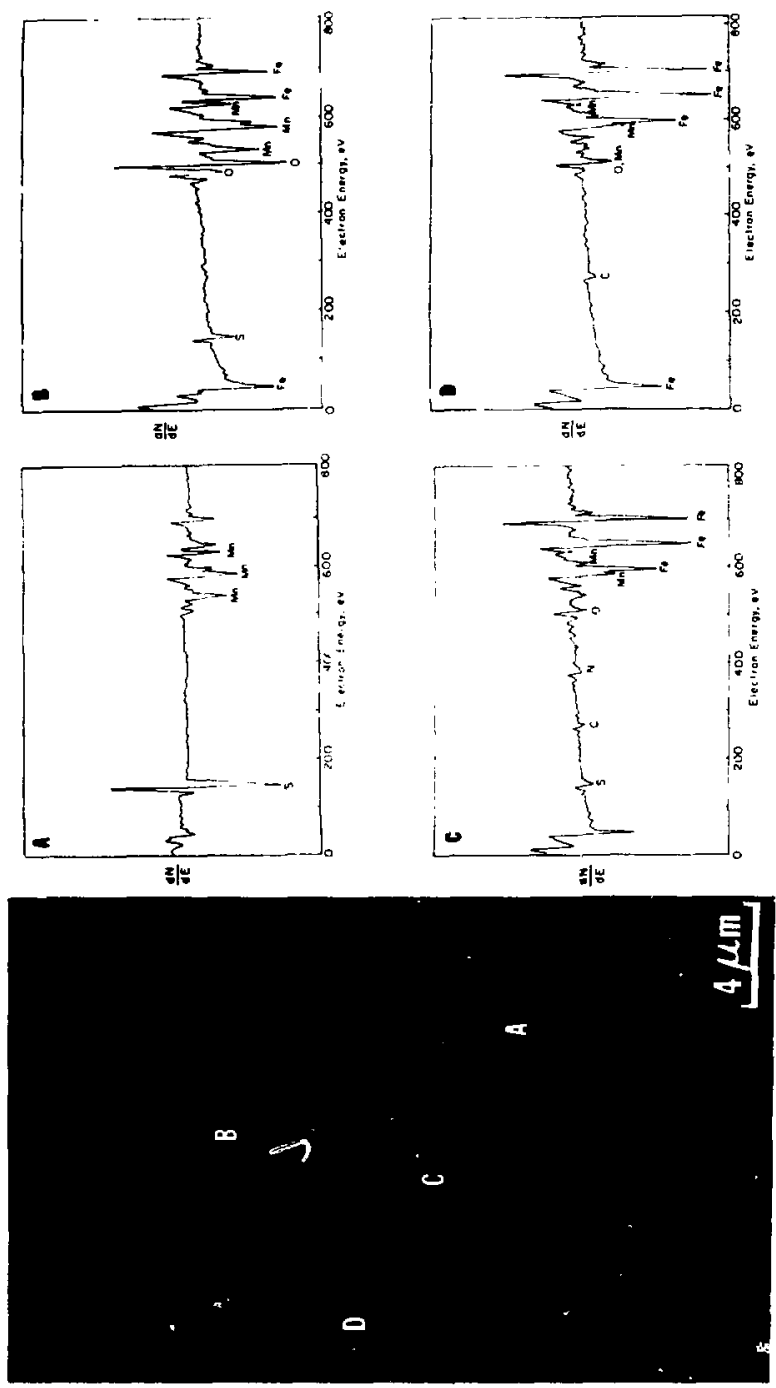

Figure 12

XBP 800-1350AA 
I

69
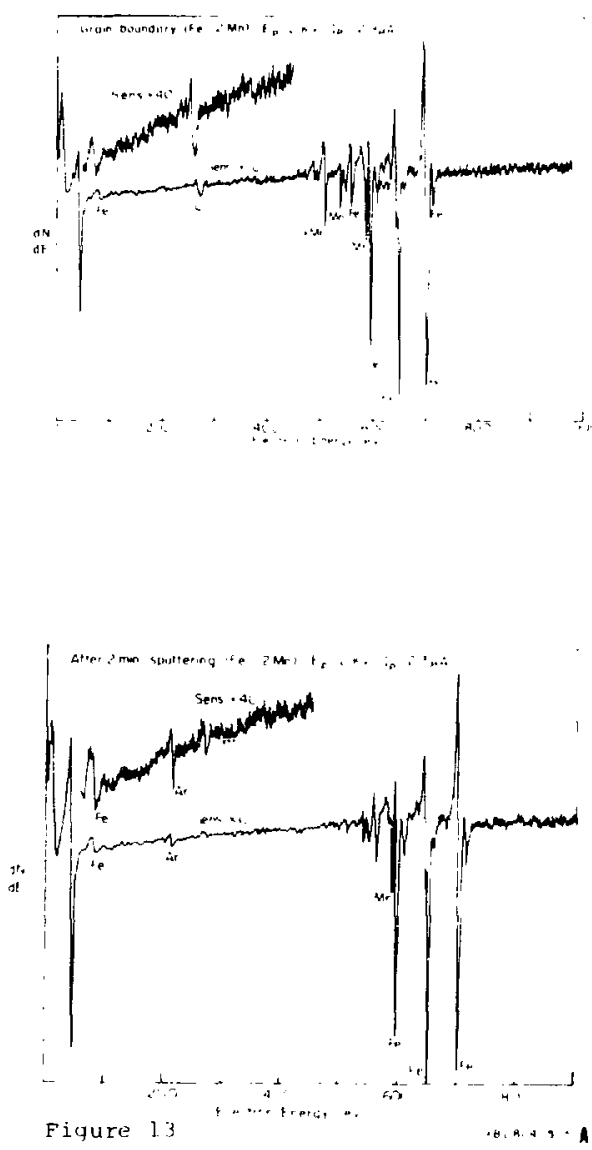

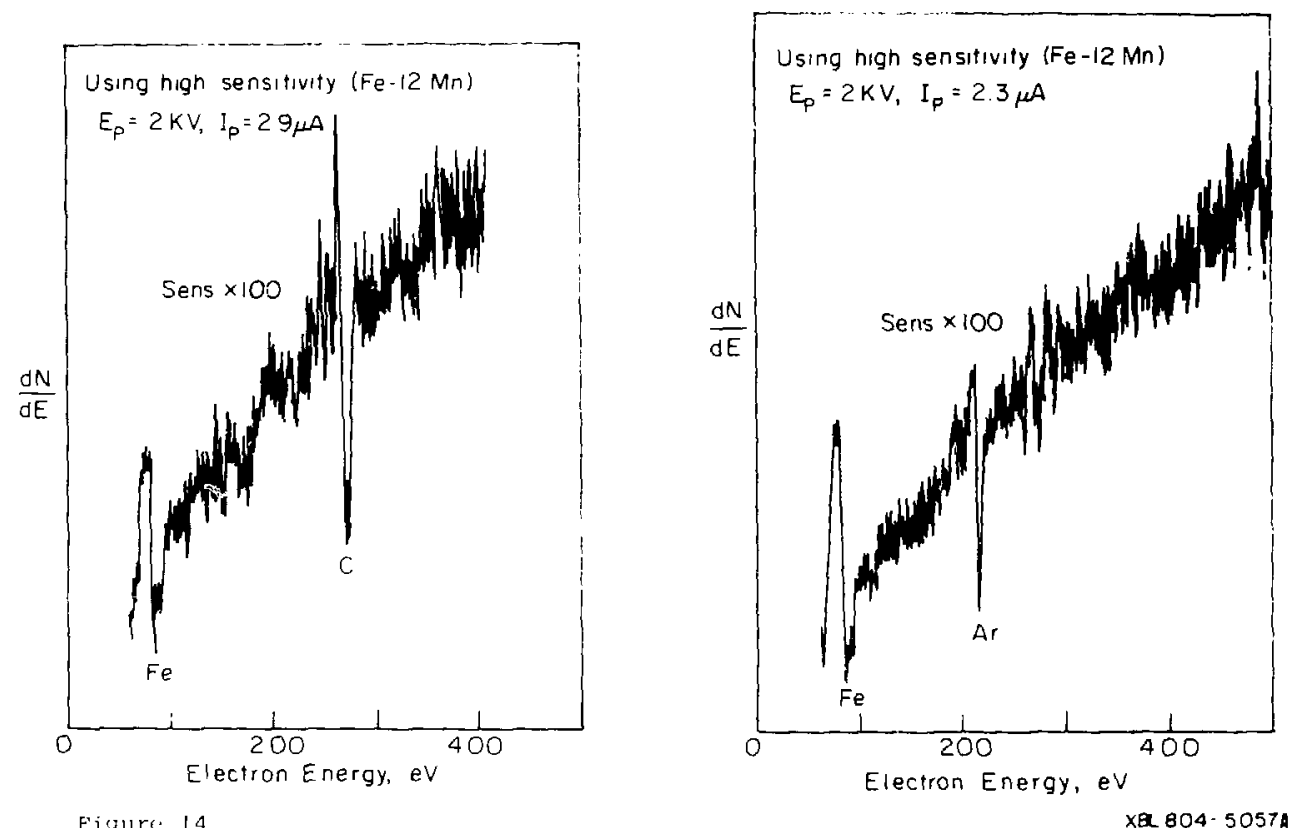

Figure 14 


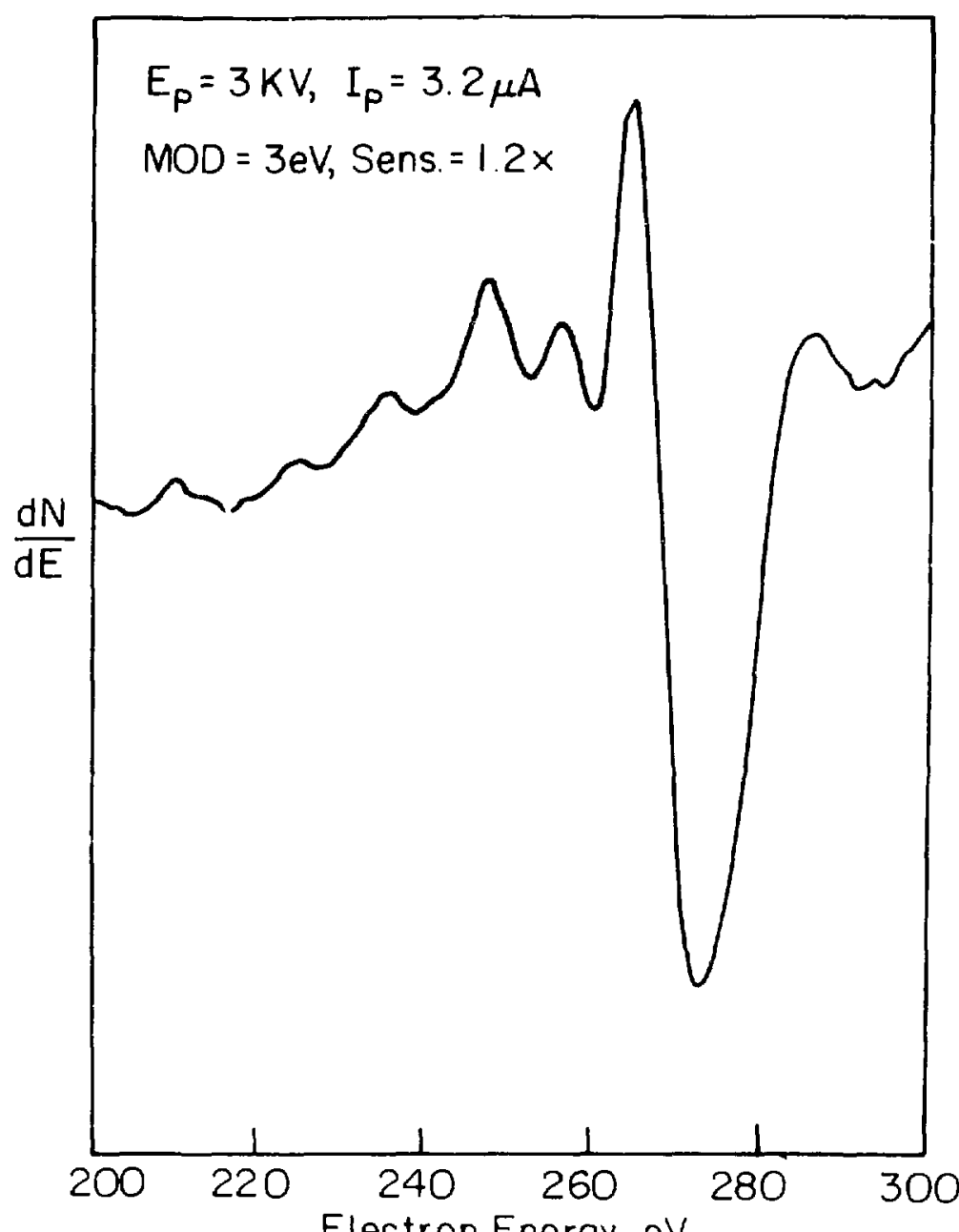

Electron Energy, eV

Frifure J5

XBL804-5058 

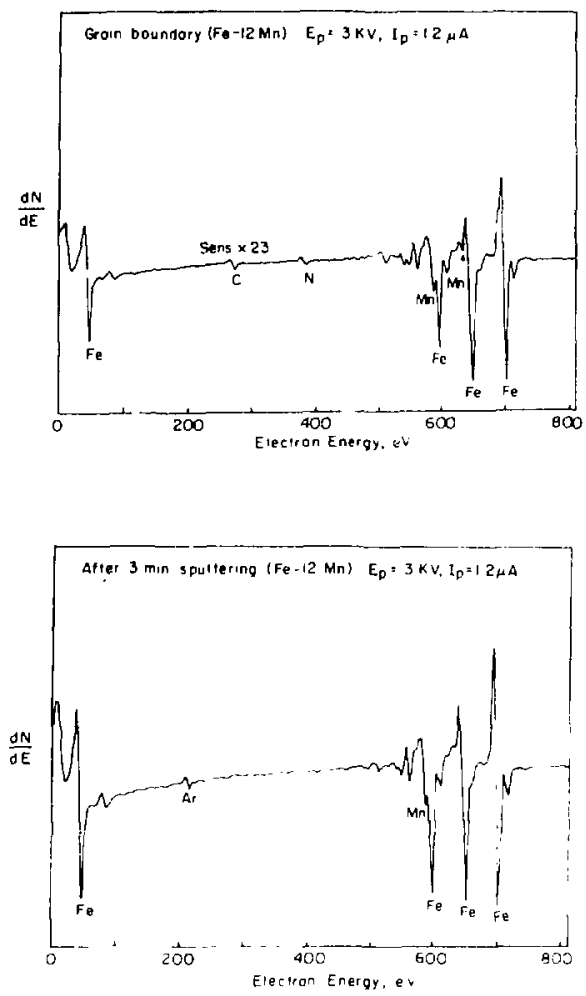

Finure 16

XBL 8011-12714 


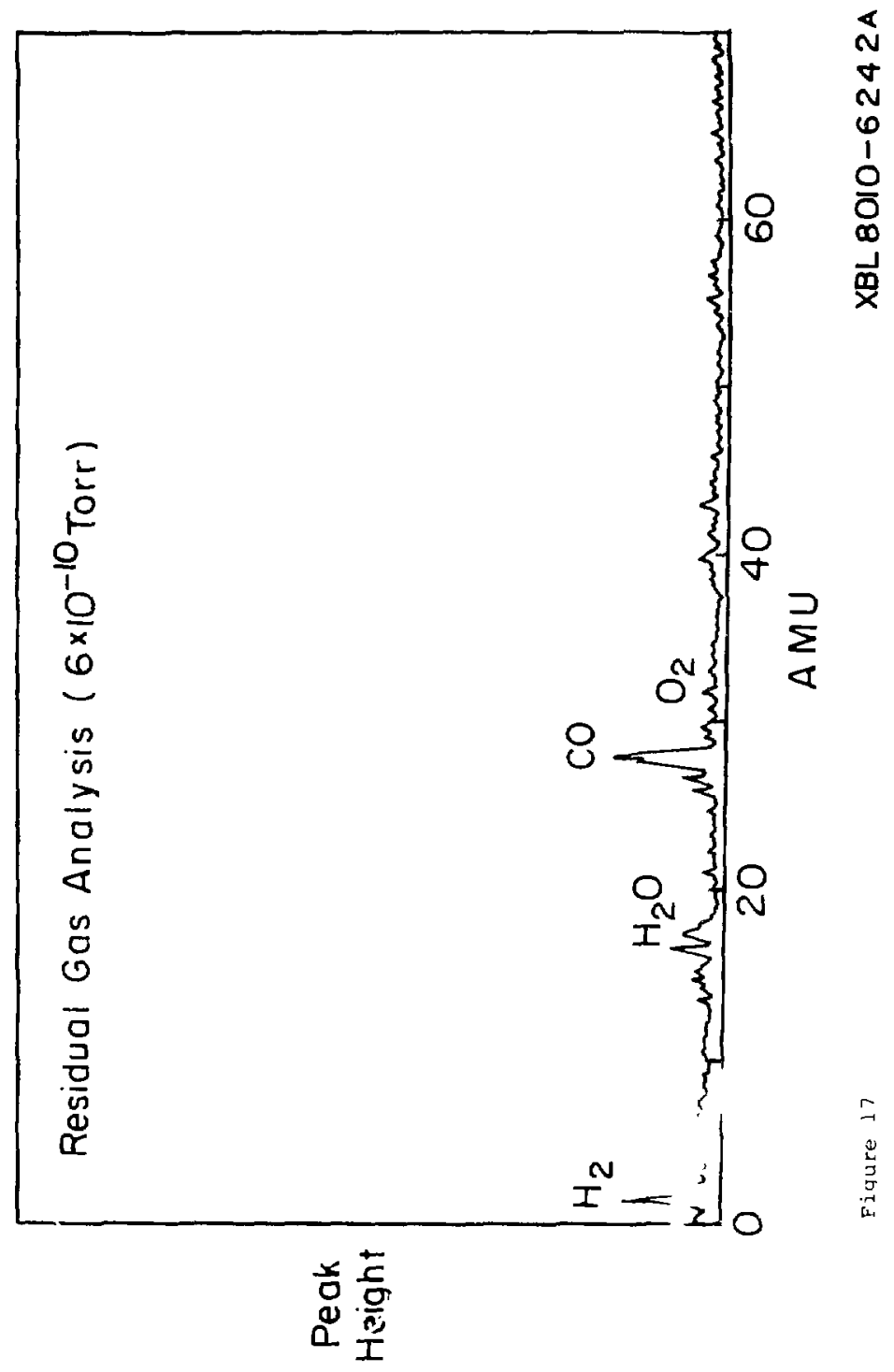



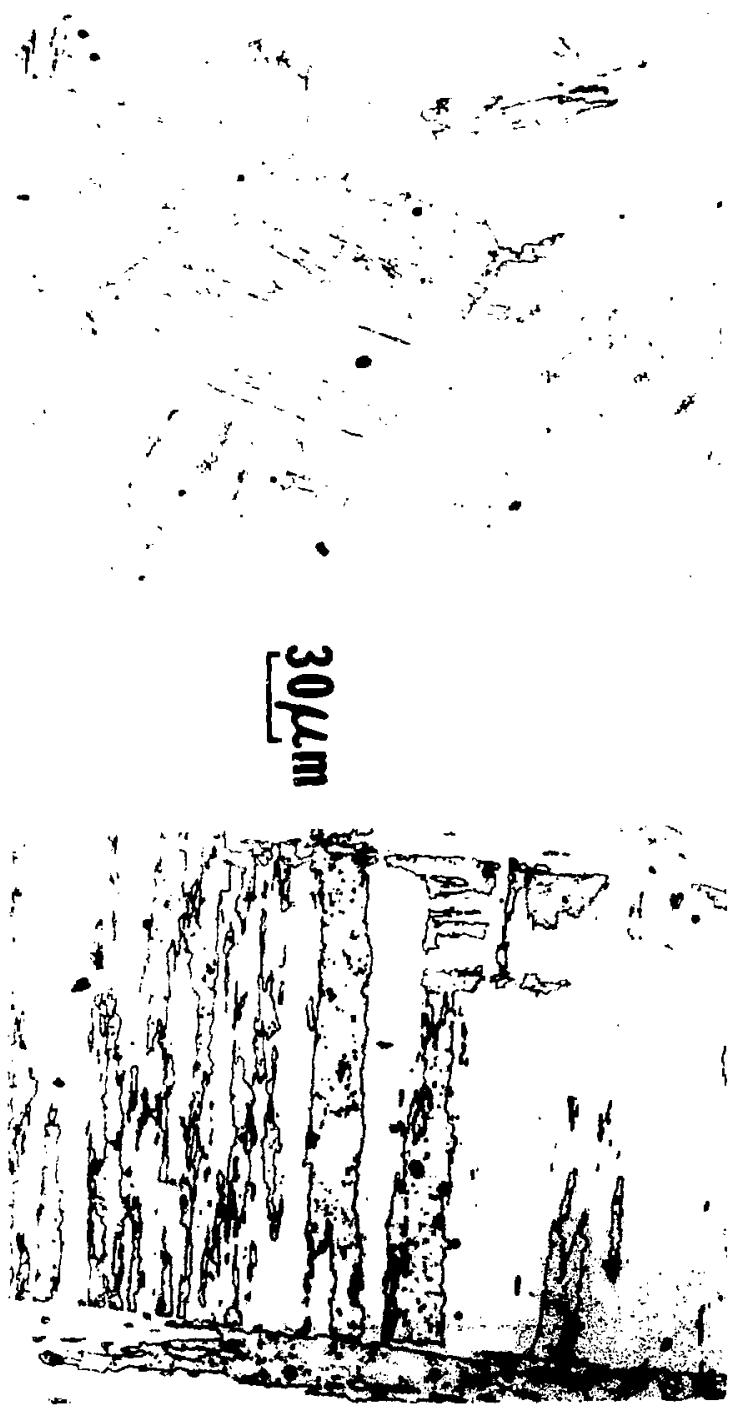


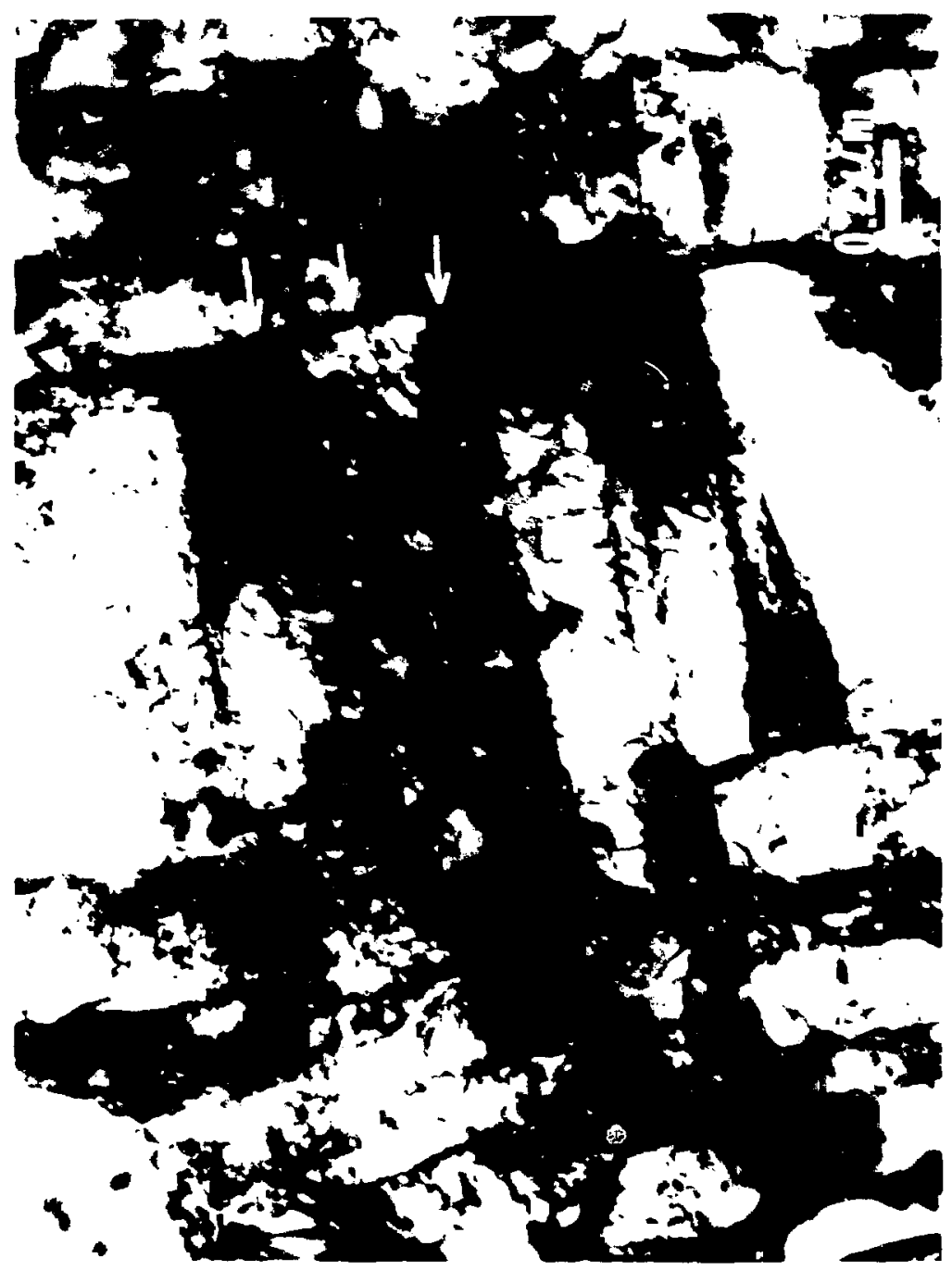



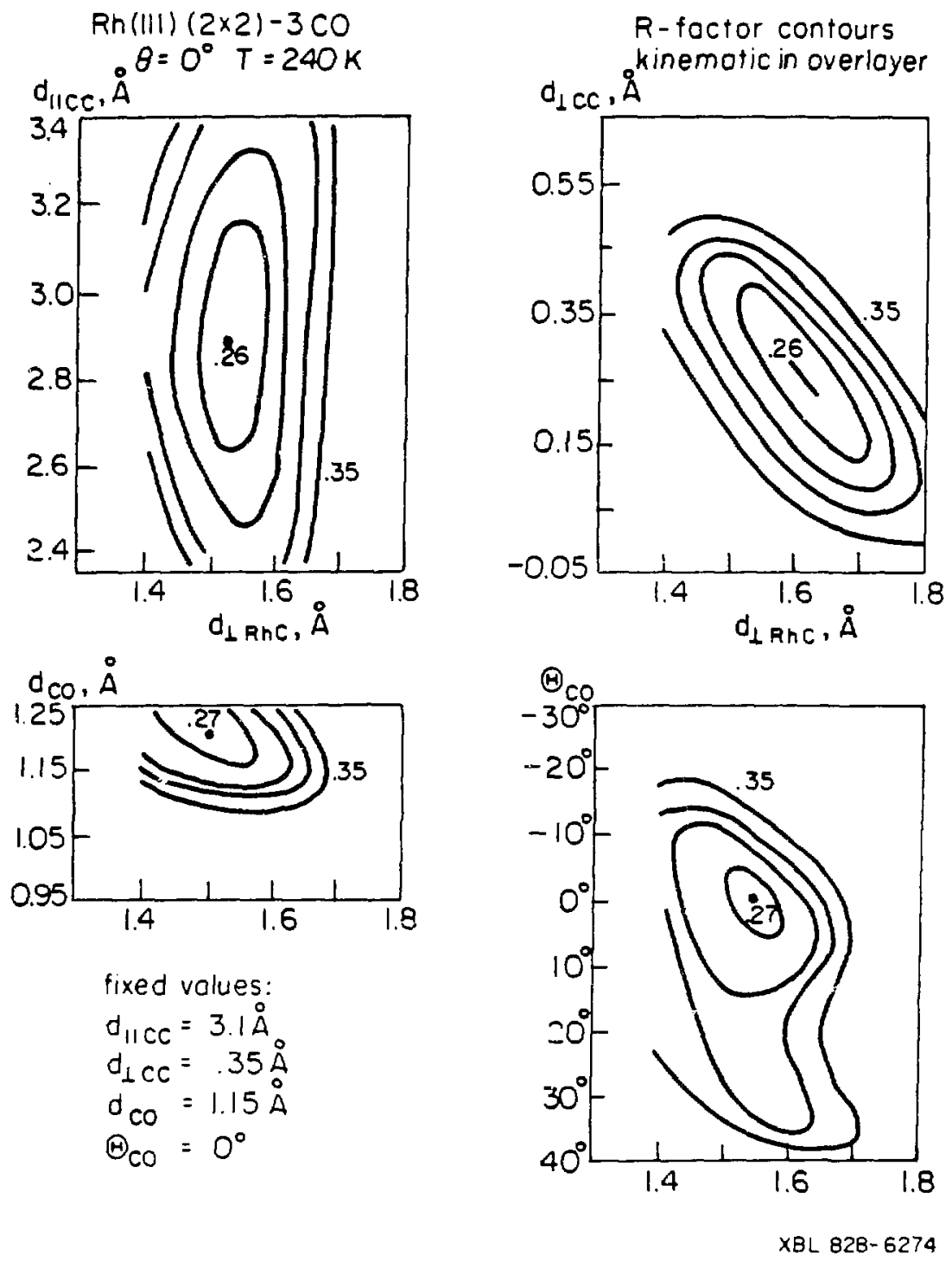

Fig. 3 


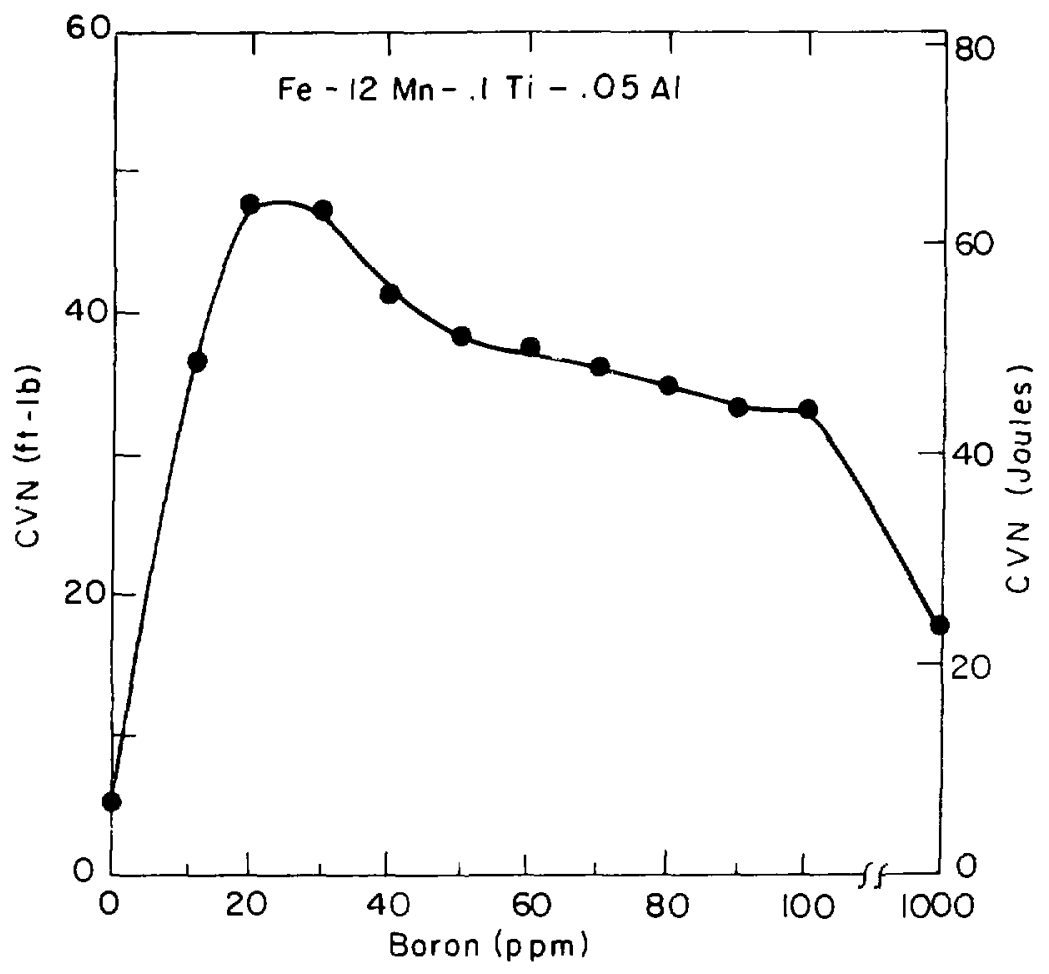

Figure 21

$X \theta L 8 \mid 2-5231$ 


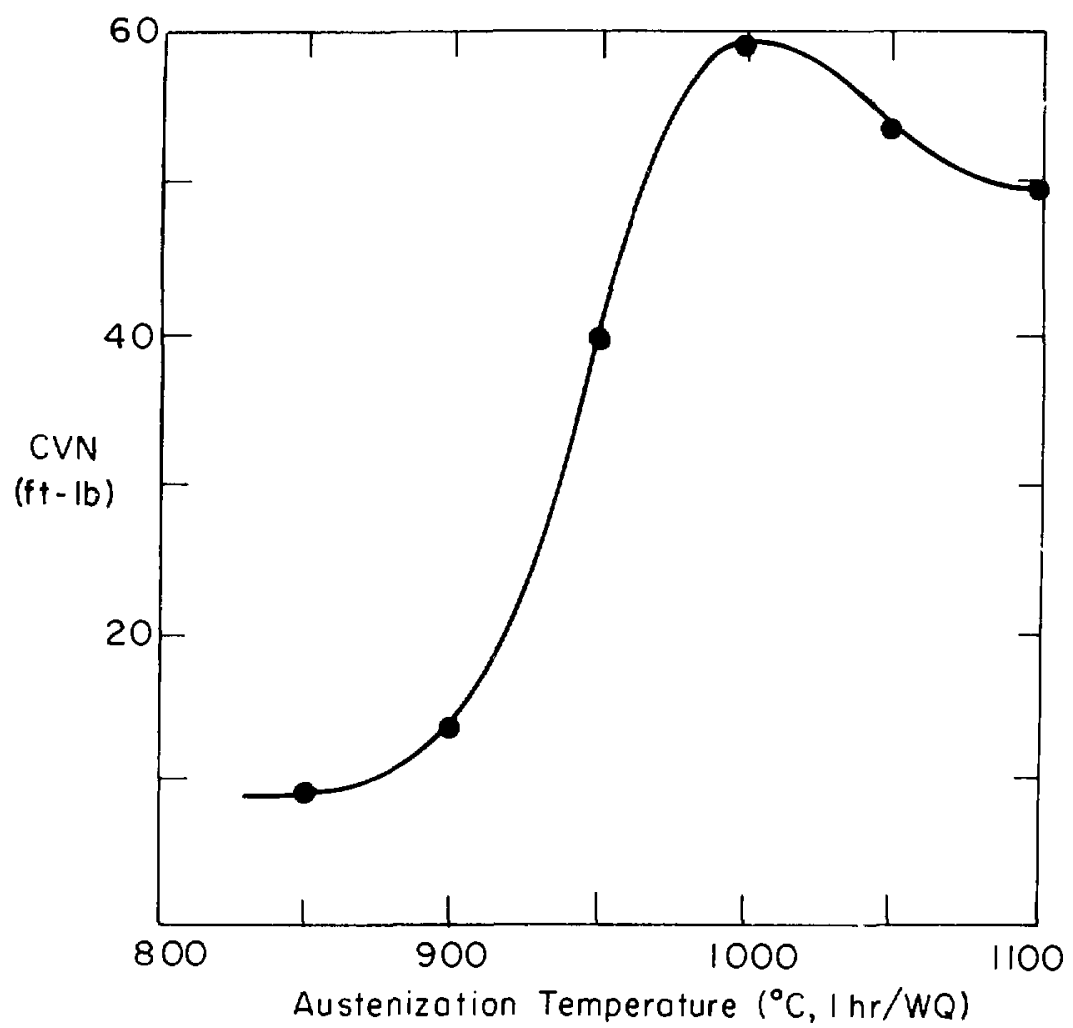

Figure 22 $X B L 812-5226$ 

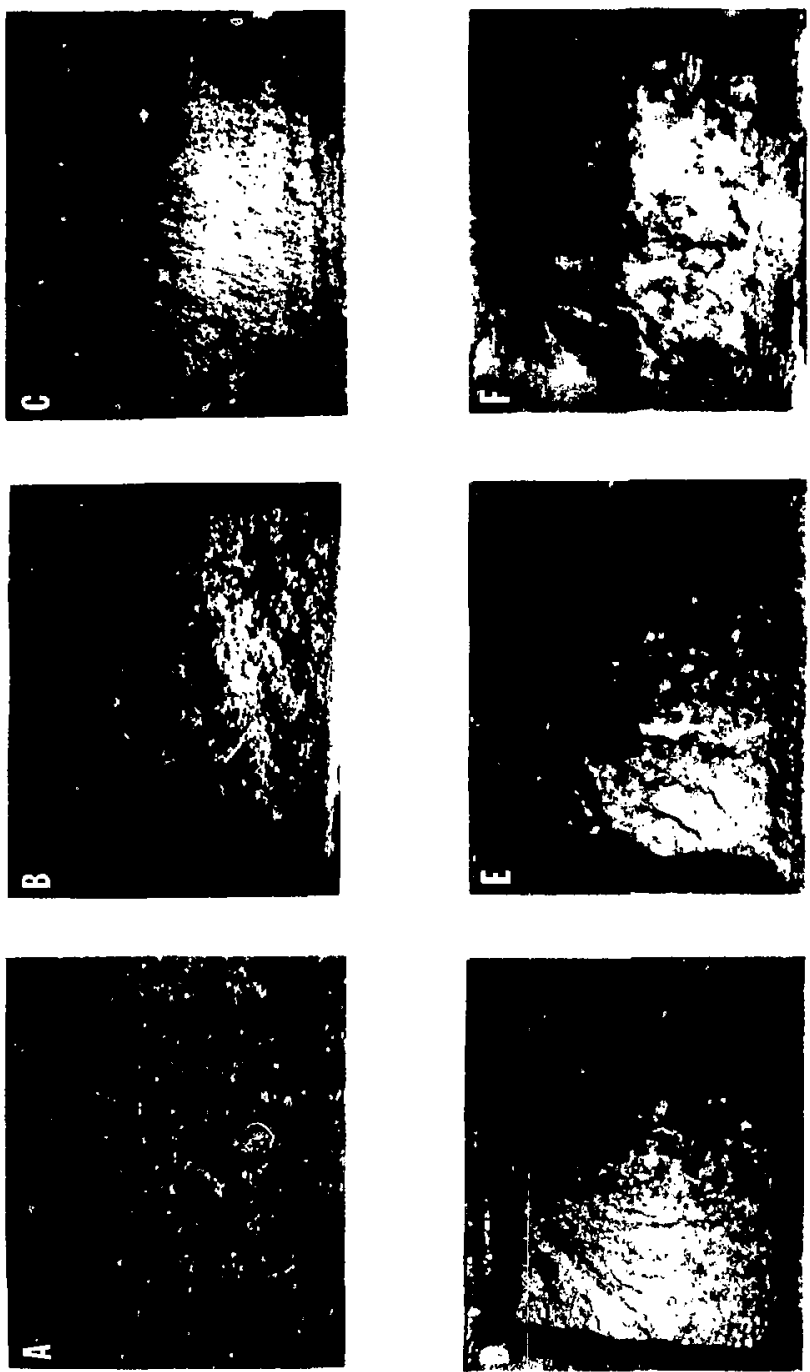


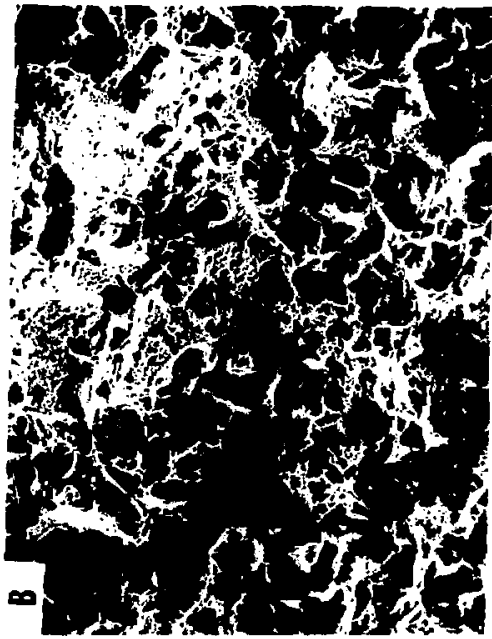

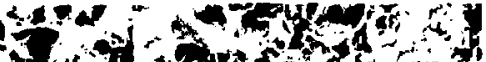

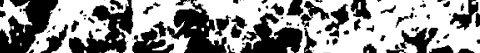

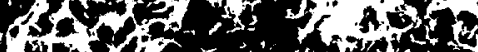

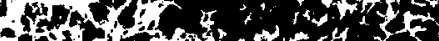

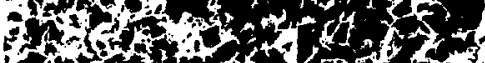

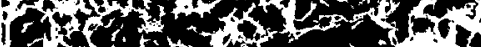

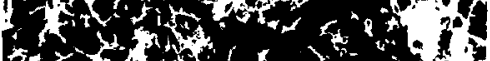

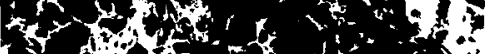

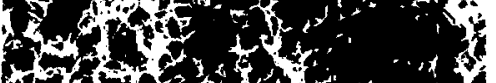

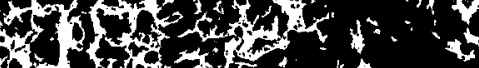

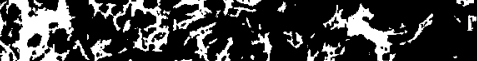

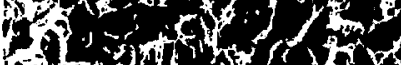

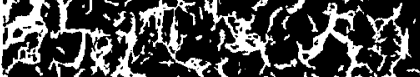

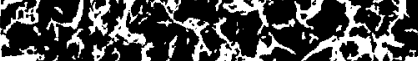

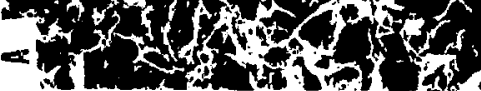
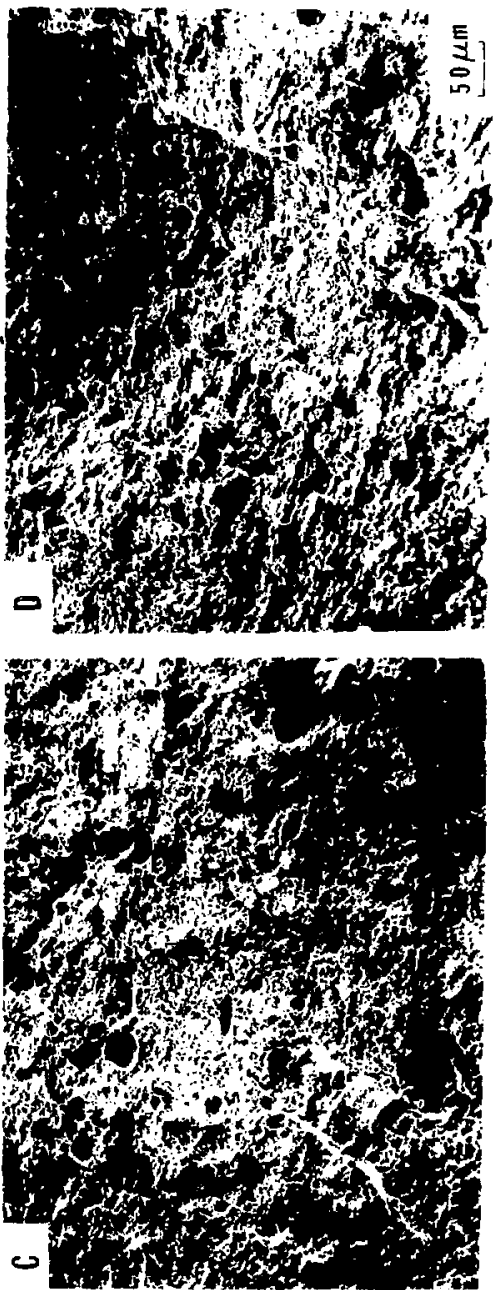


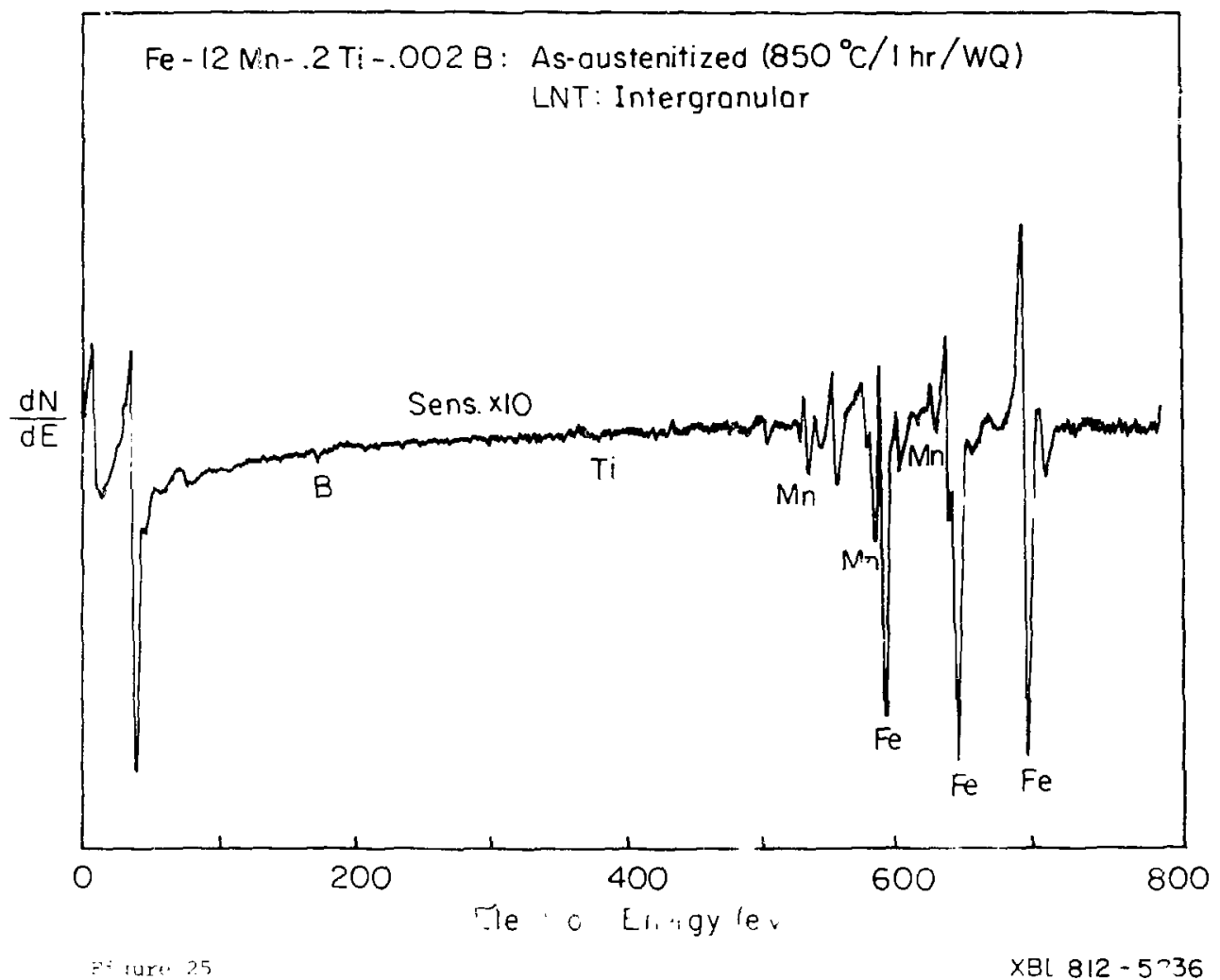




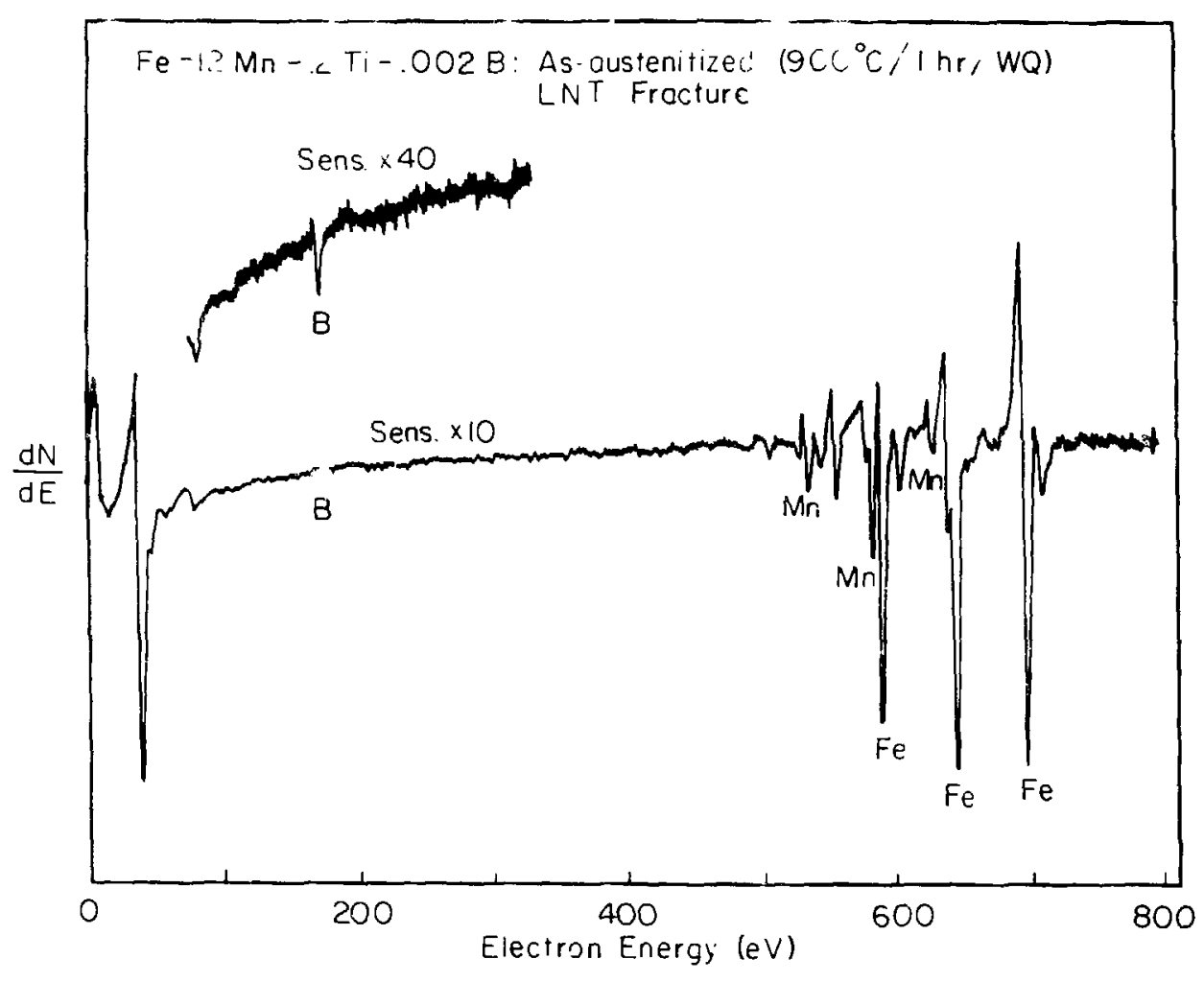




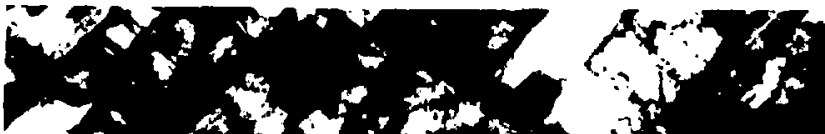

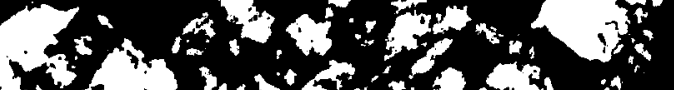

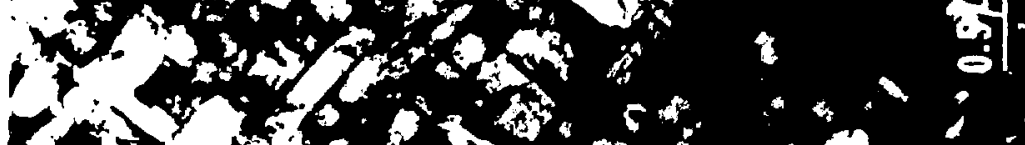

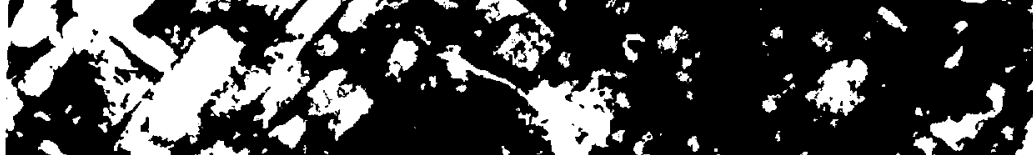

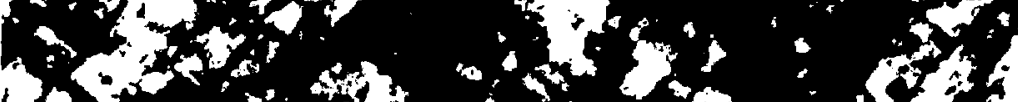

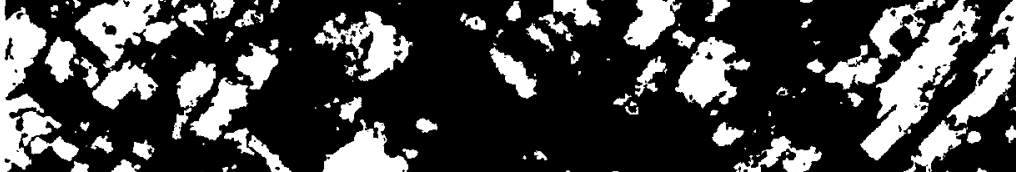

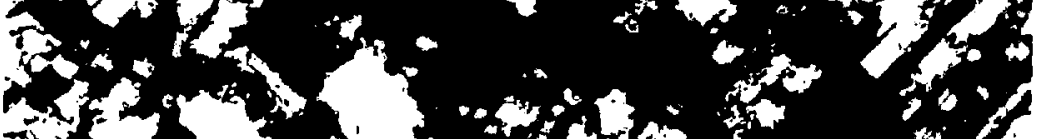

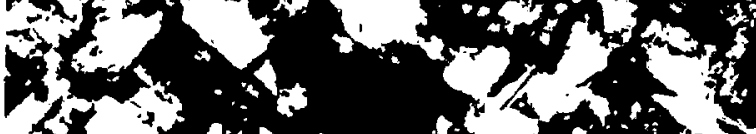

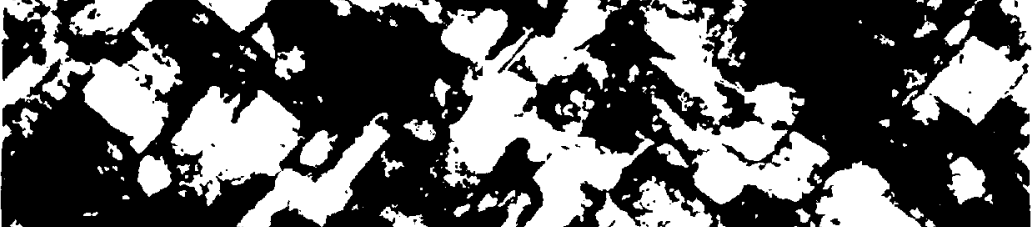

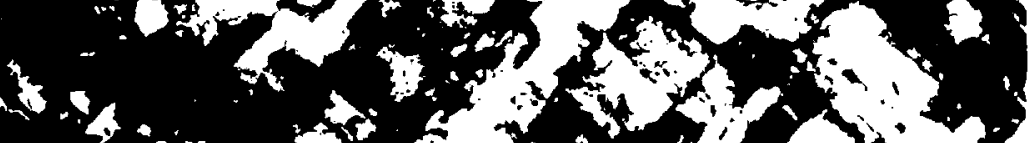
to $y=10$

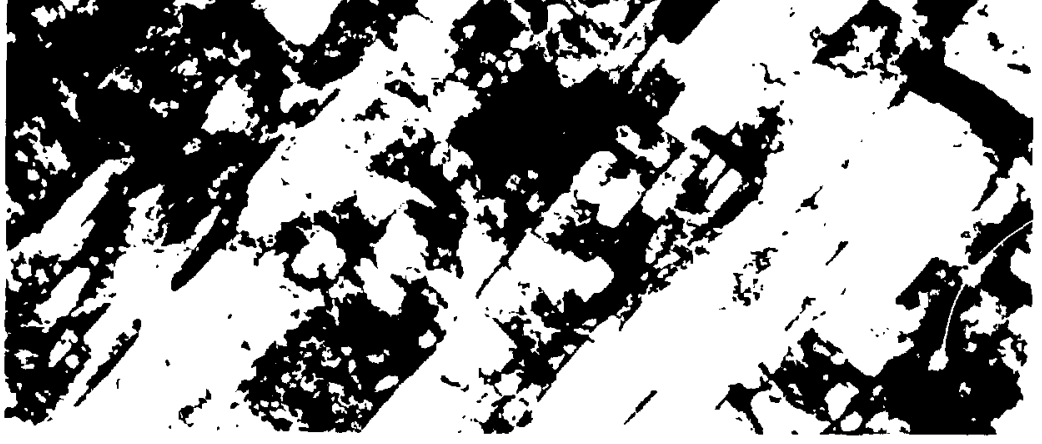



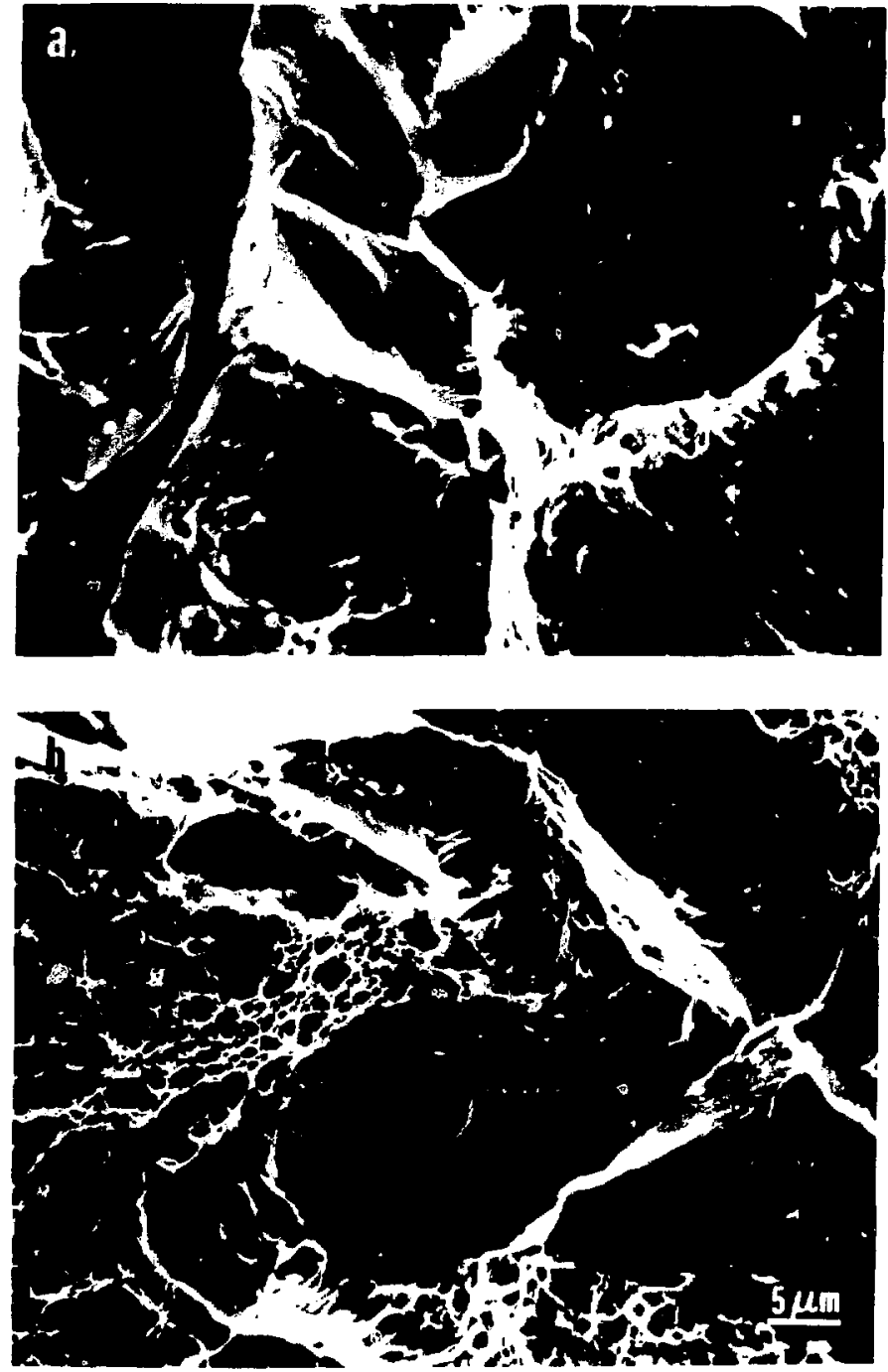

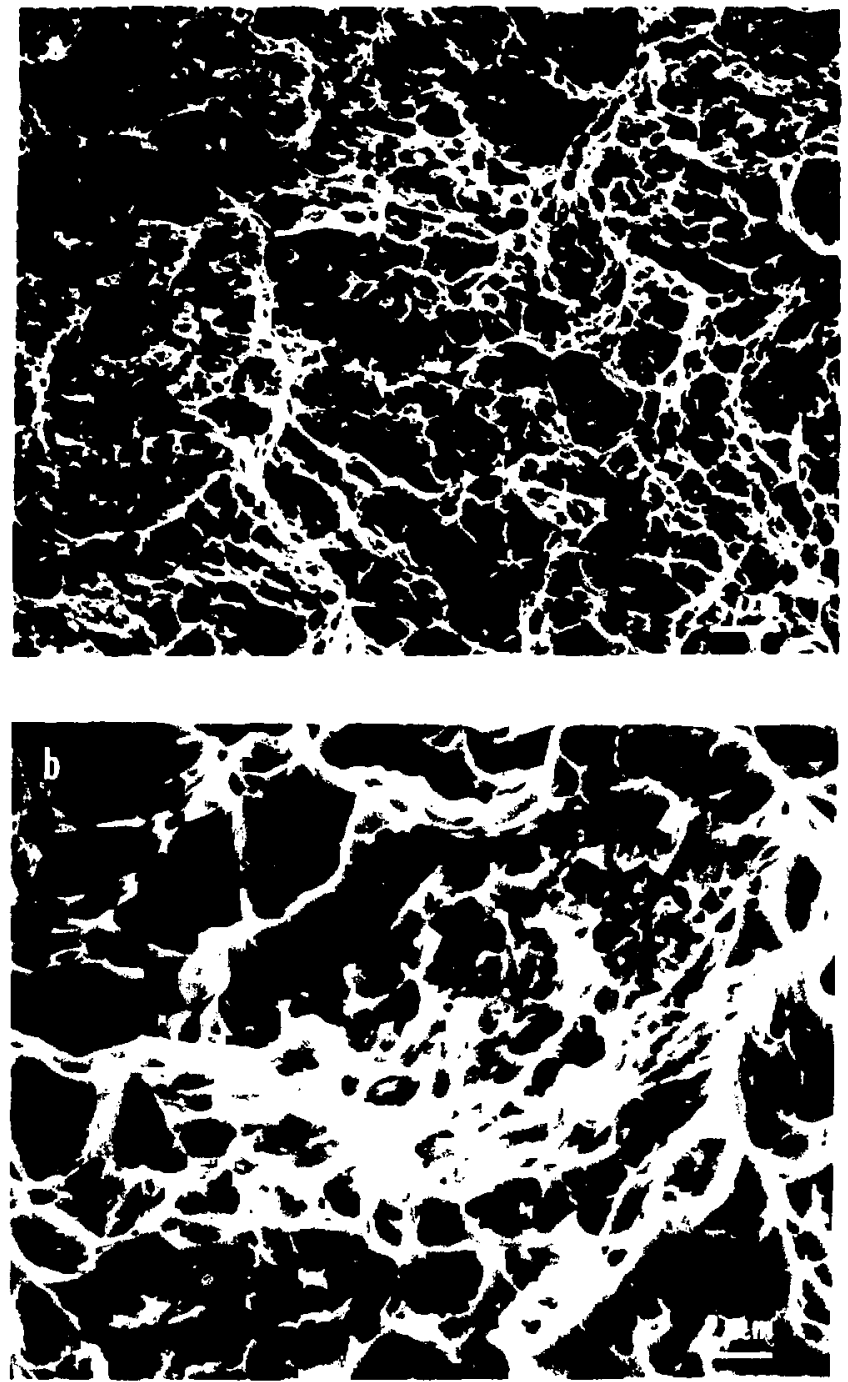


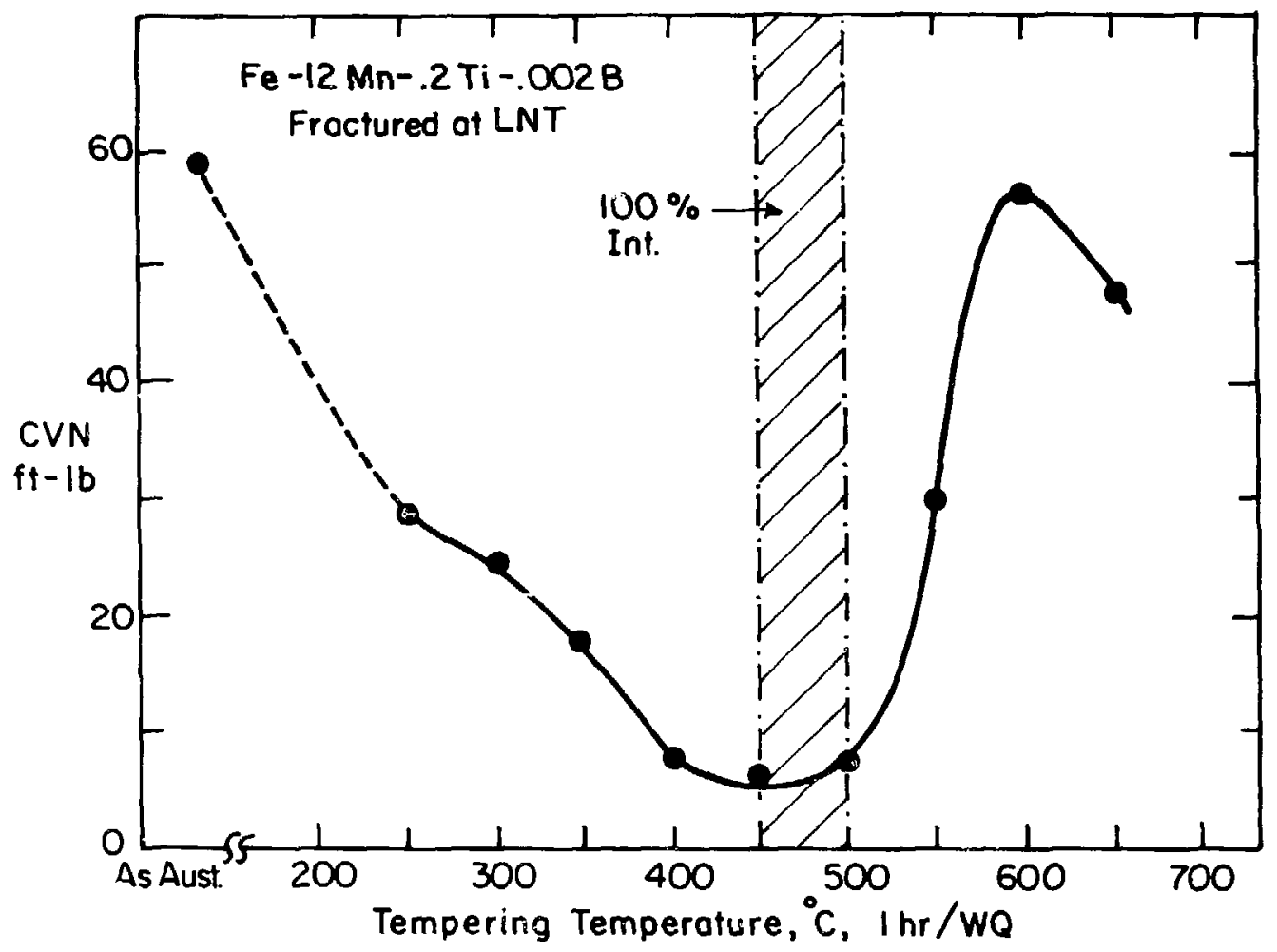

Figure 30

XEL8I10-678a

$\mathscr{g}$ 

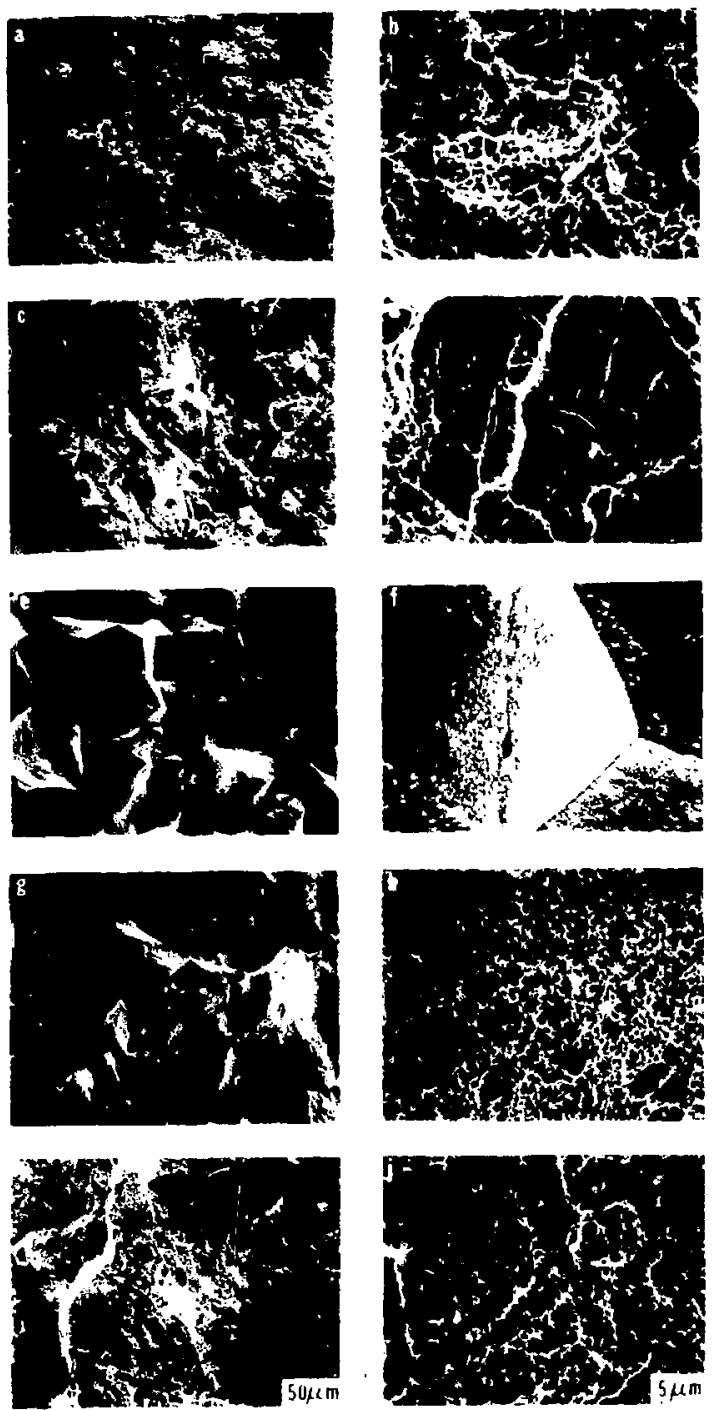

Fiente 


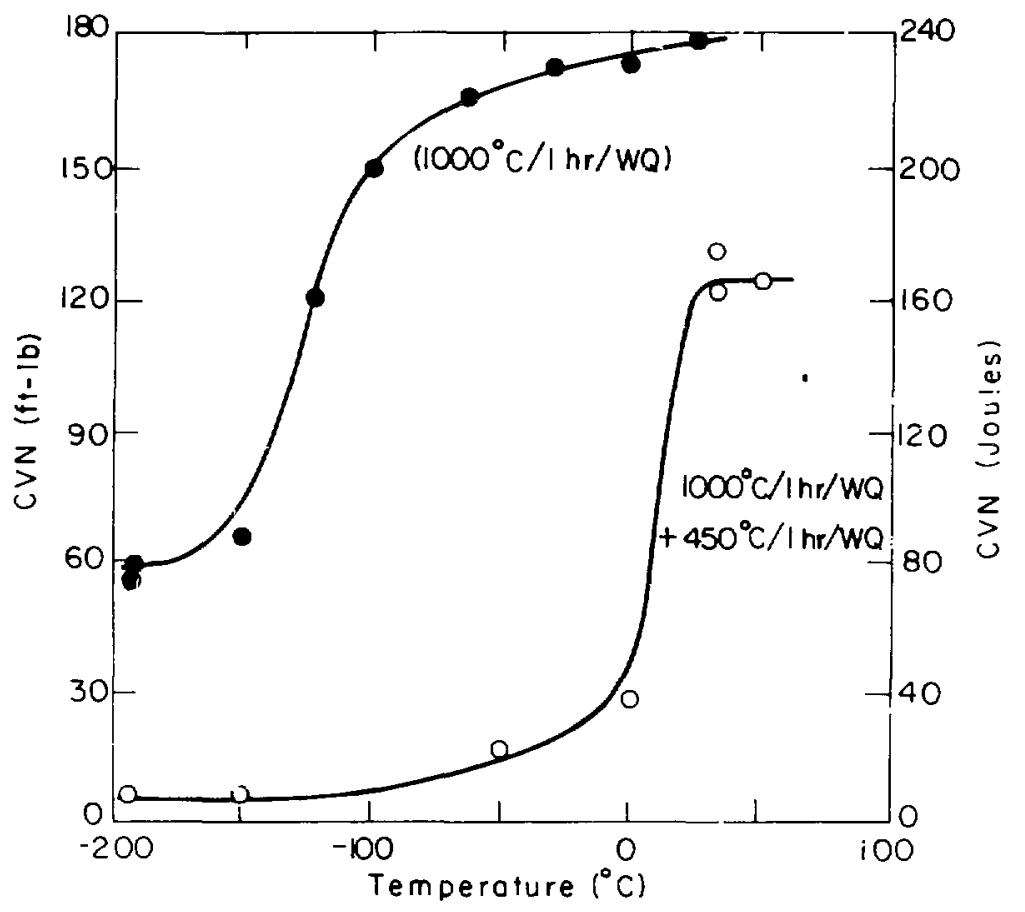

Eiqure 32

XBL 812- 5224 


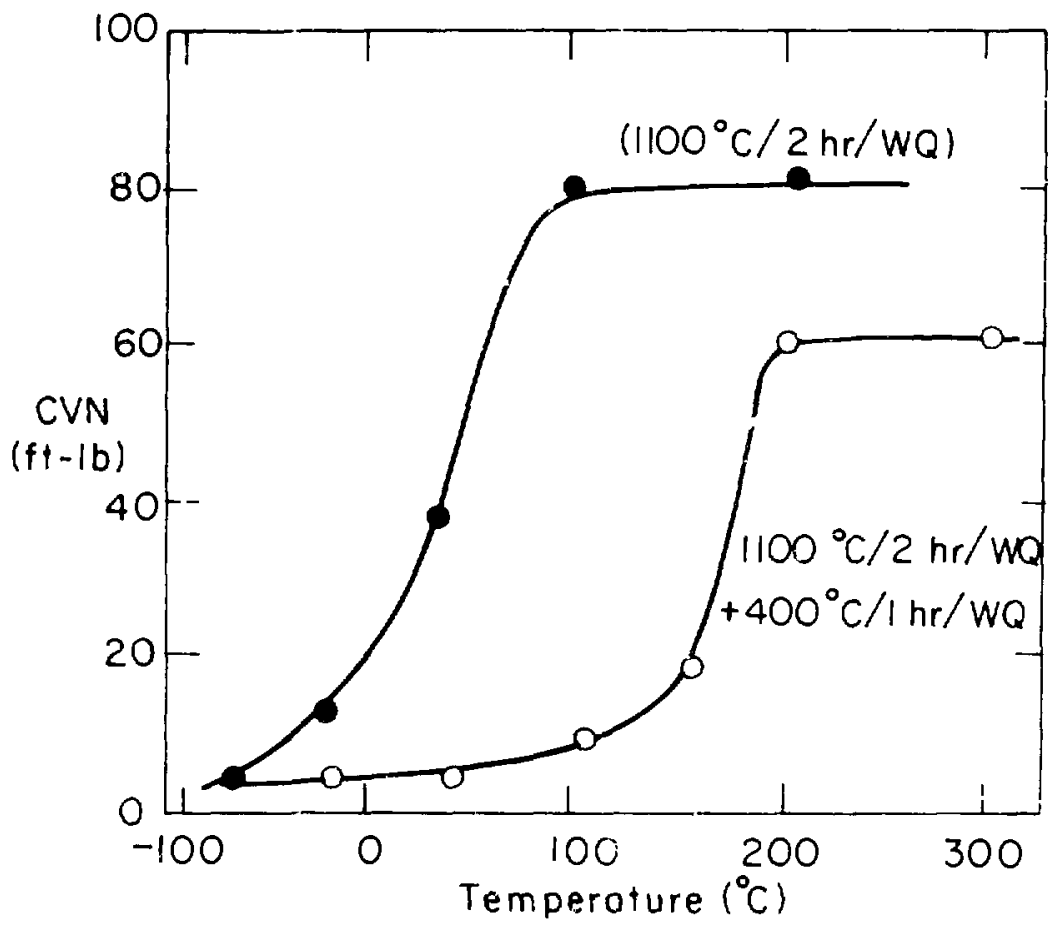

Fisure 33

XEL 812-522? 


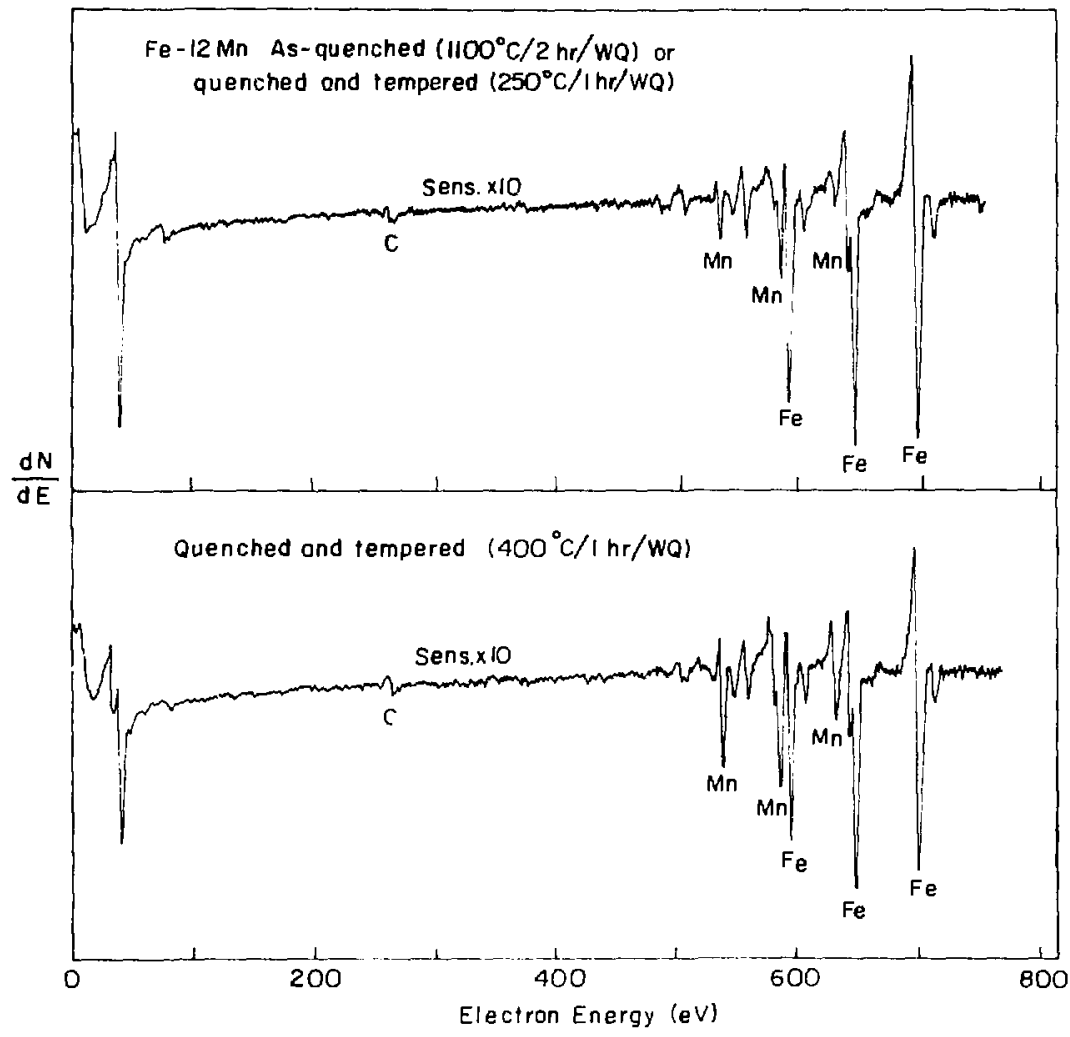

Figure 34

XBL $812-5223$ 


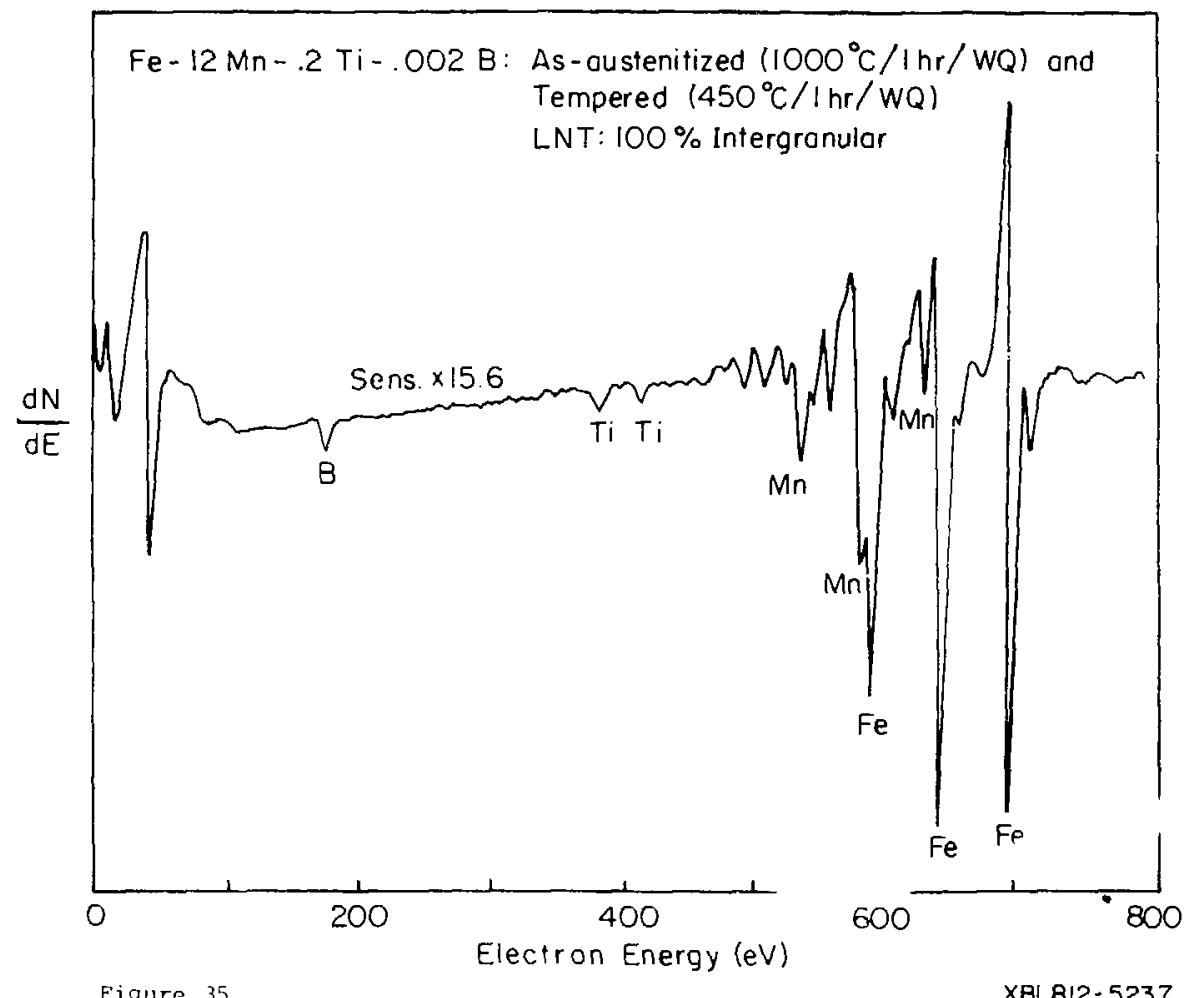




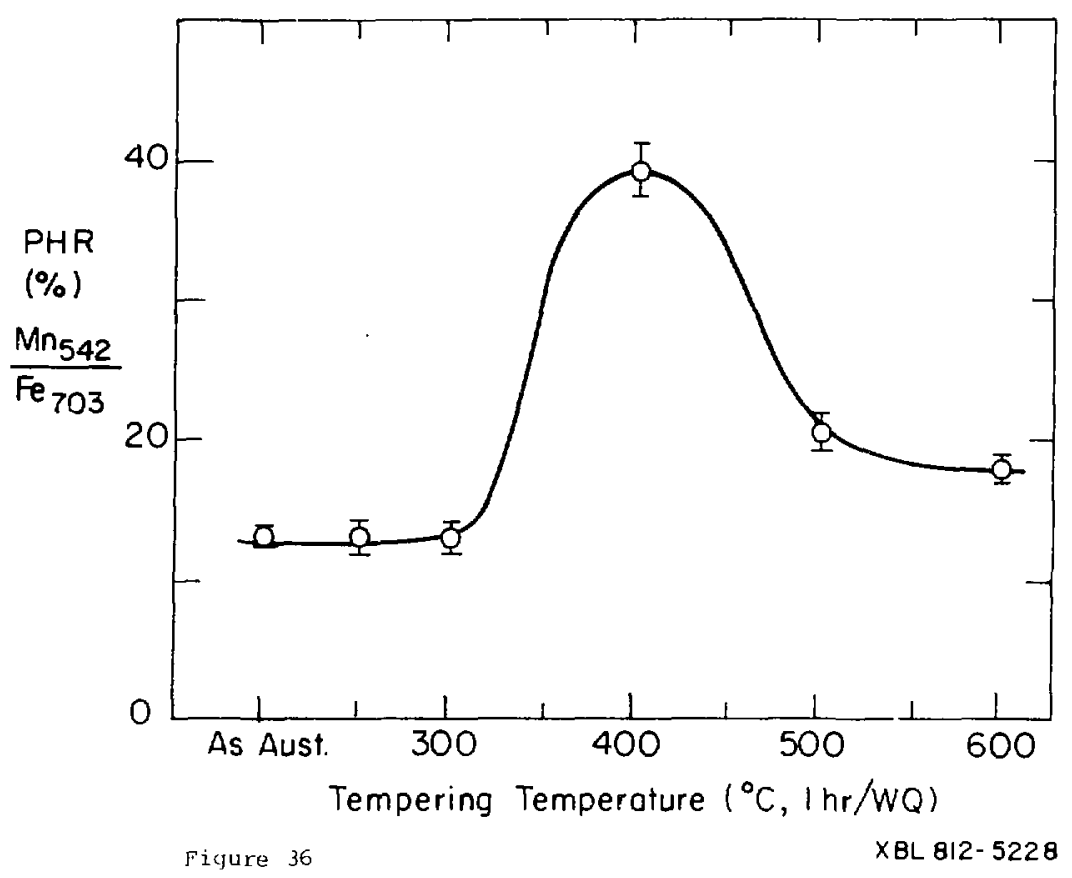




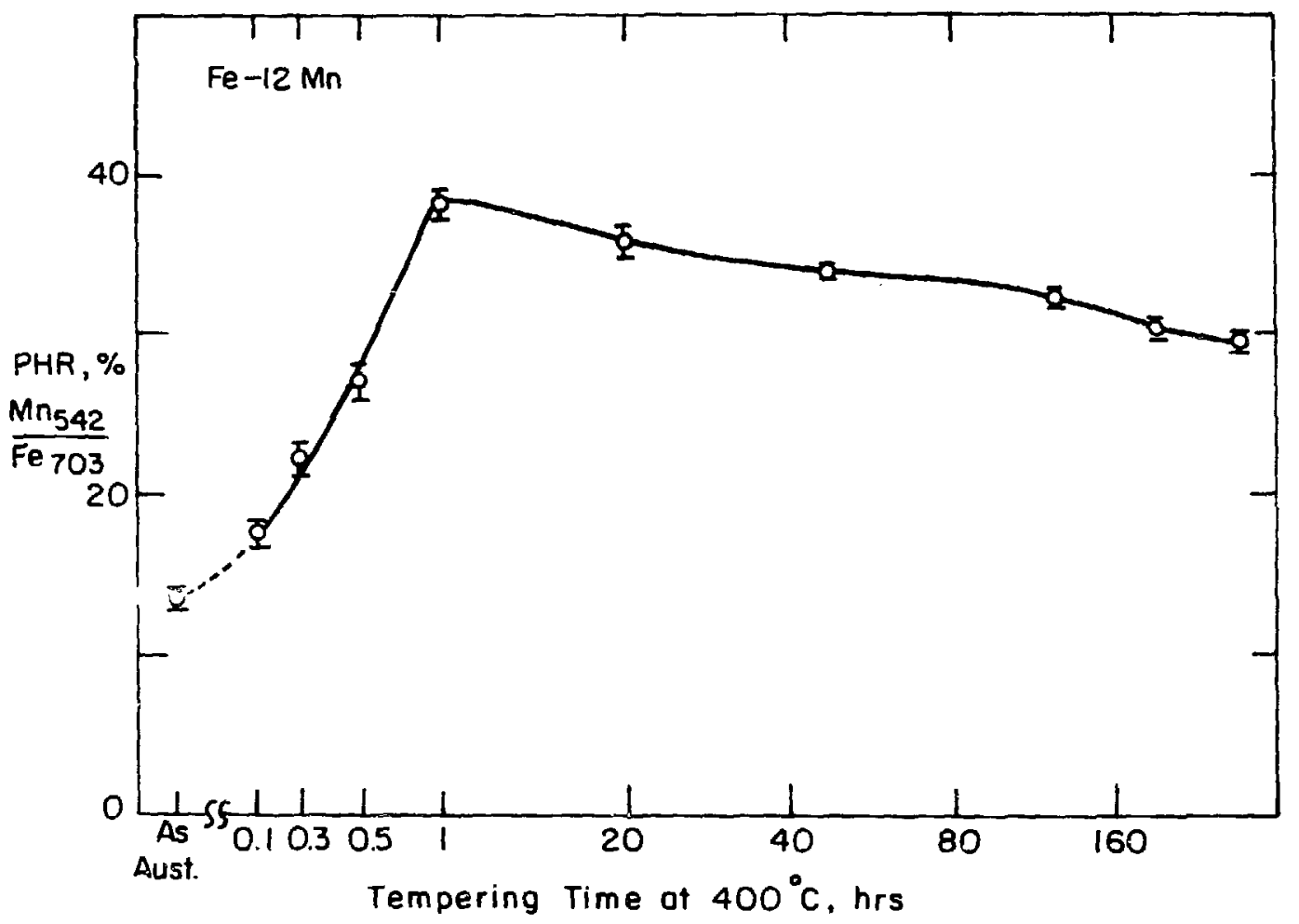



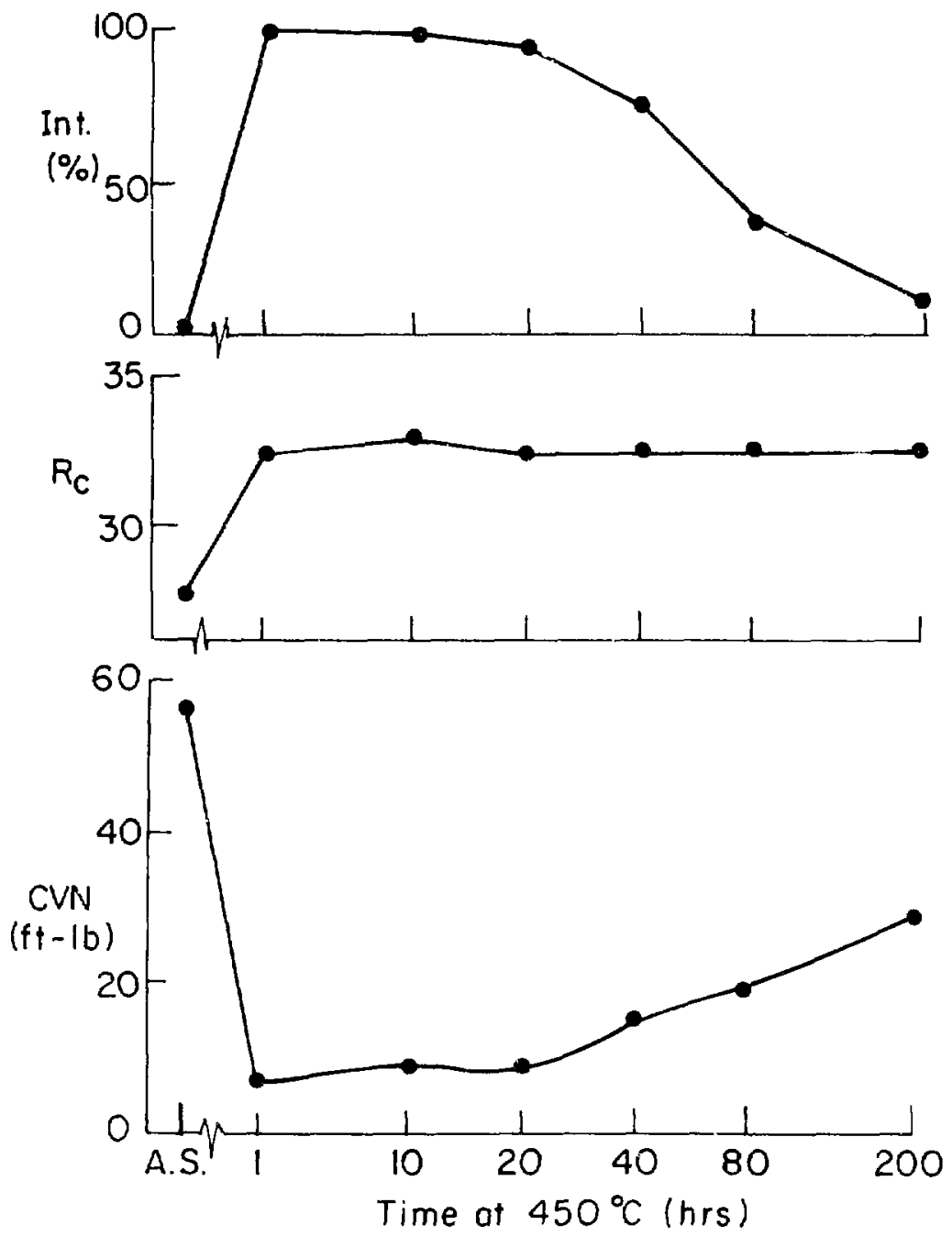

Fiqure 38

XBL 812-5225 


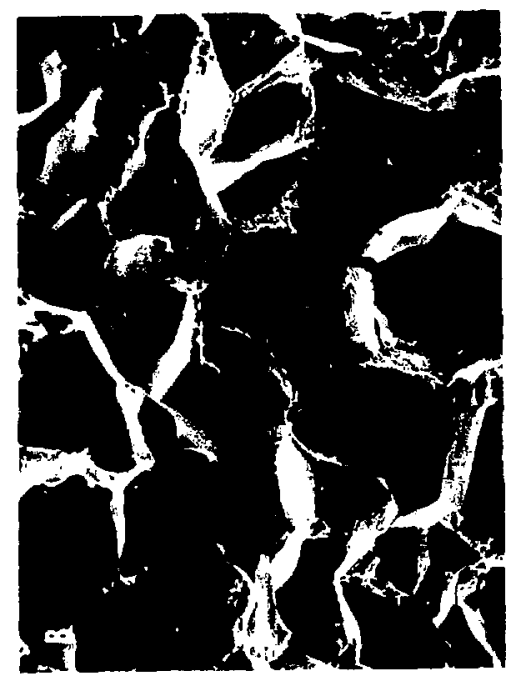

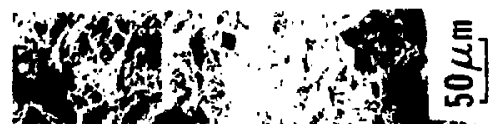
raty at a

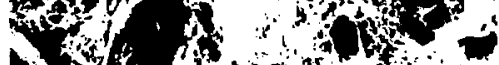

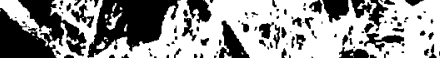

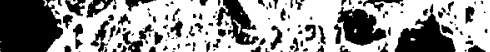

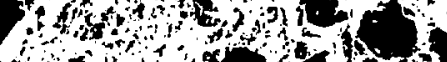
FI

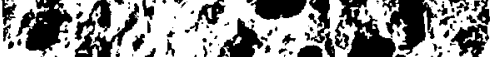

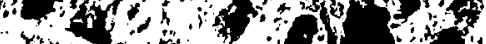
\&y

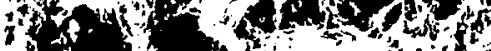

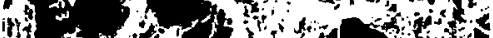

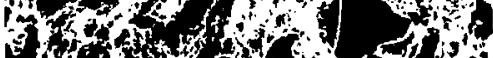

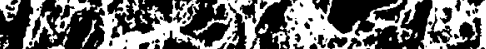

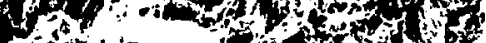

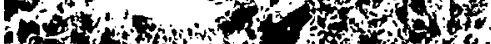
Ap $40-A^{\prime}$ as of
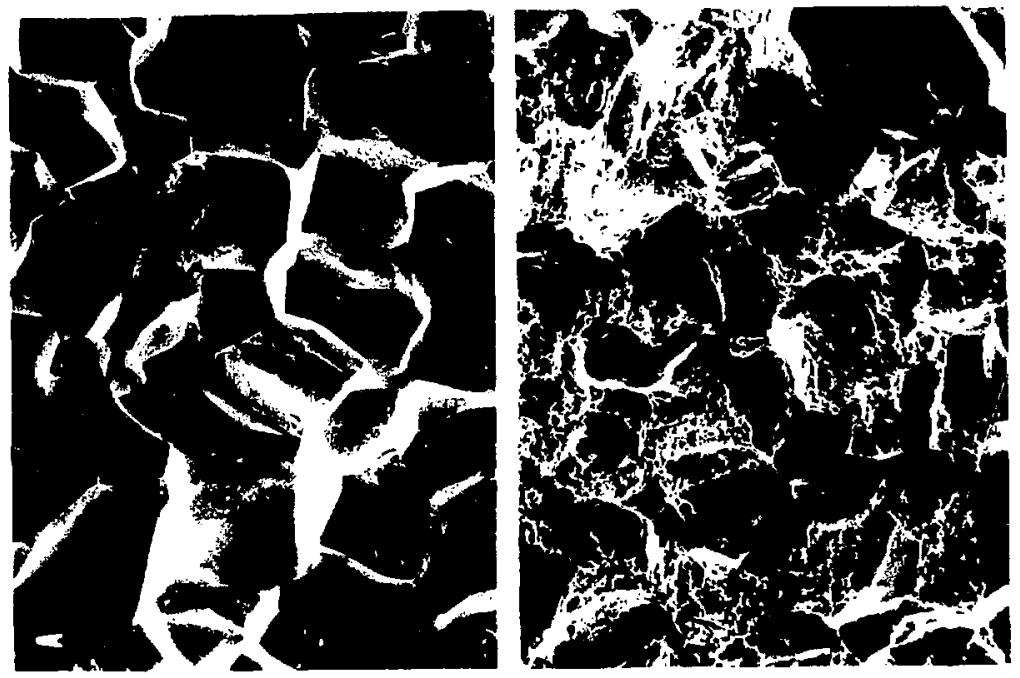


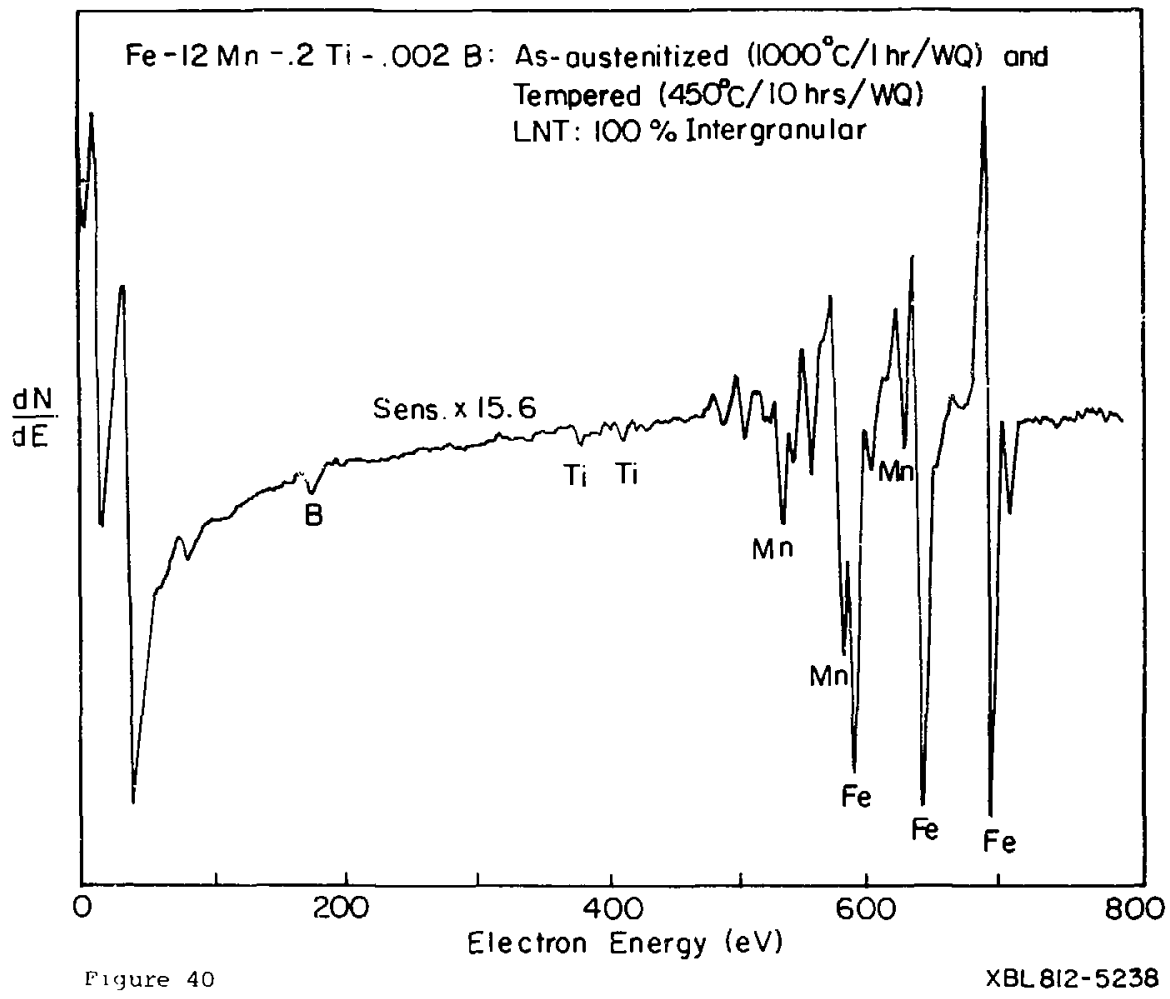




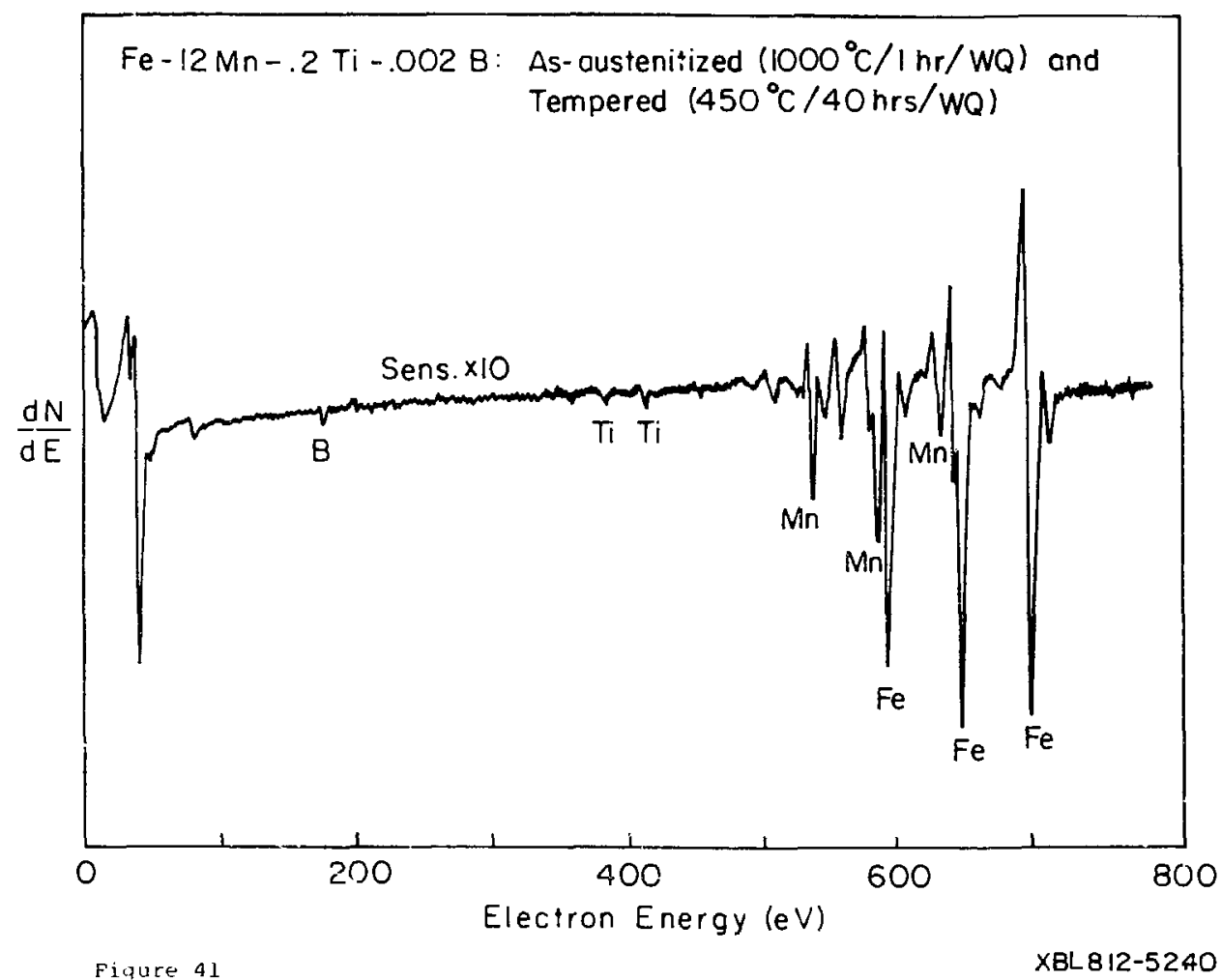




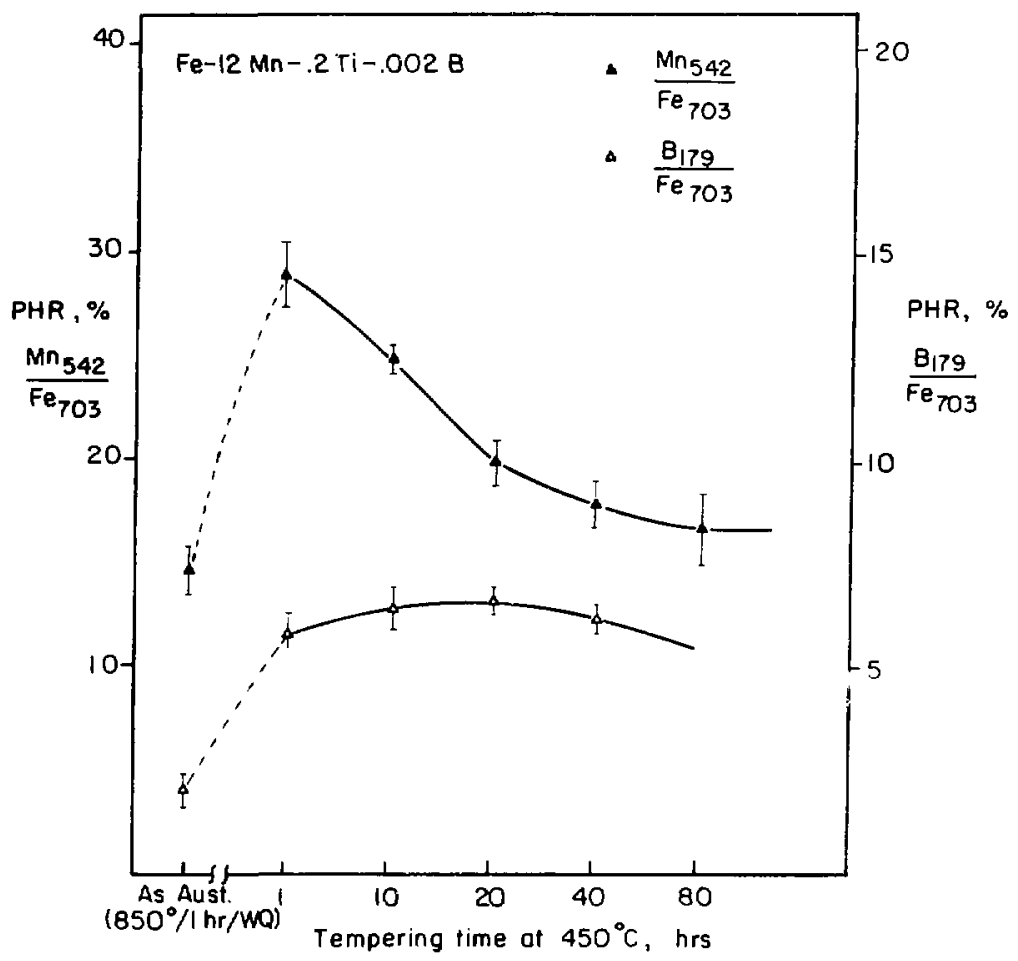

Figure 42

XBL 814-9449 


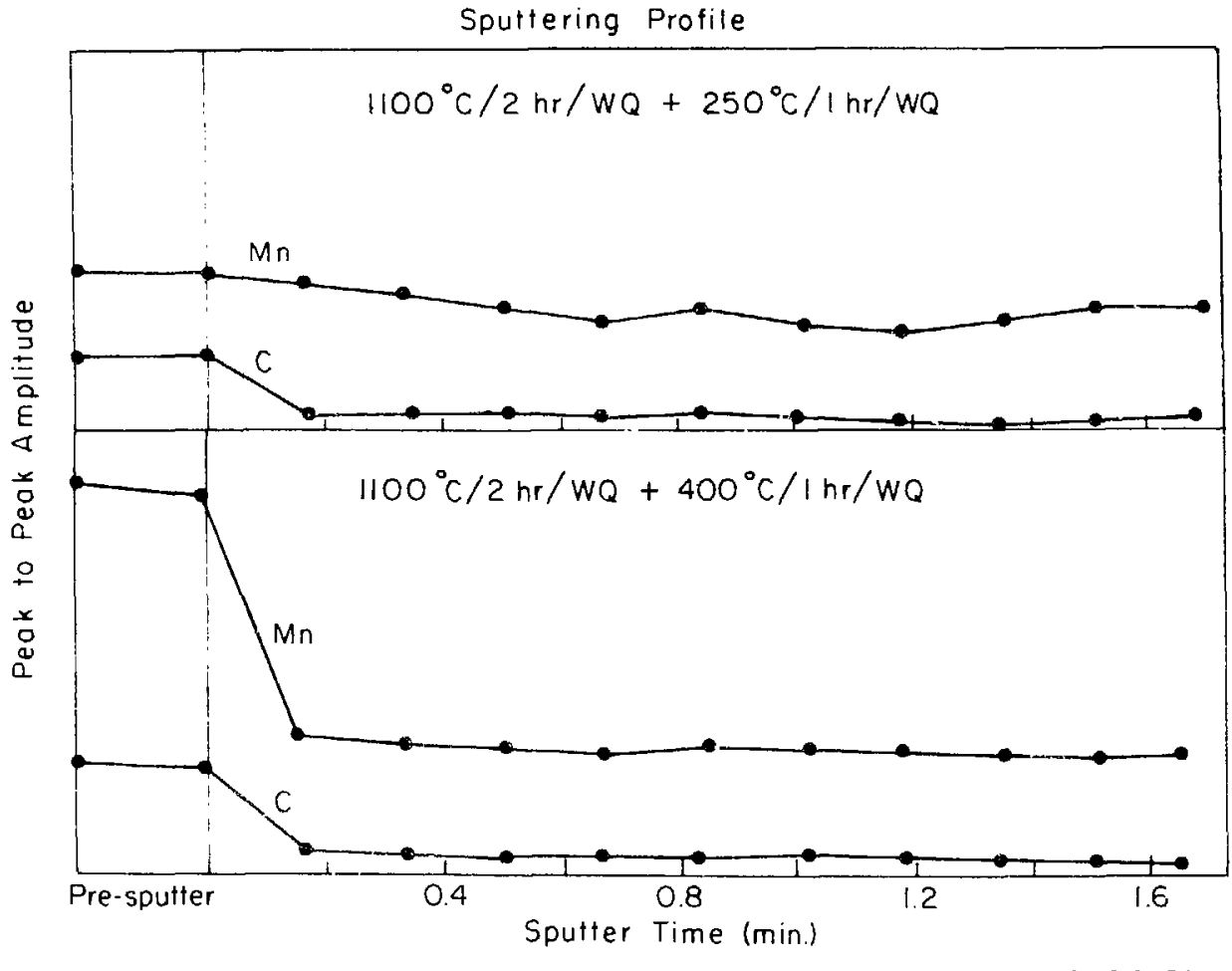

Fiqure 43

XBL 812-5230 


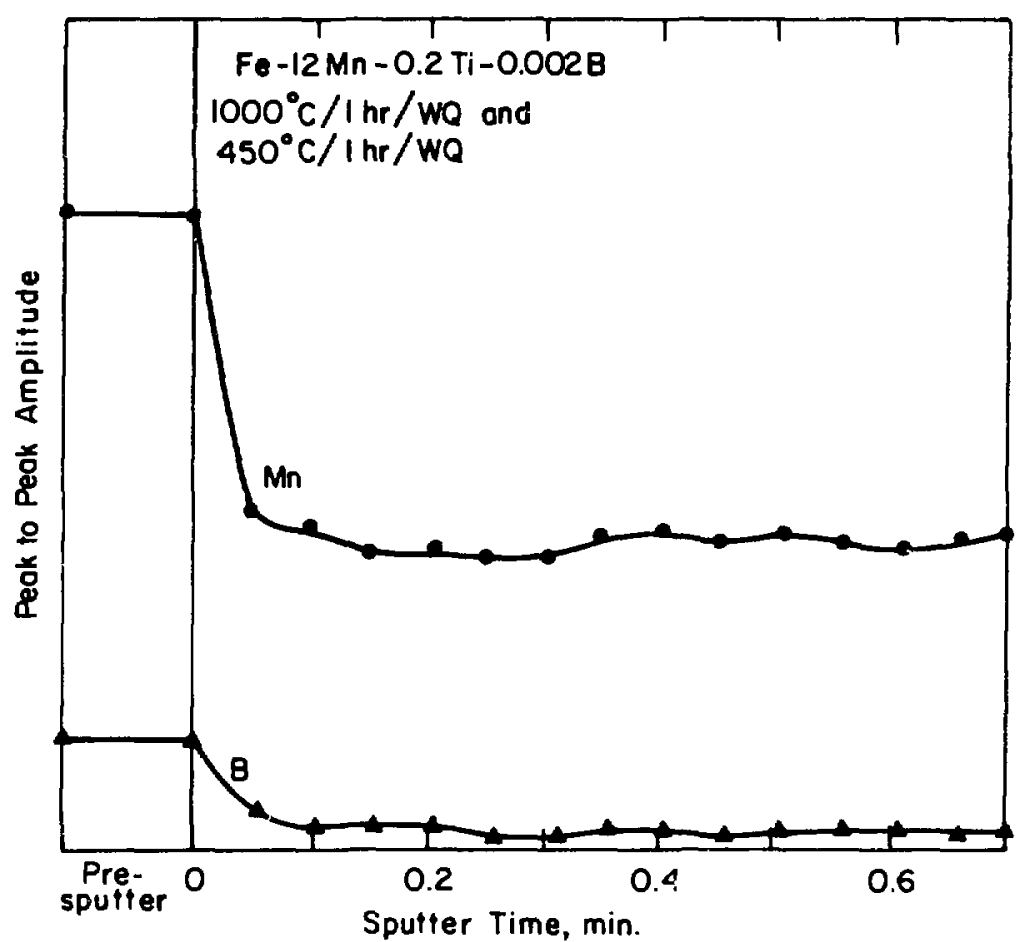

Figure 44

XBL 8110-6799 


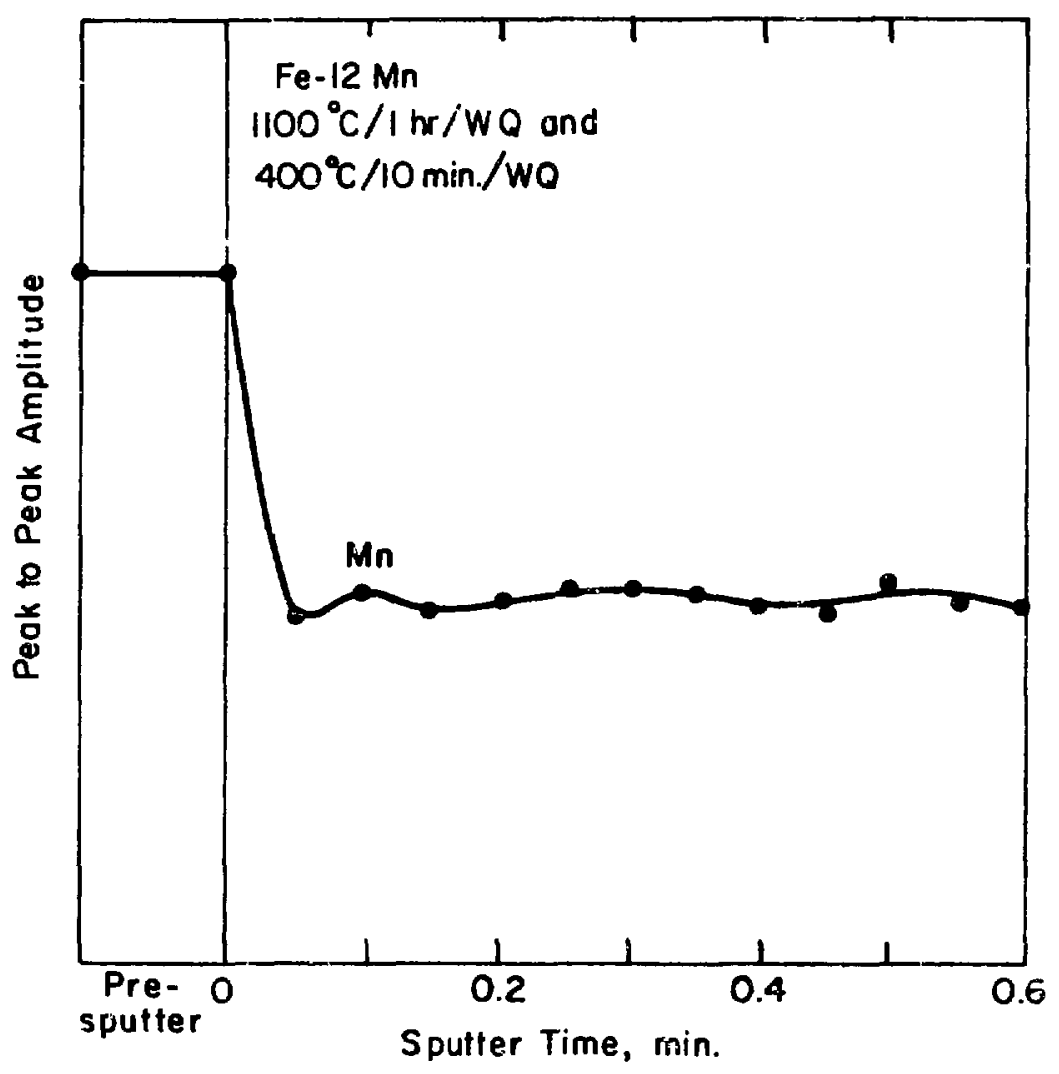

Figure 45

X日LBIIO-6795 


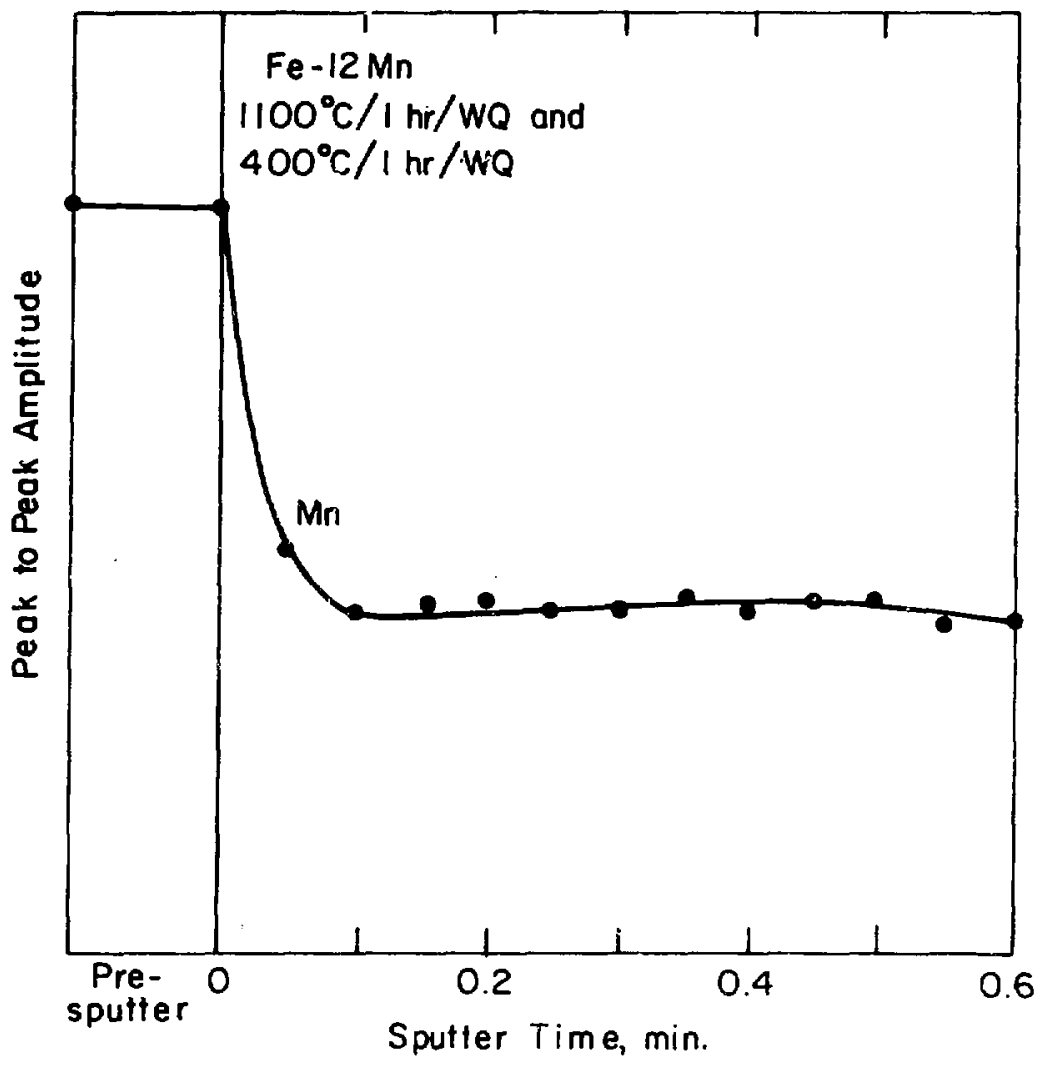

Figure 46 


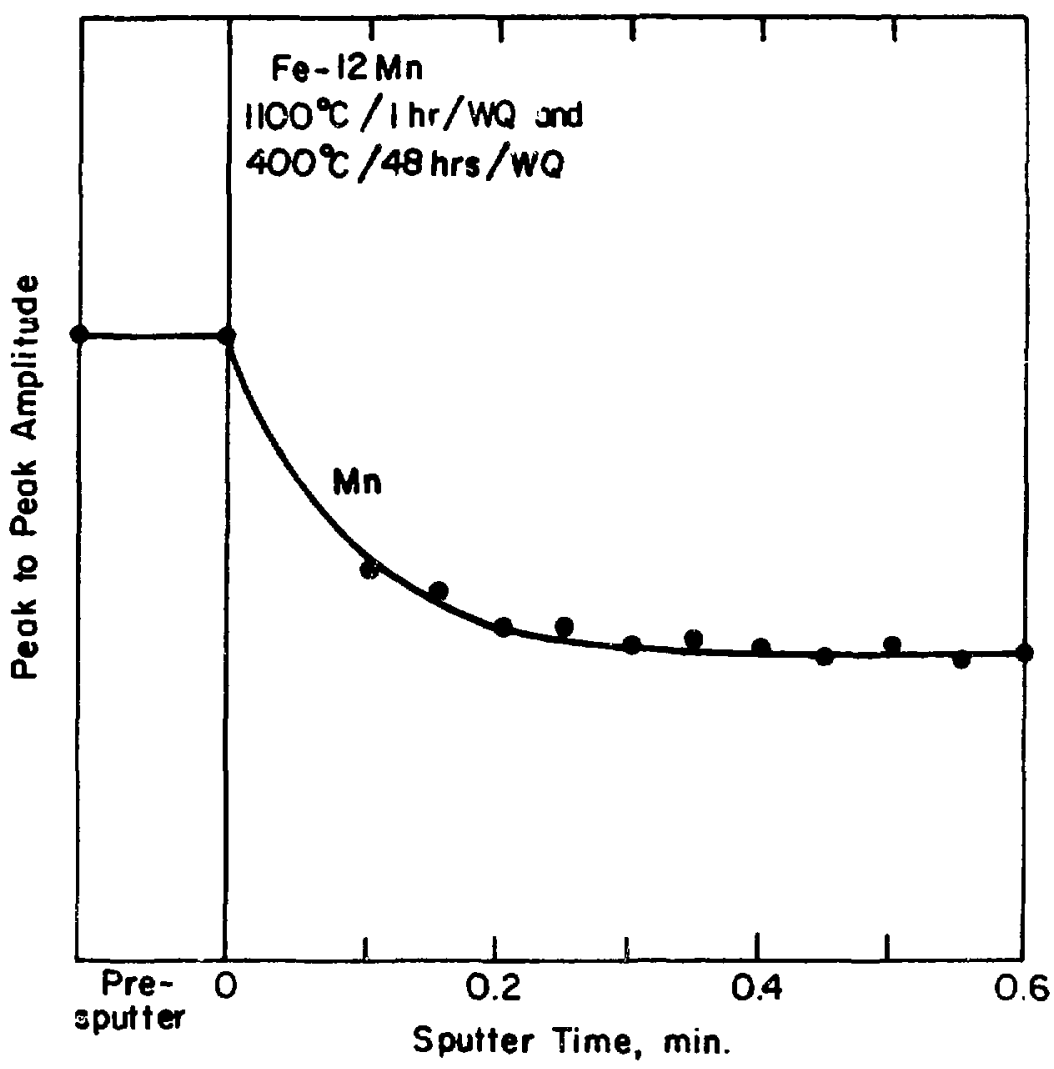

Figure 47 


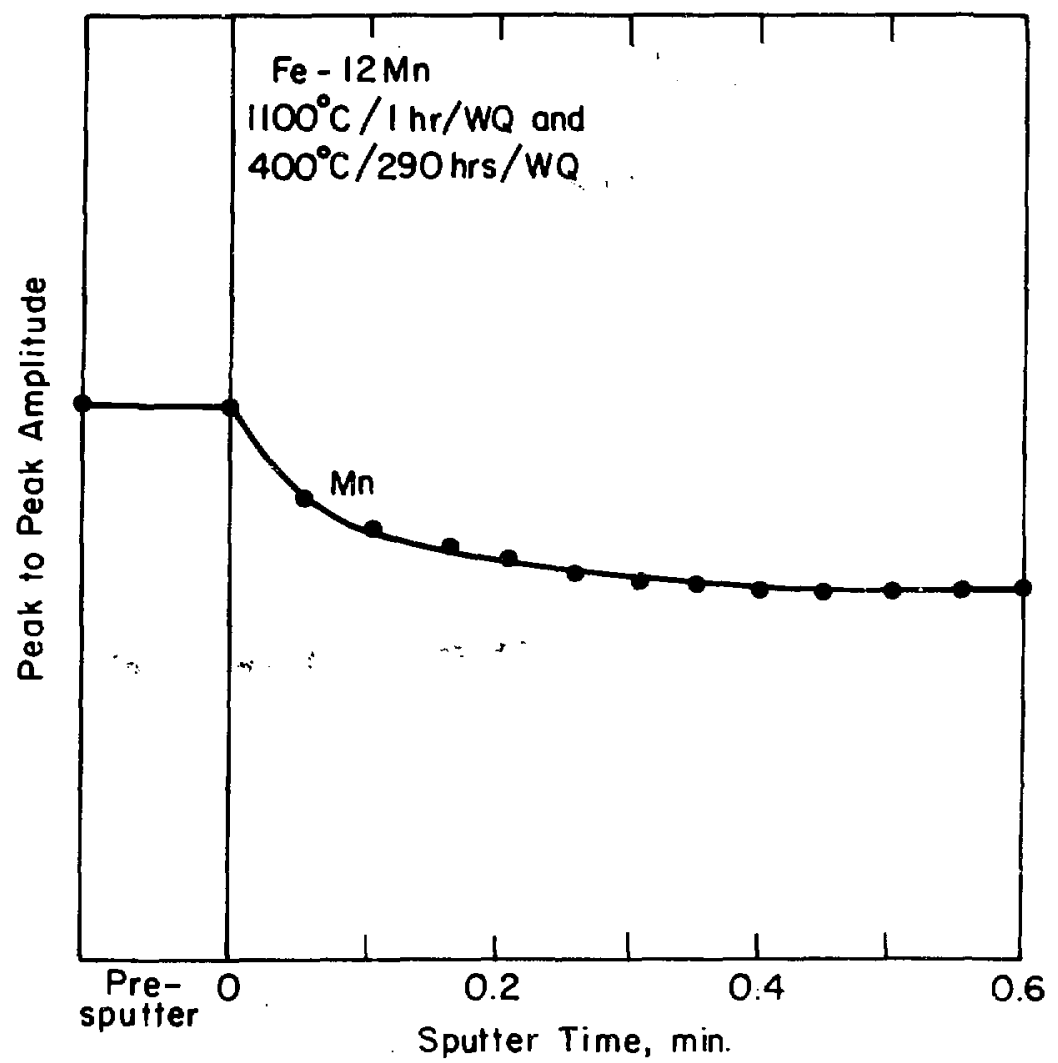

Figure 48

XBL 8110-6798 


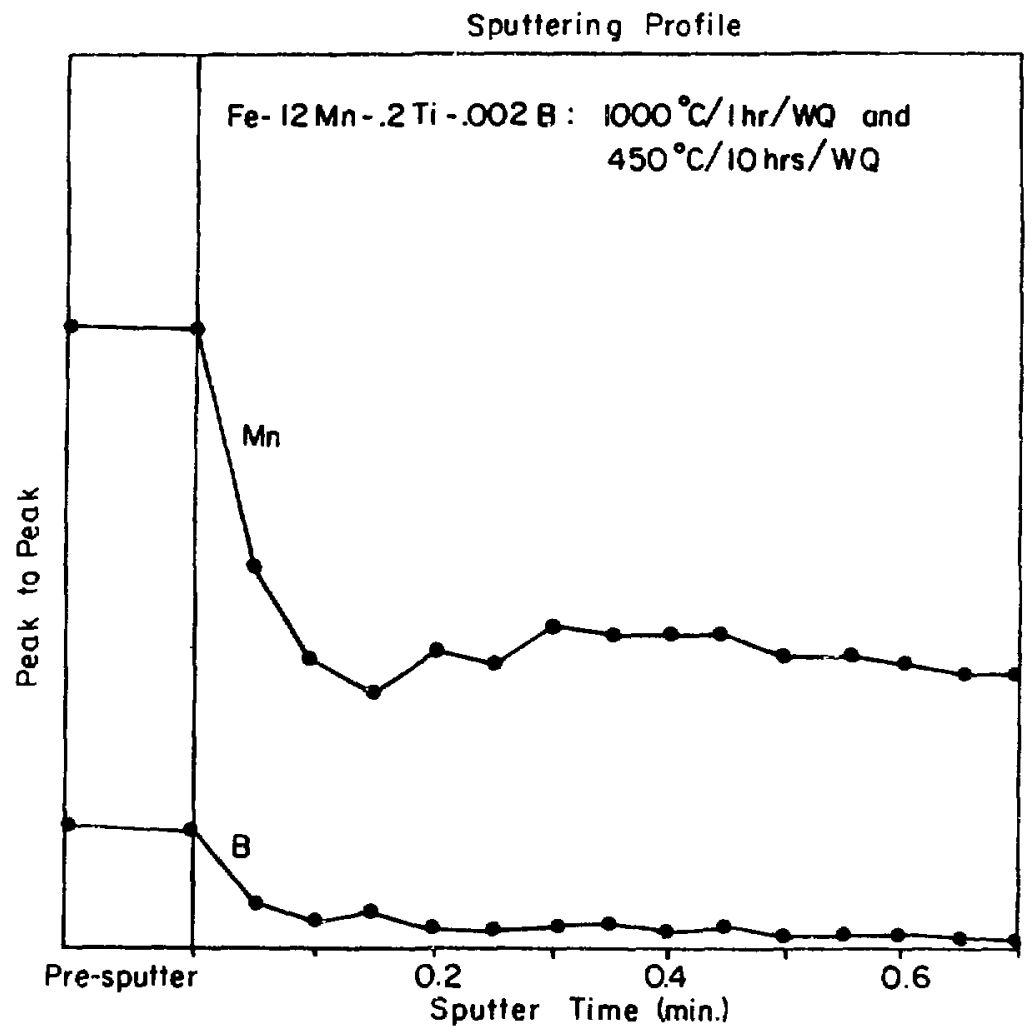

Figure 49

X日L 812-5232 


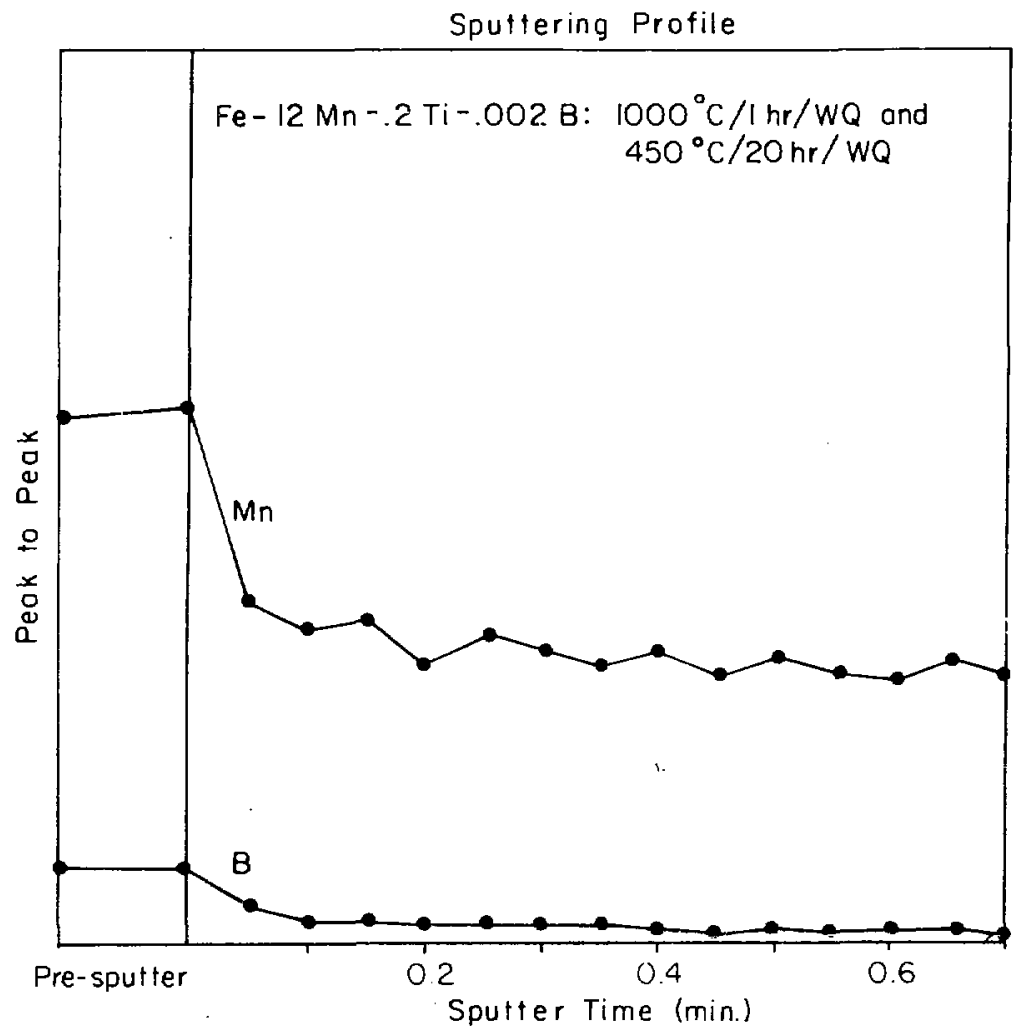

Figure 50 $X B L 812-5233$ 


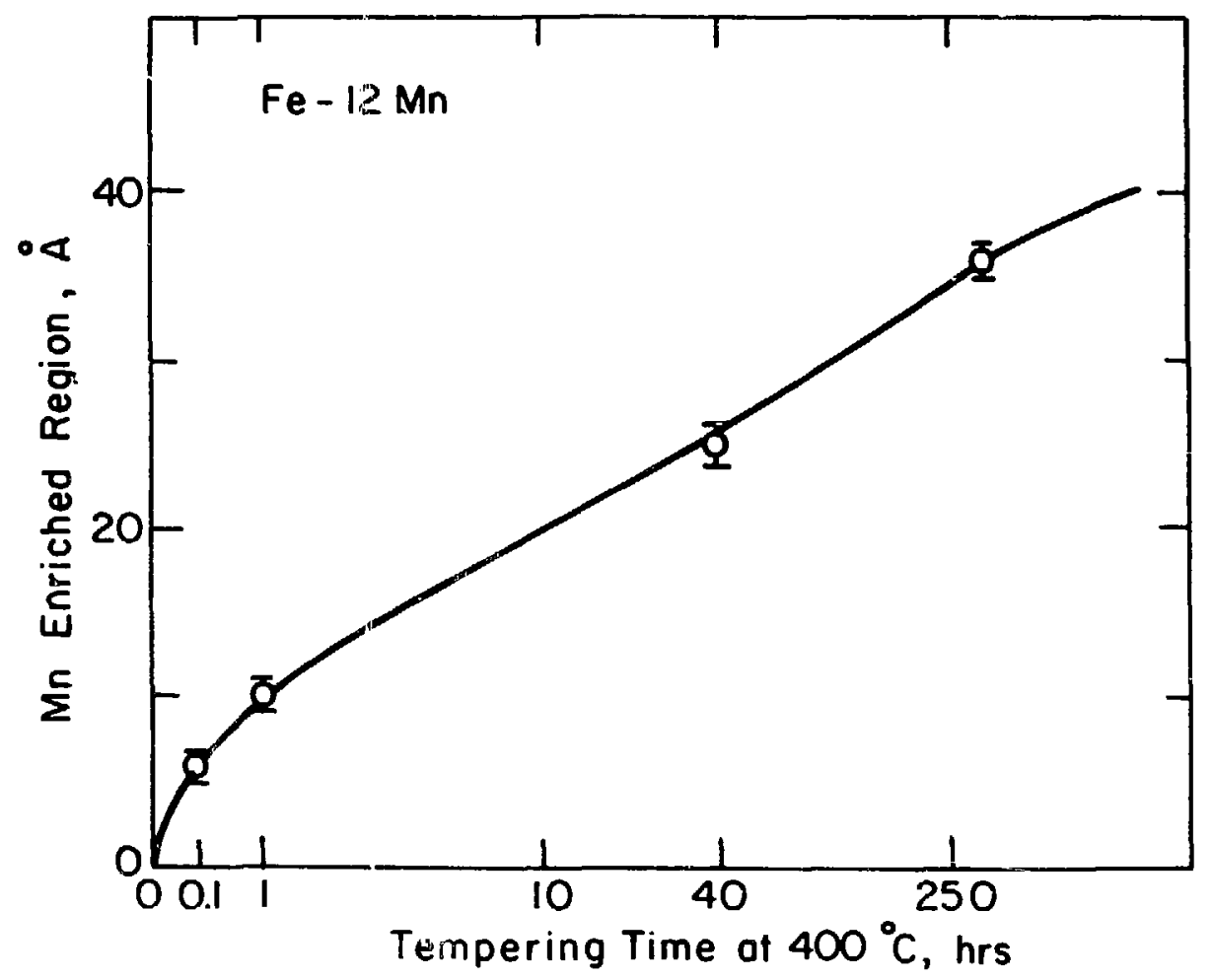

Figure 51 


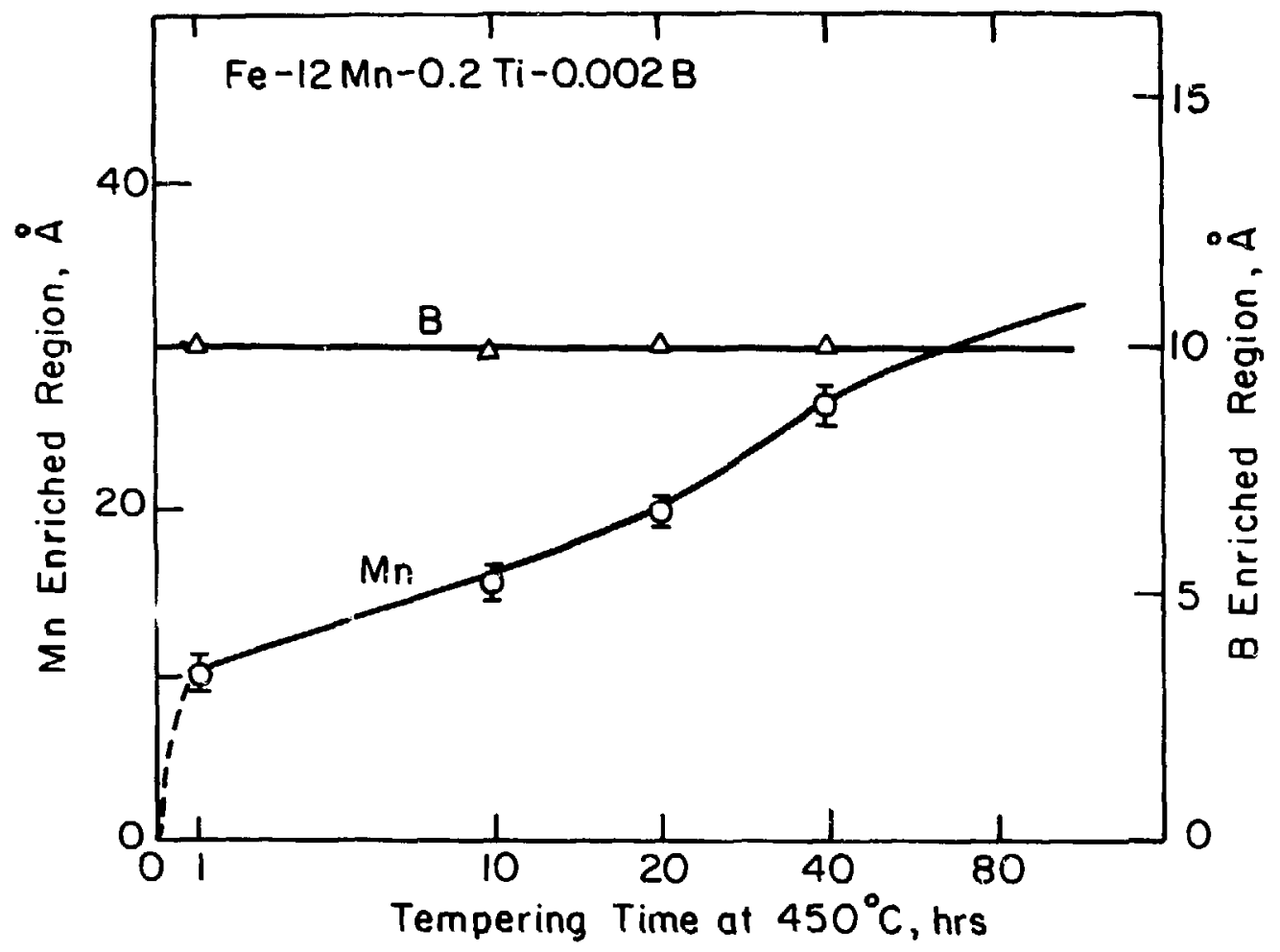



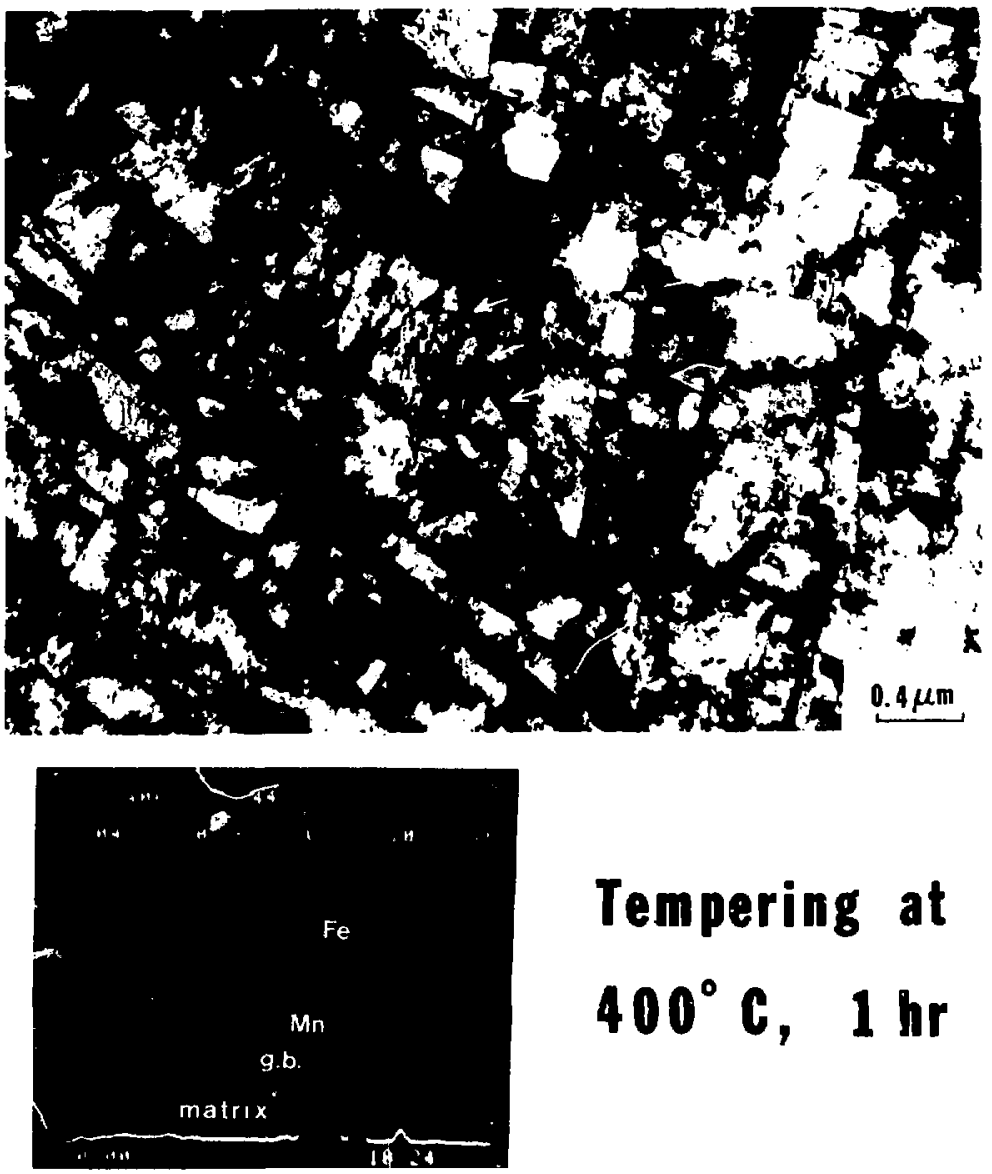

Tempering at $400^{\circ} \mathrm{C}, 1 \mathrm{hr}$ 

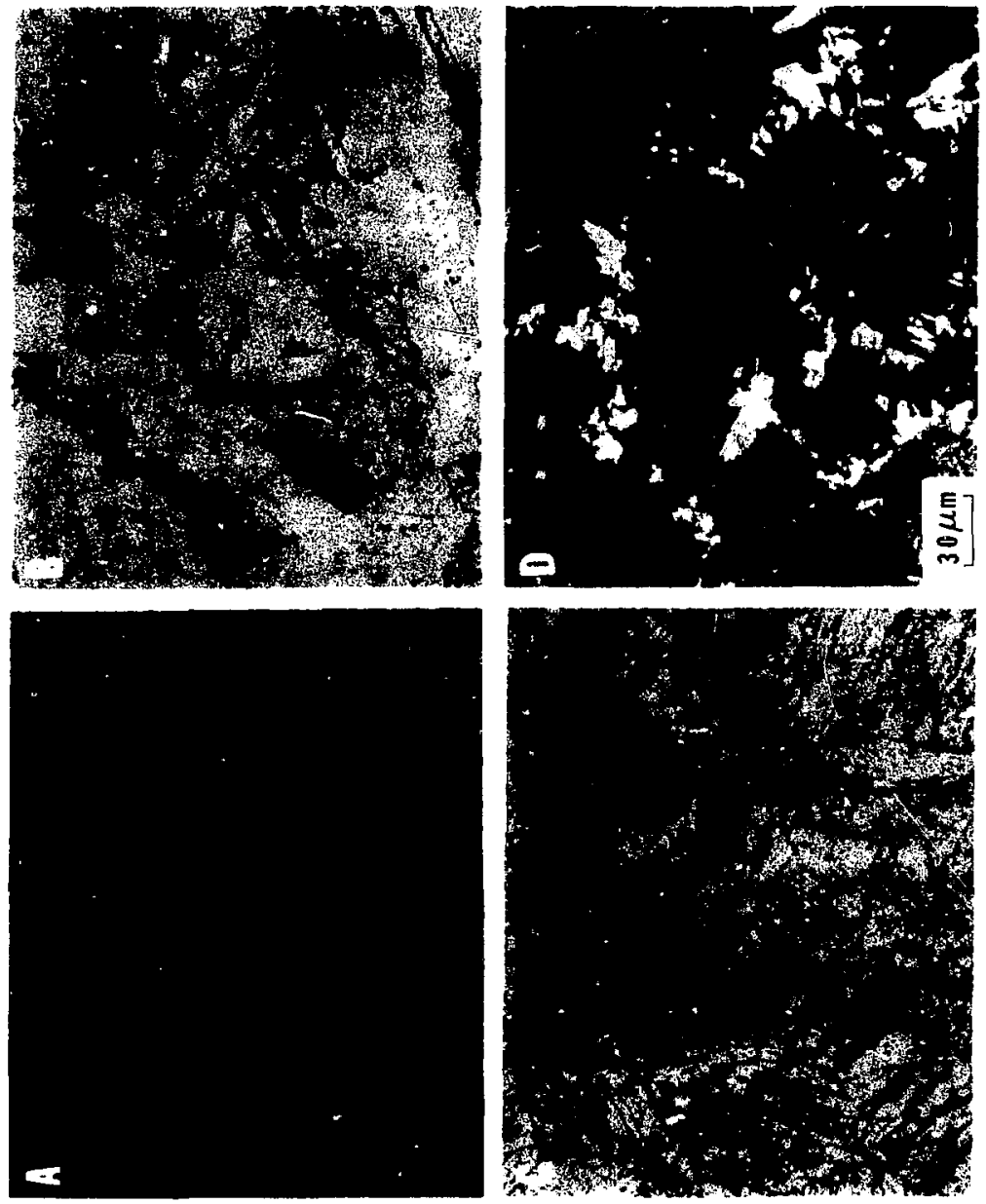

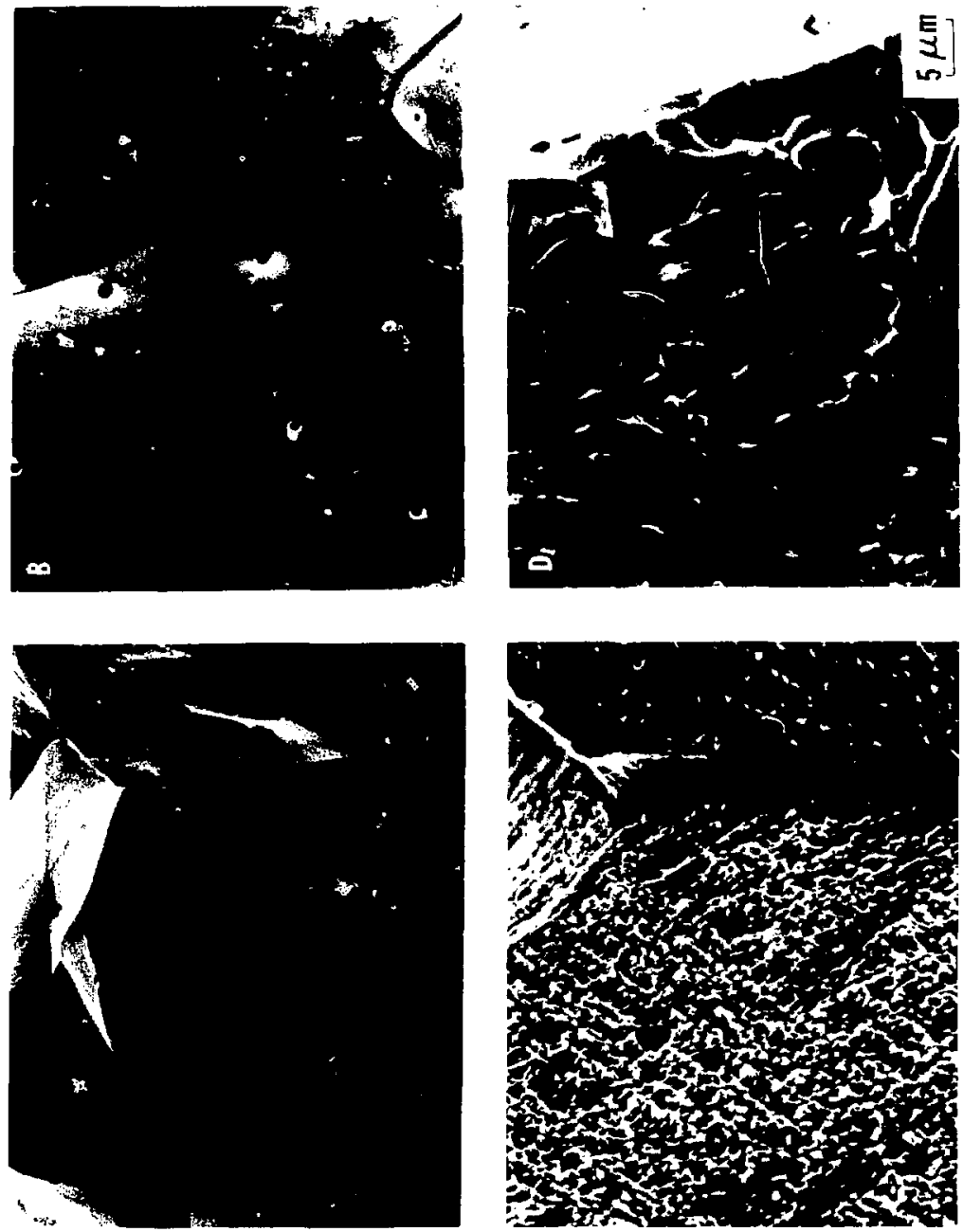

Finure 55

XPJ $\quad 910 \cdots 20731$ 

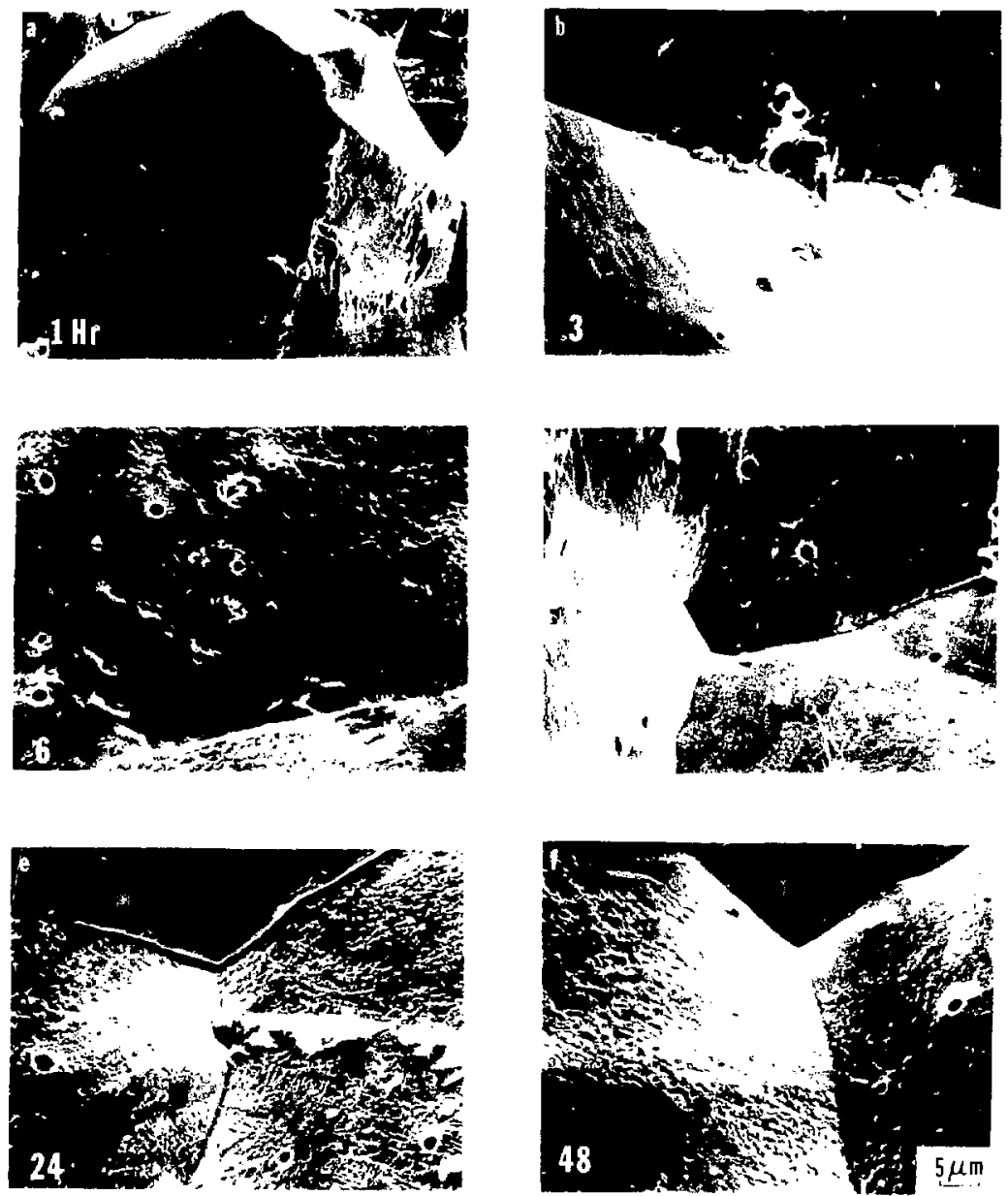

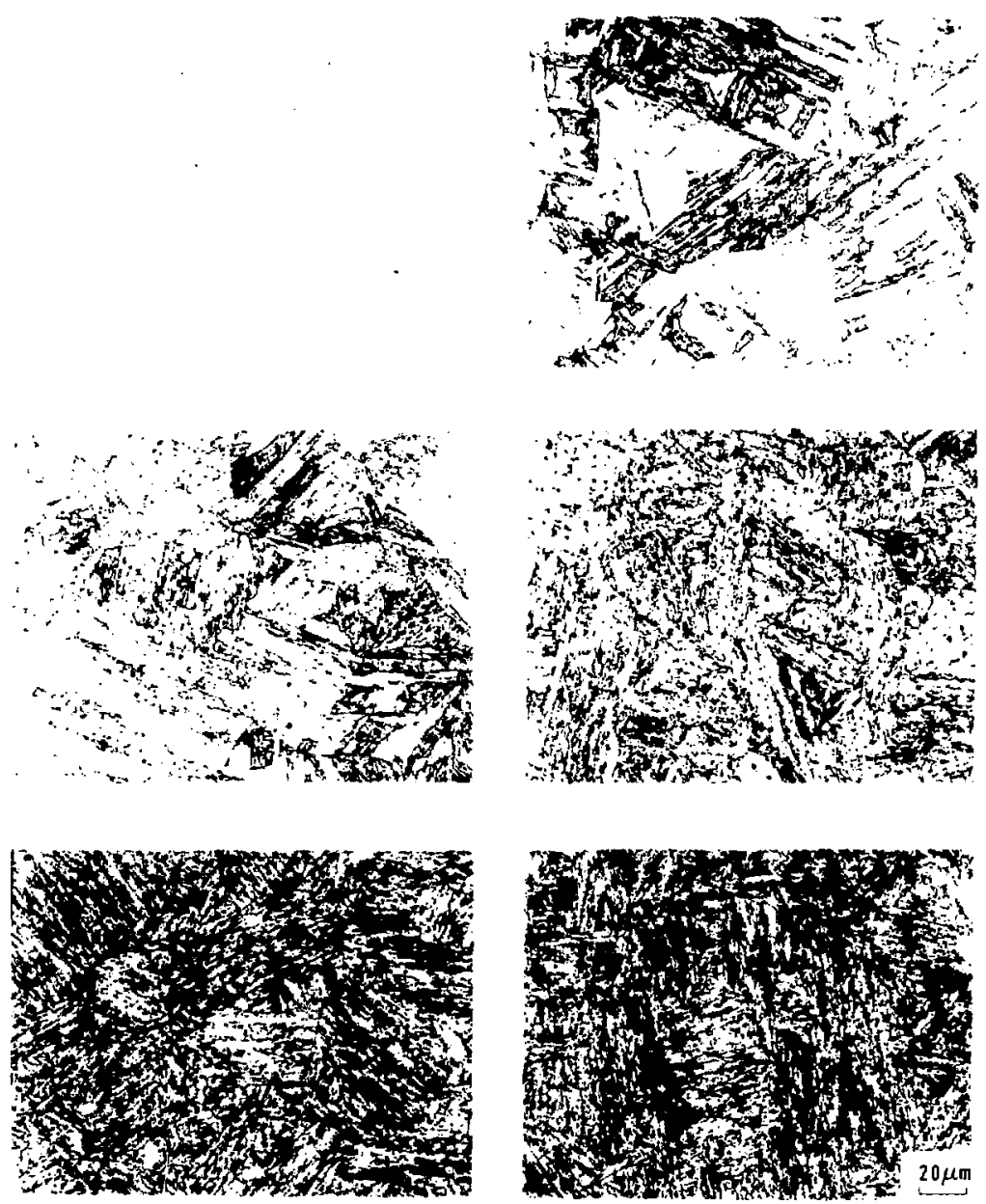

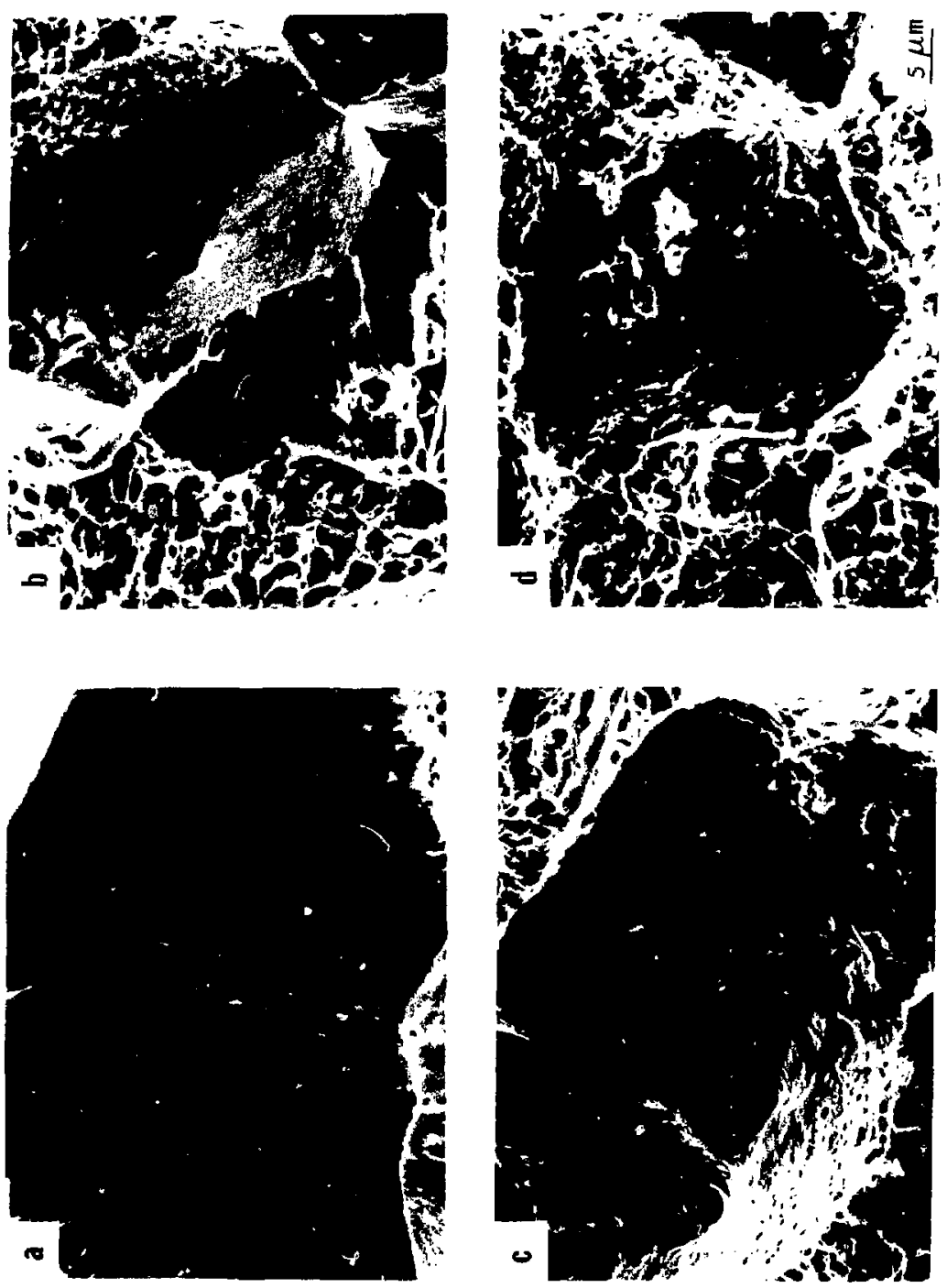

Firsirr 


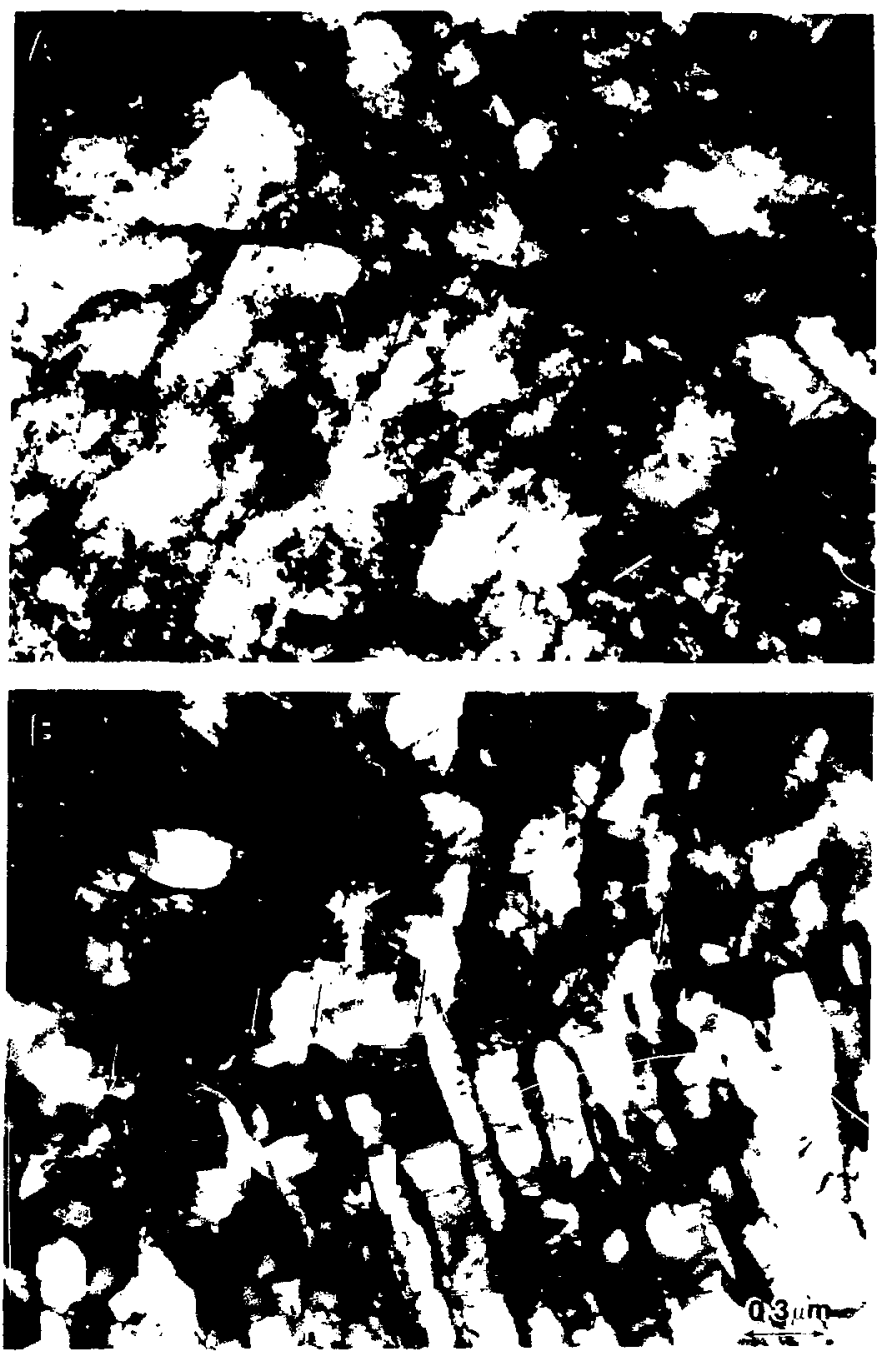

Figure 59

$\mathrm{X}+\mathrm{H}-221-872$ 

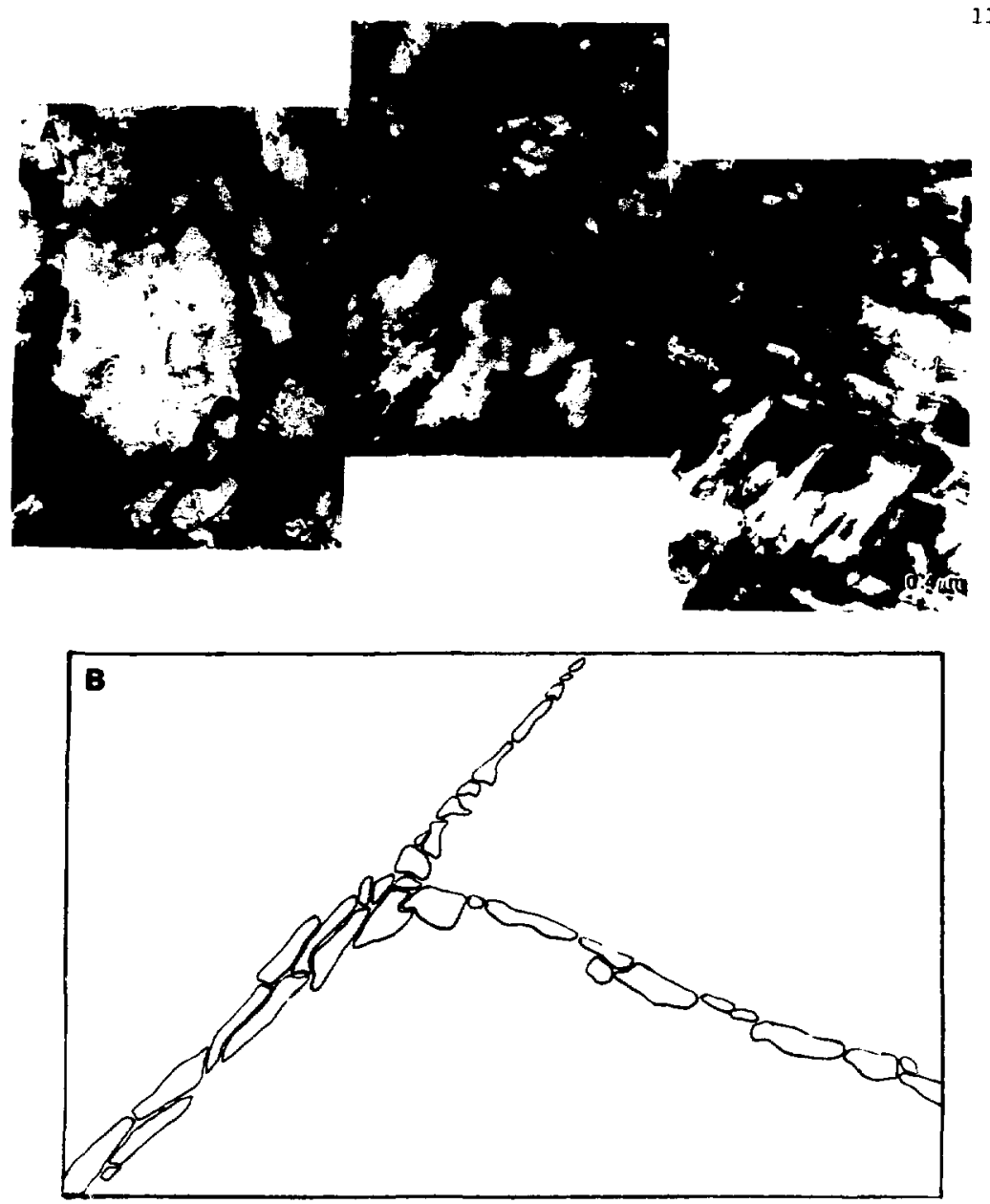

Figure 60

XBB $821-973$ 


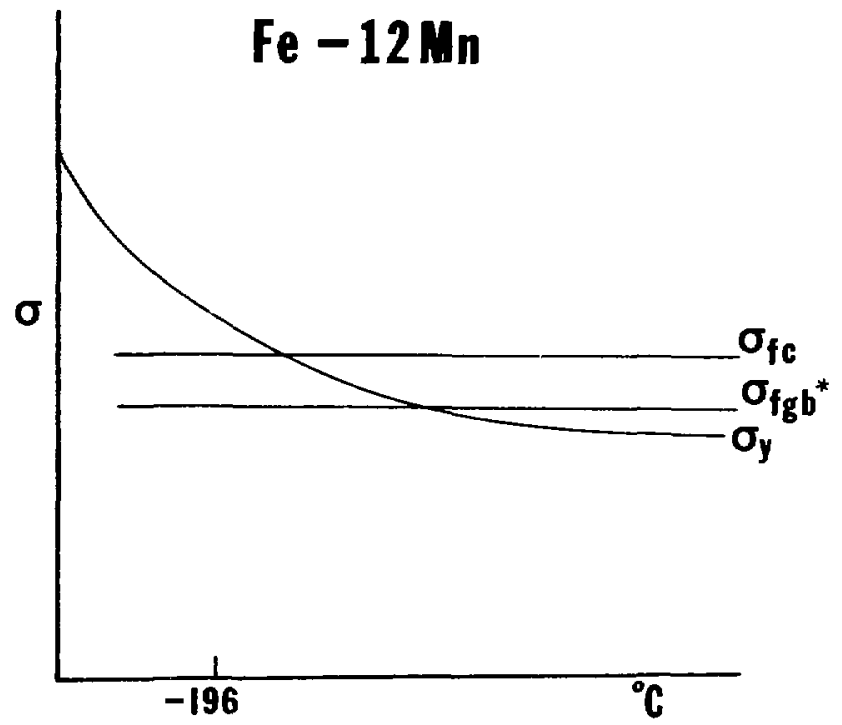

Figure ol

XBL 8112-12974 